\title{
Suspended particulate matter - source or sink for chemical mixtures of organic micropollutants in a small river under baseflow conditions?
}

Lili Niu, Jörg Ahlheim, Clarissa Glaser, Roman Gunold, Luise Henneberger, Maria König, Martin Krauss, Marc Schwientek, Christiane Zarfl, Beate I. Escher*

\section{AUTHOR INFORMATION}

\section{Corresponding Author}

Beate I. Escher-Department Cell Toxicology, Helmholtz Centre for Environmental ResearchUFZ, 04318 Leipzig, Germany

\section{Authors}

Lili Niu -UFZ - Helmholtz Centre for Environmental Research, Department of Cell Toxicology, 04318 Leipzig, Germany

Jörg Ahlheim - UFZ - Helmholtz Centre for Environmental Research, Department of Effect Directed Analysis, 04318 Leipzig, Germany

Clarissa Glaser - Eberhard Karls University of Tübingen, Center for Applied Geoscience, Schnarrenbergstr. 94-96, 72076 Tübingen, Germany

Roman Gunold - UFZ - Helmholtz Centre for Environmental Research, Department of Effect Directed Analysis, 04318 Leipzig, Germany 
Suspended particulate matter - source or sink for chemical mixtures ... in a small river under baseflow conditions?

Luise Henneberger - UFZ - Helmholtz Centre for Environmental Research, Department of Cell Toxicology, 04318 Leipzig, Germany

Maria König - UFZ - Helmholtz Centre for Environmental Research, Department of Cell Toxicology, 04318 Leipzig, Germany

Martin Krauss - UFZ - Helmholtz Centre for Environmental Research, Department of Effect Directed Analysis, 04318 Leipzig, Germany

Marc Schwientek - Eberhard Karls University of Tübingen, Center for Applied Geoscience, Schnarrenbergstr. 94-96, 72076 Tübingen, Germany; present address: LGRB - Geological Survey of the Federal State of Baden-Württemberg, Ruppmannstr. 21, 70565 Stuttgart, Germany

Christiane Zarfl - Eberhard Karls University of Tübingen, Center for Applied Geoscience, Schnarrenbergstr. 94-96, 72076 Tübingen, Germany

Beate I. Escher - Department Cell Toxicology, Helmholtz Centre for Environmental ResearchUFZ, 04318 Leipzig, Germany and Eberhard Karls University of Tübingen, Center for Applied Geoscience, Schnarrenbergstr. 94-96, 72076 Tübingen, Germany 


\section{TABLE OF CONTENTS}

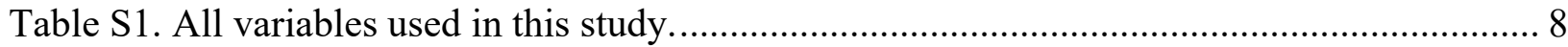

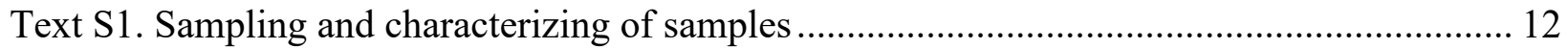

Table S2. Physicochemical properties of river water. ............................................................... 13

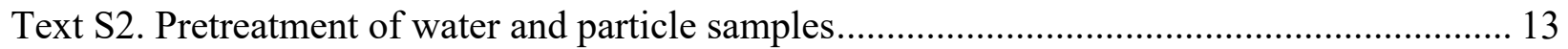

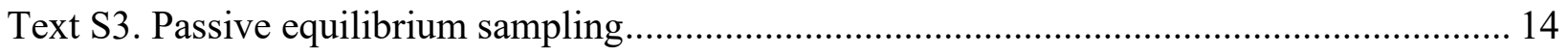

Table S3. Depletion fractions fPDMS of chemical mixtures by polydimethylsiloxane (PDMS) from suspended particulate matter (SPM) and sediment in passive equilibrium sampling................... 16

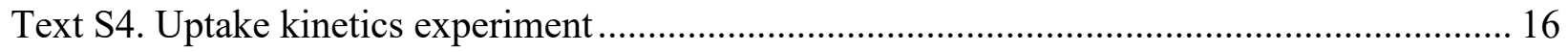

Fig. S1. Time- and thicknesses-series of uptake kinetics for polychlorinated biphenyls (PCBs) between polydimethylsiloxane (PDMS) and sediment. The curves were fitted using a onecompartment uptake model (Eq. S9). .................................................................................... 17

Table S4. Kinetic parameters of PCB indicators between sediment and different thicknesses of polydimethylsiloxane (PDMS) sheets during passive equilibrium sampling.............................. 17

Fig. S2. Correlations (A) between the $\log K_{\text {ow }}$ and the $t_{95 \%}$ (Eq. S10) and (B) between the $\log K_{\text {ow }}$ and the ratio of polychlorinated biphenyls (PCBs) extracted by polydimethylsiloxane (PDMS) on day 50 .

Table S5. Summary of chemicals determined by LC and GC instruments (modified from Niu et al..$^{3}$ ) - see Supporting Information excel file. 18

Table S6. Concentrations of detected chemicals in water samples, suspended particulate matter (SPM), sediment and polydimethylsiloxane (PDMS) extracts - see Supporting Information excel file. 18

Table S7. Toxicity data of individual chemicals used in iceberg modeling for AhR CALUX, PPAR $\gamma$ GeneBLAzer and AREc32 bioassays (reprinted with permission from Niu, L. L.; Carmona, E.; Konig, M.; Krauss, M.; Muz, M.; Xu, C.; Zou, D. L.; Escher, B. I., Mixture Risk Drivers in Freshwater Sediments and Their Bioavailability Determined Using Passive Equilibrium Sampling. Environ. Sci. Technol. 2020, 54, (20), 13197-13206. Copyright (2020) American Chemical Society). ${ }^{3}$ - see Supporting Information excel file.

Table S8. Toxicity data of individual chemicals used in iceberg modeling for algae assay (reprinted from Glauch and Escher, 2020) ${ }^{4}$ - see Supporting Information excel file. 
Text S5. Data evaluation of bioassays .................................................................................... 19

Text S6. Comparison of LVSPE and filtration methods on water monitoring ............................. 20

Fig. S3. Comparison of concentrations of dissolved and suspended particulate matter (SPM)bound chemicals obtained from the large volume solid phase extraction (LVSPE) and the conventional filtration method. SPE: solid phase extraction. Concentrations are from Table S6.21

Fig. S4. Comparison of individual chemical concentrations in total water column estimated by the large volume solid phase extraction (LVSPE) and the filtration method. SPM: suspended particulate matter; SPE: solid phase extraction. Concentrations are from Table S6.

Fig. S5. (A) The frequency distribution of $\mathrm{C}_{\mathrm{tot}, \mathrm{LVSPE}} / \mathrm{C}_{\mathrm{tot}, \mathrm{SPM}+\mathrm{SPE}}$ and (C) its relationship with the octanol water partition constants $K_{\text {ow }}$ of chemicals. LVSPE: large volume solid phase extraction; SPM: suspended particulate matter; SPE: solid phase extraction. $\log K_{\mathrm{ow}}$ and concentrations are from Table S6.

Table S9. Number of chemicals measured, detected and with available toxicity data - see Supporting Information excel file.

Fig. S6. (A, C and E) Sum of chemical concentrations for different chemical groups and (B, D and F) composition of surface water extracts estimated by solid phase extraction (SPE) and passive equilibrium sampling (PES) method. PPCPs: pharmaceuticals and personal care products; PFCs: perfluorinated compounds; PAHs: polycyclic aromatic hydrocarbons; PCBs: polychlorinated biphenyls; OCPs: organochlorine pesticides; PBDE: polybrominated diphenyl ethers. Concentrations and grouping into compound classes are given in Table S6.

Table S10. Top 20 chemicals identified according to their contributions to the total detected concentrations. - see Supporting Information excel file.

Fig. S7. (A, C and E) Sum of chemical concentrations for different chemical groups and (B, D and F) composition of suspended particulate matter (SPM)- and sediment-associated contaminants. PPCPs: pharmaceuticals and personal care products; PFCs: perfluorinated compounds; PAHs: polycyclic aromatic hydrocarbons; PCBs: polychlorinated biphenyls; OCPs: organochlorine pesticides; PBDE: polybrominated diphenyl ethers. Concentrations and grouping into compound classes are given in Table S6. 24

Fig. S8. Comparison of chemical concentrations in suspended particulate matter (SPM) and sediment for (A) neutral and hydrophobic chemicals and (B) charged or hydrophilic chemicals. Detailed concentrations are given in Table S6. 
Fig. S9. (A) Sum of chemical concentrations for different chemical groups (B) and composition of organic carbon-bound chemicals in suspended particulate matter (SPM) and sediment. PPCPs: pharmaceuticals and personal care products; PFCs: perfluorinated compounds; PAHs: polycyclic aromatic hydrocarbons; PCBs: polychlorinated biphenyls; OCPs: organochlorine pesticides; PBDE: polybrominated diphenyl ethers. Concentrations and grouping into compound classes are given in Table S6.

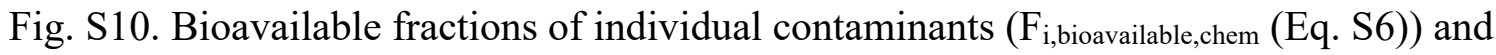
chemical mixtures ( $\mathrm{F}_{\mathrm{i}, \text { bioavailable,bio }}$ (Eq. $\left.\mathrm{S} 8\right)$ ) in suspended particulate matter (SPM) and sediment.

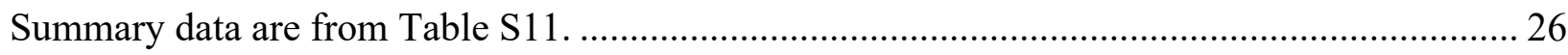

Table S11. Bioavailable fractions $\mathrm{F}_{\text {bioavailable }}$ (Eqs. S6 and S8) of individual chemicals and chemical mixtures.

Fig. S11. Concentration-effect and concentration-cytotoxicity curves of water, suspended particulate matter (SPM) and sediment by accelerated solvent extraction (ASE) and polydimethylsiloxane (PDMS) samples in AhR CALUX. On the left are depicted all cytotoxicity and activation data, in the middle only valid activation data (effect $<30 \%$, concentration $<$ inhibition concentration $10 \%\left(\mathrm{IC}_{10}\right)$ to derive the effect concentration $\mathrm{EC}_{10}$ and on the right only valid cytotoxicity data (cytotoxicity $<40 \%$ ) to derive the $\mathrm{IC}_{10}$. The resulting $\mathrm{IC}_{10}$ and $\mathrm{EC}_{10}$ are listed in Table S12. 28

Fig. S12. Concentration-effect and concentration-cytotoxicity curves of water, suspended particulate matter (SPM) and sediment by accelerated solvent extraction (ASE) and polydimethylsiloxane (PDMS) samples in PPAR $\gamma$ GeneBLAzer. On the left are depicted all cytotoxicity and activation data, in the middle only valid activation data (effect $<30 \%$, concentration < inhibition concentration $10 \%\left(\mathrm{IC}_{10}\right)$ to derive the effect concentration $\mathrm{EC}_{10}$ and on the right only valid cytotoxicity data (cytotoxicity $<40 \%$ ) to derive the $\mathrm{IC}_{10}$. The resulting $\mathrm{IC}_{10}$ and $\mathrm{EC}_{10}$ are listed in Table $\mathrm{S} 12$.

Fig. S13. Concentration-effect and concentration-cytotoxicity curves of water, suspended particulate matter (SPM) and sediment by accelerated solvent extraction (ASE) and polydimethylsiloxane (PDMS) samples in AREc32 assay. On the left are depicted all cytotoxicity and activation data, in the middle only valid activation data (induction ratio $<4$, concentration $<$ inhibition concentration $10 \%\left(\mathrm{IC}_{10}\right)$ and on the right only valid cytotoxicity data (cytotoxicity $<40 \%$ ). The resulting $\mathrm{IC}_{10}$ and $\mathrm{EC}_{10}$ are listed in Table $\mathrm{S} 12$. 
Fig. S14. Concentration-effect and concentration-inhibition of growth rate curves of water, samples in combined algae testing assay. On the left are depicted all growth inhibition and photosynthesis inhibition data, in the middle only valid activation data (induction ratio $<4$, concentration $<$ inhibition concentration $10 \%\left(\mathrm{IC}_{10}\right)$ and on the right only valid growth inhibition data $(<40 \%)$. The light green ones indicate $2 \mathrm{~h}$ photosynthesis inhibition, the dark green ones indicate $24 \mathrm{~h}$ photosynthesis inhibition. The resulting $\mathrm{IC}_{10}$ and $\mathrm{EC}_{10}$ are listed in Table S12.... 36 Table S12. The effect concentration that caused $10 \%$ of the maximum effect $\left(\mathrm{EC}_{10}\right)$ or an induction ratio of $1.5\left(\mathrm{EC}_{\mathrm{IR} 1.5}\right)$ and $10 \%$ of the maximum inhibitory concentration $\left(\mathrm{IC}_{10}\right)$ in water, suspended particulate matter (SPM), sediment and polydimethylsiloxane (PDMS) samples. The errors refer to standard errors propagated from the standard error of the regression of the concentration response curve according to Escher et al. (2018) ${ }^{5}$ or calculated from standard deviation (SD/number of replicates) of triplicated experiments.

Table S13. Bioanalytical equivalent concentrations (BEQbio) and toxic unit for cytotoxicity (TU $\mathrm{Tio}_{\mathrm{o}}$ ) of chemical mixtures in water, suspended particulate matter (SPM), sediment and polydimethylsiloxane (PDMS) samples The errors refer to standard errors propagated from the standard error of the regression of the concentration response curve according to Escher et al. $(2018)^{5}$ or calculated from standard deviation (SD/number of replicates) of triplicated experiments.

Text S7. Cytotoxicity of chemical mixtures in water, suspended particulate matter and sediment in in vitro bioassay and the growth inhibition they caused on algae 38

Fig. S15. Contribution of detected chemicals to the observed cytotoxicity in in vitro bioassays and the growth inhibition of algae. 39

Table S14. Bioanalytical equivalent concentrations $\left(\mathrm{BEQ}_{\mathrm{chem}}\right)$ and toxic units $\left(\mathrm{TU}_{\text {chem }}\right)$ estimated from chemical concentrations of detected chemicals in water, bulk suspended particulate matter (SPM), bulk sediment and organic carbon (OC) of particles for AhR CALUX, PPAR $\gamma$ GeneBLAzer and AREc32 assays - see Supporting Information excel file. 39

Table S15. Bioanalytical equivalent concentrations $\left(\mathrm{BEQ}_{\mathrm{chem}}\right)$ and toxic units $\left(\mathrm{TU}_{\text {chem }}\right)$ estimated from chemical concentrations of detected chemicals in water for algae assay - see Supporting Information excel file. 39

Fig. S16. Contribution of detected chemicals to the observed effects regarding (A) the activation of AhR, (B) binding to PPAR $\gamma$, (C) oxidative stress response and (D) photosynthesis inhibition in algae. 
Text 8. Extrapolations to estimate the total number of chemicals in water, suspended particulate matter, sediment and the bioavailable fractions of particles. 40

Table S16. Extrapolated number of bioactive and cytotoxic chemicals in water, suspended particulate matter (SPM), sediment and polydimethylsiloxane (PDMS) extracts - see Supporting Information excel file.

Fig. S17. Contribution of individual chemicals to the total bioanalytical equivalent concentrations (BEQchem) of water samples. Calculated from data of Table S14 and S15.

Table S17. Top 10 risk drivers (top 6 for algae toxicity) in chemical mixtures identified by iceberg modeling and their contribution to $\mathrm{BEQ}_{\mathrm{chem}}$ - see Supporting Information excel file..... 44

Fig. S18. Comparison of biological effects caused by exhaustively extracted suspended particulate matters (SPM) and sediment samples with and without clean-up. $\mathrm{EC}_{10}$ : concentration causing $10 \%$ of the maximum effect; $\mathrm{EC}_{\mathrm{IR} 1.5}$ : concentration causing an induction ratio of $1.5 \ldots 44$ Fig. S19. Contribution of individual chemicals to the total bioanalytical equivalent concentrations (BEQchem) of particle samples and their polydimethylsiloxane (PDMS) extracts. Calculated from data of Table S14.

Fig. S20. Spatial variation of chemical concentrations in (A) dissolved phase, (B) suspended particulate matter (SPM) and its organic carbon (OC) phase, (C) water column and (D) sediment and its OC phase.

Fig. S21. Spatial variation of bioanalytical equivalent concentrations (BEQ) of chemical mixtures in (A) surface water estimated by solid phase extraction (SPE), (B) suspended particulate matter (SPM), sediment and the organic carbon (OC) phase. 48 
Table S1. All variables used in this study.

\begin{tabular}{|c|c|c|c|}
\hline Variable & Unit & Annotation & Location \\
\hline $\mathrm{C}_{\mathrm{i}, \mathrm{OC}}$ & $\mathrm{ng} / \mathrm{goC}$ & Concentration of chemical i bound to $\mathrm{OC}^{\mathrm{a}}$ & Eq. 1 \\
\hline $\mathrm{C}_{\mathrm{i}, \mathrm{w}}$ & $\mathrm{ng} / \mathrm{L}$ & Concentration of chemical i in water phase & Eq. 1 \\
\hline$K_{\mathrm{i}, \mathrm{oc}}$ & $\mathrm{kg} / \mathrm{L}$ & Partition constant between $\mathrm{OC}^{\mathrm{a}}$ in particles and water & Eq. 1 \\
\hline $\mathrm{C}_{\mathrm{w}, \text { tot }}$ & $\mathrm{ng} / \mathrm{L}$ & $\begin{array}{l}\text { Chemical concentrations in total water column, } \\
\text { including dissolved and } \mathrm{SPM}^{\mathrm{b}} \text {-bound phases }\end{array}$ & Fig. 1A \\
\hline $\mathrm{C}_{\mathrm{DOC}}$ & $\mathrm{ng} / \mathrm{g}$ OC & Concentrations of chemicals bound to $\mathrm{DOC}^{\mathrm{c}}$ & Fig. 1A \\
\hline $\mathrm{C}_{\text {free,sed }}$ & $\mathrm{ng} / \mathrm{L}$ & $\begin{array}{l}\text { Freely dissolved concentrations in pore water of } \\
\text { sediment }\end{array}$ & Fig. 1A \\
\hline Coc,sed & $\mathrm{ng} / \mathrm{g}_{\mathrm{OC}}$ & $\begin{array}{l}\text { Concentrations of chemicals bound to } \mathrm{OC}^{\mathrm{a}} \text { of } \\
\text { sediment }\end{array}$ & Fig. 1A \\
\hline $\mathrm{C}_{\text {sed }}$ & $\mathrm{ng} / \mathrm{g}_{\mathrm{dw}}$ & Concentrations of chemicals in bulk sediment & Fig. 1A \\
\hline $\mathrm{n}_{\mathrm{i}, \mathrm{w},(\mathrm{LV}) \mathrm{SPE}}$ & mol & $\begin{array}{l}\text { Dissolved molar amount of chemical i after } \mathrm{SPE}^{\mathrm{d}} \text { or } \\
\text { LVSPE }^{\mathrm{e}}\end{array}$ & Fig. 1B \\
\hline $\mathrm{n}_{\mathrm{i}, \text { free,(LV)SPE }}$ & mol & $\begin{array}{l}\text { Freely dissolved molar amount of chemical i in water } \\
\text { after spe }{ }^{\mathrm{d}} \text { or LVSPE }\end{array}$ & Fig. 1B \\
\hline $\mathrm{n}_{\mathrm{i}, \mathrm{DOC}}$ & mol & Molar amount of chemical i bound to $\mathrm{DOC}^{\mathrm{c}}$ & Fig. 1B \\
\hline $\mathrm{n}_{\mathrm{i}, \mathrm{w}, \mathrm{tot}, \mathrm{SPE}+\mathrm{SPM}}$ & mol & $\begin{array}{l}\text { Molar amount of chemical i in total water column } \\
\text { collected by conventional filtration method }\end{array}$ & Fig. 1B \\
\hline $\mathrm{n}_{\mathrm{i}, \mathrm{SPM}}$ & mol & Molar amount of chemical i bound to $\mathrm{SPM}^{\mathrm{b}}$ & Fig. 1B \\
\hline $\mathrm{n}_{\mathrm{i}, \mathrm{w}, \mathrm{SPE}}$ & mol & Molar amount of chemical i in water after $\mathrm{SPE}^{\mathrm{d}}$ & Fig. 1B \\
\hline $\mathrm{n}_{\mathrm{i}, \mathrm{w}, \mathrm{tot}, \mathrm{LVSPE}}$ & mol & $\begin{array}{l}\text { Molar amount of chemical i in total water column } \\
\text { collected by } \mathrm{LVSPE}^{\mathrm{e}} \text { filter }\end{array}$ & Fig. 1B \\
\hline $\mathrm{n}_{\mathrm{i}, \mathrm{SPM}, \mathrm{LVSPE}}$ & mol & $\begin{array}{l}\text { Molar amount of chemical i bound to } \mathrm{SPM}^{\mathrm{b}} \text { collected } \\
\text { by LVSPE } \mathrm{L}^{\mathrm{e}} \text { filter }\end{array}$ & Fig. 1B \\
\hline $\mathrm{n}_{\mathrm{i}, \mathrm{w}, \mathrm{LVSPE}}$ & mol & Molar amount of chemical i in water after LVSPE ${ }^{\mathrm{e}}$ & Fig. 1B \\
\hline $\mathrm{n}_{\mathrm{i}, \mathrm{PDMS}, \mathrm{SPM}}$ & mol & $\begin{array}{l}\text { Molar amount of chemical i partitioned into } \mathrm{PDMS}^{\mathrm{f}} \\
\text { after } \mathrm{PES}^{\mathrm{g}} \text { of } \mathrm{SPM}^{\mathrm{b}}\end{array}$ & Fig. 1B \\
\hline $\mathrm{n}_{\mathrm{i}, \mathrm{SPM}, \mathrm{ASE}}$ & mol & $\begin{array}{l}\text { Molar amount of chemical i bound to } \mathrm{SPM}^{\mathrm{b}} \text { extracted } \\
\text { by } \mathrm{ASE}^{\mathrm{h}} \text { after PES }\end{array}$ & Fig. 1B \\
\hline $\mathrm{n}_{\mathrm{i}, \mathrm{SPM},(\mathrm{LV}) \mathrm{SPE}}$ & mol & $\begin{array}{l}\text { Molar amount of chemical i bound to } \mathrm{SPM}^{\mathrm{b}} \text { collected } \\
\text { by conventional filtration method or LVSEP }\end{array}$ & Fig. 1B \\
\hline $\mathrm{n}_{\mathrm{i}, \mathrm{PDMS}, \mathrm{sed}}$ & mol & $\begin{array}{l}\text { Molar amount of chemical i partitioned into } \mathrm{PDMS}^{\mathrm{f}} \\
\text { after } \mathrm{PES}^{\mathrm{g}} \text { of sediment }\end{array}$ & Fig. 1B \\
\hline $\mathrm{n}_{\mathrm{i}, \text { sed,ASE }}$ & mol & $\begin{array}{l}\text { Molar amount of chemical i bound to sediment } \\
\text { extracted by } \mathrm{ASE}^{\mathrm{h}} \text { after PES }\end{array}$ & Fig. 1B \\
\hline $\mathrm{C}_{\mathrm{i}, \mathrm{w},(\mathrm{LV}) \mathrm{SPE}}$ & $\mathrm{ng} / \mathrm{L}$ & $\begin{array}{l}\text { Concentration of chemical } i \text { in water after } \mathrm{SPE}^{\mathrm{d}} \text { or } \\
\text { LVSPE }^{\mathrm{e}}\end{array}$ & Fig. 1B \\
\hline $\mathrm{C}_{\mathrm{i}, \text { free, }(\mathrm{LV}) \mathrm{SPE}}$ & $\mathrm{ng} / \mathrm{L}$ & $\begin{array}{l}\text { Freely dissolved concentration of chemical i after } \\
\mathrm{SPE}^{\mathrm{d}} \text { or LVSPE }\end{array}$ & Fig. 1B \\
\hline
\end{tabular}




\begin{tabular}{|c|c|c|c|}
\hline Variable & Unit & Annotation & Location \\
\hline $\mathrm{C}_{\mathrm{i}, \mathrm{w}, \mathrm{tot}, \mathrm{SPE}+\mathrm{SPM}}$ & $\mathrm{ng} / \mathrm{L}$ & $\begin{array}{l}\text { Concentration of chemical i in total water column } \\
\text { collected by conventional filtration method }\end{array}$ & Fig. 1B \\
\hline $\mathrm{C}_{\mathrm{i}, \mathrm{w}, \text { tot,LVSPE }}$ & $\mathrm{ng} / \mathrm{L}$ & $\begin{array}{l}\text { Concentration of chemical i in total water column } \\
\text { collected by LVSPE } \text { filter }^{\mathrm{e}}\end{array}$ & Fig. 1B \\
\hline $\mathrm{C}_{\mathrm{i}, \mathrm{PDMS}, \mathrm{SPM}}$ & $\mathrm{ng} / \mathrm{g}_{\mathrm{PDMS}}$ & $\begin{array}{l}\text { Concentration of chemical i partitioned into PDMS } \\
\text { after } \text { PES }^{g} \text { of } \mathrm{SPM}^{\mathrm{b}}\end{array}$ & Fig. 1B \\
\hline $\mathrm{C}_{\mathrm{i}, \text { free,SPM,PES }}$ & $\mathrm{ng} / \mathrm{L}$ & $\begin{array}{l}\text { Freely dissolved concentration of chemical i after } \\
\mathrm{PES}^{\mathrm{g}} \text { of } \mathrm{SPM}^{\mathrm{b}}\end{array}$ & Fig. 1B \\
\hline $\mathrm{C}_{\mathrm{i}, \mathrm{OC}, \mathrm{SPM}}$ & $\mathrm{ng} / \mathrm{goC}$ & Concentration of chemical i bound to $\mathrm{OC}^{\mathrm{a}}$ of $\mathrm{SPM}^{\mathrm{b}}$ & Fig. 1B \\
\hline $\mathrm{C}_{\mathrm{i}, \mathrm{SPM}}$ & $\mathrm{ng} / \mathrm{g}_{\mathrm{dw}}$ & Concentration of chemical i bound to $\mathrm{SPM}^{\mathrm{b}}$ & Fig. 1B \\
\hline $\mathrm{C}_{\mathrm{i}, \mathrm{SPM}, \mathrm{LVSPE}}$ & $\mathrm{ng} / \mathrm{g}_{\mathrm{dw}}$ & $\begin{array}{l}\text { Concentration of chemical i bound to } \mathrm{SPM}^{\mathrm{b}} \text { collected } \\
\text { by } \mathrm{LVSPE}^{\mathrm{e}} \text { filter }\end{array}$ & Fig. 1B \\
\hline $\mathrm{C}_{\mathrm{i}, \mathrm{PDMS} \text {,sed }}$ & $\mathrm{ng} / \mathrm{g}_{\mathrm{PDMS}}$ & $\begin{array}{l}\text { Concentration of chemical i partitioned into } \mathrm{PDMS}^{\mathrm{f}} \\
\text { after PES } \mathrm{P}^{\mathrm{g}} \text { of sediment }\end{array}$ & Fig. 1B \\
\hline $\mathrm{C}_{\mathrm{i}, \mathrm{OC}, \mathrm{sed}}$ & $\mathrm{ng} / \mathrm{g}_{\mathrm{OC}}$ & Concentration of chemical $\mathrm{i}$ bound to $\mathrm{OC}^{\mathrm{a}}$ of sediment & Fig. 1B \\
\hline $\mathrm{C}_{\mathrm{i}, \mathrm{sed}}$ & $\mathrm{ng} / \mathrm{g}_{\mathrm{dw}}$ & Concentration of chemical i bound to sediment & Fig. 1B \\
\hline $\mathrm{V}_{\mathrm{w}}$ & $\mathrm{L}$ & Water volume & Fig. 1B \\
\hline mPDMS & $\mathrm{g}_{\mathrm{PDMS}}$ & Mass of SPM ${ }^{b}$ & Fig. 1B \\
\hline $\mathrm{m}_{\mathrm{SPM}}$ & $\mathrm{g}_{\mathrm{dw}}$ & Mass of PDMS ${ }^{f}$ collected by filtration method & Fig. 1B \\
\hline $\mathrm{m}_{\text {SPM,LVSPE }}$ & $\mathrm{g}_{\mathrm{dw}}$ & Mass of PDMS ${ }^{\mathrm{f}}$ collected by LVSPE & Fig. 1B \\
\hline $\mathrm{m}_{\text {sed }}$ & $g_{d w}$ & Mass of sediment & Fig. 1B \\
\hline$K_{\mathrm{i}, \mathrm{PDMS} / \mathrm{w}}$ & $\mathrm{kg} / \mathrm{L}$ & Partition constant between $\mathrm{PDMS}^{\mathrm{f}}$ and water & Fig. 1B \\
\hline$K_{\mathrm{PDMS} / \mathrm{OC}}$ & & Partition constant between $\mathrm{PDMS}^{\mathrm{f}}$ and $\mathrm{OC}^{\mathrm{a}}$ & Fig. 1B \\
\hline$D_{\mathrm{i}, \mathrm{SPM} / \mathrm{w}}$ & $\mathrm{L} / \mathrm{kg}$ & $\begin{array}{l}\text { Distribution ratio of chemicals between } \mathrm{SPM}^{\mathrm{b}} \text { and } \\
\text { water }\end{array}$ & Fig. 1B \\
\hline$D_{\mathrm{i}, \mathrm{SPM} / \mathrm{sed}}$ & $\begin{array}{l}\mathrm{kg}_{\mathrm{sed}, \mathrm{dw}} / \mathrm{kg}_{\mathrm{SP}} \\
\mathrm{M}, \mathrm{dw}\end{array}$ & $\begin{array}{l}\text { Distribution ratio of chemicals between } \mathrm{SPM}^{\mathrm{b}} \text { and } \\
\text { sediment }\end{array}$ & Fig. 1B \\
\hline $\mathrm{f}_{\mathrm{i}, \mathrm{SPM}}$ & & $\begin{array}{l}\text { Fraction of the SPM-bound chemical } i \text { in the total } \\
\text { water column }\end{array}$ & Eq. 6 \\
\hline$D_{\text {mixture, } \mathrm{SPM} / \mathrm{w}}$ & $\mathrm{mL} / \mathrm{g}_{\mathrm{SPM}, \mathrm{dw}}$ & Distribution ratio between $\mathrm{SPM}^{\mathrm{b}}$ and water & Table 1 \\
\hline$D_{\text {mixture,SPM/sed }}$ & $\mathrm{g}_{\mathrm{sed}, \mathrm{dw}} / \mathrm{g}_{\mathrm{SPM}, \mathrm{dw}}$ & $\begin{array}{l}\text { Distribution ratio of BEQs between SPM and } \\
\text { sediment }\end{array}$ & Table 1 \\
\hline$f_{\text {mixture,SPM }}$ & & Fraction of BEQ bound to SPM & Eq. 9 \\
\hline BEQSPM & $\mu \mathrm{g}_{\mathrm{ref}} / \mathrm{g}_{\mathrm{SPM}, \mathrm{dw}}$ & $\begin{array}{l}\text { Bioanalytical equivalent concentration of } \mathrm{SPM}^{\mathrm{b}} \\
\text { mixtures collected by metal filter }\end{array}$ & $\begin{array}{l}\text { Eq } 7 \text { and } \\
8\end{array}$ \\
\hline $\mathrm{BEQ}_{\mathrm{w}, \mathrm{SPE}}$ & $\mu \mathrm{g}_{\mathrm{ref}} / \mathrm{mL}$ & $\begin{array}{l}\text { Bioanalytical equivalent concentration of water } \\
\text { samples measured after } \mathrm{SPE}^{\mathrm{d}}\end{array}$ & Eq 7 \\
\hline$B E Q_{\text {sed }}$ & $\mu \mathrm{g}_{\mathrm{ref}} / \mathrm{g}_{\mathrm{sed}, \mathrm{dw}}$ & $\begin{array}{l}\text { Bioanalytical equivalent concentration of chemical } \\
\text { mixtures extracted from sediment }\end{array}$ & Eq 8 \\
\hline $\mathrm{BEQ}_{\text {chem }}$ & $\mathrm{ng}_{\mathrm{ref}} / \mathrm{L}$ & $\begin{array}{l}\text { Bioanalytical equivalent concentration predicted from } \\
\text { the detected chemicals and their relative effect } \\
\text { potency REP }\end{array}$ & Eq. S16 \\
\hline
\end{tabular}




\begin{tabular}{|c|c|c|c|}
\hline Variable & Unit & Annotation & Location \\
\hline $\mathrm{TU}_{\text {chem }}$ & $\begin{array}{l}\mathrm{L}_{\text {bioassay }} / \mathrm{g} \text { or } \\
\mathrm{L}_{\text {bioassay }} / \mathrm{L}\end{array}$ & $\begin{array}{l}\text { Cytotoxicity toxic unit calculated from detected } \\
\text { chemicals }\end{array}$ & Eq. S18 \\
\hline $\mathrm{BEQ}_{\text {bio }}$ & $\begin{array}{l}\mathrm{ng}_{\mathrm{ref}} / \mathrm{L} \text { or } \\
\mu \mathrm{g}_{\mathrm{ref}} / \mathrm{g}\end{array}$ & $\begin{array}{l}\text { Bioanalytical equivalent concentration, measured in } \\
\text { bioassay }\end{array}$ & Main text \\
\hline $\mathrm{TU}_{\text {bio }}$ & $\begin{array}{l}\mathrm{L}_{\text {bioassay }} / \mathrm{g} \text { or } \\
\mathrm{L}_{\text {bioassay }} / \mathrm{L}\end{array}$ & Toxic unit for cytotoxicity, measured in bioassay & Main text \\
\hline REP & & Relative effect potency & Main text \\
\hline [DOC $]$ & $\mathrm{kg}_{\mathrm{DOC}} / \mathrm{L}$ & Concentration of $\mathrm{DOC}^{\mathrm{c}}$ & $\begin{array}{l}\text { Fig. 1B, } \\
\text { Table } 1\end{array}$ \\
\hline [SPM] & $\mathrm{mg}_{\mathrm{dw}} / \mathrm{L}$ & Concentration of $\mathrm{SPM}^{\mathrm{d}}$ in water column & Table 1 \\
\hline [OC,SPM] & $\begin{array}{l}\mathrm{g}_{\mathrm{oc}} / \mathrm{g}_{\mathrm{SPM}, \mathrm{dw}} \text { or } \\
\mathrm{mg} / \mathrm{L}\end{array}$ & $\mathrm{OC}^{\mathrm{a}}$ content of $\mathrm{SPM}^{\mathrm{b}}$ & Table 1 \\
\hline$[\mathrm{OC}$, sed $]$ & $\mathrm{g}_{\mathrm{OC}} / \mathrm{g}_{\mathrm{sed}, \mathrm{dw}}$ & $\mathrm{OC}^{\mathrm{a}}$ content of sediment & Table 1 \\
\hline $\mathrm{m}_{\mathrm{w}} / \mathrm{m}_{\text {sed }}$ & $\%$ & Water content of sediment & Table 1 \\
\hline $\mathrm{n}_{\mathrm{i}, \mathrm{particle}, \mathrm{ww}}$ & mol & Total molar amount of chemicals in bulk particles & SI \\
\hline $\mathrm{n}_{\mathrm{i}, \mathrm{OC}}$ & mol & Molar amount of chemical i bound to $\mathrm{OC}^{\mathrm{a}}$ & SI \\
\hline $\mathrm{n}_{\mathrm{i}, \mathrm{pw}}$ & mol & Molar amount of chemical i dissolved in pore water & SI \\
\hline $\mathrm{n}_{\mathrm{i}, \text { residual }}$ & mol & Molar amount of inaccessible chemical i & SI \\
\hline$f_{\text {PDMS }}$ & & Mass ratios of $\mathrm{PDMS}^{\mathrm{f}}$ to sediment or $\mathrm{SPM}^{\mathrm{b}}$ & SI \\
\hline $\mathrm{F}_{\mathrm{i}, \text { bioavailable,chem }}$ & & $\begin{array}{l}\text { Bioavailable fractions of individual chemicals in } \\
\text { particles }\end{array}$ & SI \\
\hline$F_{\text {bioavailable,bio }}$ & & $\begin{array}{l}\text { Bioavailable fraction of chemical mixtures from the } \\
\text { bioassays }\end{array}$ & SI \\
\hline BEQoc & $\mu \mathrm{g}_{\mathrm{ref}} / \mathrm{g}_{\mathrm{OC}}$ & $\begin{array}{l}\text { Bioanalytical equivalent concentration of chemical } \\
\text { mixtures bound to } \mathrm{OC}^{\mathrm{a}}\end{array}$ & SI \\
\hline $\mathrm{BEQ}_{\mathrm{w}}$ & $\mu \mathrm{g}_{\mathrm{ref}} / \mathrm{L}$ & $\begin{array}{l}\text { Bioanalytical equivalent concentration of chemical } \\
\text { mixtures in water }\end{array}$ & SI \\
\hline BEQpDMs & $\mu g_{\text {ref }} / g_{\text {PDMS }}$ & $\begin{array}{l}\text { Bioanalytical equivalent concentration of chemical } \\
\text { mixtures partitioned into PDMS }\end{array}$ & SI \\
\hline REF & & Relative enrichment factor & SI \\
\hline EF & & Enrichment factor & SI \\
\hline $\mathrm{EC}_{10}$ & $\begin{array}{l}\mathrm{mL} / \mathrm{mL}_{\text {bioassay }} \\
\text { or } \\
\mathrm{g} / \mathrm{mL}_{\text {bioassay }} \\
\mathrm{mL} / \mathrm{mL}_{\text {bioassay }}\end{array}$ & Concentration causing $10 \%$ of the maximum effect & SI \\
\hline $\mathrm{EC}_{\mathrm{IR} 1.5}$ & $\begin{array}{l}\text { or } \\
\mathrm{g} / \mathrm{mL}_{\text {bioassay }} \\
\mathrm{mL} / \mathrm{mL}_{\text {bioassay }}\end{array}$ & Concentration causing an induction ratio IR of 1.5 & SI \\
\hline $\mathrm{IC}_{10}$ & $\begin{array}{l}\text { or } \\
\mathrm{g} / \mathrm{mL}_{\text {bioassay }}\end{array}$ & $10 \%$ of the maximum inhibitory concentration & SI \\
\hline
\end{tabular}


${ }^{a} \mathrm{OC}$ : organic carbon; ${ }^{\mathrm{b}} \mathrm{SPM}$ : suspended particulate matter; ${ }^{\mathrm{C}} \mathrm{DOC}$ : dissolved organic carbon; ${ }^{\mathrm{d}} \mathrm{SPE}$ : solid phase extraction; ${ }^{\mathrm{e}} \mathrm{LVSPE}$ : large volume solid phase extraction; fPDMS:

polydimethylsiloxane; ${ }^{\mathrm{g} E E S}$ : passive equilibrium sampling; ${ }^{\mathrm{h}} \mathrm{ASE}$ : accelerated solvent extraction; 


\section{Text S1. Sampling and characterizing of samples}

For the filtration of suspended particulate matter (SPM) from the water phase, 2-3 pieces of metal filters were used at each site due to the clogging and they were wrapped in aluminum foil after sampling. After delivery to the lab at University of Tübingen, the SPM was removed from metal filters with ultrasonication. The SPM from individual filters was combined together and freezedried prior to further transport and analysis.

The cartridge equipped in the large volume solid-phase extraction (LVSPE) was filled with $10 \mathrm{~g}$ of Chromabond HR-X sorbent (Macherey Nagel, Germany). The cartridges were preconditioned with $200 \mathrm{~mL}$ of ethyl acetate, $200 \mathrm{~mL}$ of methanol and $100 \mathrm{~mL}$ of water before use according to the method established by Schulze et al. ${ }^{1}$ A total of $40 \mathrm{~L}$ at Site A and $20 \mathrm{~L}$ water at Site B was automatically loaded on the SPE cartridges of LVSPE with 80 or 40 cycles of $500 \mathrm{~mL}$ sub-samples. After sampling, both the ends of the cartridge were closed, and the cartridges were stored in cool bags. A clean LVSPE cartridge and filter were prepared as travel blanks during the sampling campaign. A machine blank was also done on site by setting several eircles cycles with MilliQ water through LVSPE to check any possible contamination.

The mass concentration of SPM in water ([SPM], $\mathrm{mg}_{\mathrm{dw}} / \mathrm{L}$ ) was quantified by weighing the ultrasonicated SPM after freeze-drying. The particles captured by LVSPE were also determined gravimetrically after drying. The dissolved organic carbon content ([DOC], mgoc/L) was measured by a total organic carbon (TOC) analyzer (Elementar HighTOC, Langenselbold, Germany) after filtration through a $0.45 \mu \mathrm{m}$ cellulose acetate filter and acidification with hydrochloric acid to $\mathrm{pH}$ of 2 . The organic carbon content of SPM ([OC, SPM], goc/gSP,dw) and sediment ([OC, sediment], $\mathrm{g}_{\mathrm{OC}} / \mathrm{g}_{\mathrm{sed}, \mathrm{dw}}$ ) were determined in the same way as DOC determination with homogenization but without filtration. ${ }^{2}$ The total organic matter (TOC) content of water samples were also measured, but they were not further reported because of the small difference from the DOC in water and the consideration of the measurement uncertainty. The sediments were weighed before and after freeze-drying to determine the water content $\left(\mathrm{m}_{\mathrm{w}} / \mathrm{m}_{\text {sed }}, \%\right)$. 
Table S2. Physicochemical properties of river water.

\begin{tabular}{llll}
\hline Parameter & & Site A & Site B \\
\hline Temperature $\left({ }^{\circ} \mathrm{C}\right)$ & 12.8 & 16.6 \\
Electrical conductivity (not compensated, $\mu \mathrm{S} / \mathrm{cm})$ & 775 & 1353 \\
Electrical conductivity 25 (compensated, $\mu \mathrm{S} / \mathrm{cm})$ & 1025 & 1626 \\
Turbidity (NTU) & & $3.98 \pm 0.07$ & $2.66 \pm 0.05$ \\
$\mathrm{pH}$ & & 7.65 & 7.98 \\
Cations (mg/L) & $16.6 \pm 0.1$ & $35.5 \pm 0.1$ \\
& $\mathrm{Na}^{+}$ & $<0.4$ & $<0.4$ \\
$\mathrm{NH}_{4}{ }^{+}$ & $3.05 \pm 0.02$ & $7.54 \pm 0.03$ \\
& $\mathrm{~K}^{+}$ & $48.0 \pm 0.2$ & $49.3 \pm 0.5$ \\
$\mathrm{Mg}^{2+}$ & $169 \pm 0$ & $231 \pm 1$ \\
$\mathrm{Ca}^{2+}$ & $0.222 \pm 0.002$ & $0.205 \pm 0.002$ \\
& $\mathrm{~F}^{-}$ & $42.2 \pm 0.0$ & $72.3 \pm 0.1$ \\
$\mathrm{Cl}^{-}$ & $<0.1$ & $<0.1$ \\
& $\mathrm{NO}_{2}{ }^{-}$ & $<0.1$ & $<0.1$ \\
& $\mathrm{Br}^{-}$ & $27.9 \pm 0.0$ & $31.6 \pm 0.0$ \\
& $\mathrm{NO}_{3}{ }^{-}$ & $<0.3$ & $<0.3$ \\
$\mathrm{PO}_{4}{ }^{3-}$ & $166 \pm 1$ & $337 \pm 1$ \\
\hline $\mathrm{SO}_{4}{ }^{2-}$ & &
\end{tabular}

\section{Text S2. Pretreatment of water and particle samples}

After preconditioning with $10 \mathrm{~mL}$ of ethyl acetate, $10 \mathrm{~mL}$ of methanol and $10 \mathrm{~mL}$ of water, around $2 \mathrm{~L}$ of water samples were pass through the solid phase extraction (SPE) cartridges (500 mg HR$\mathrm{X}$ cartridges, Chromabond, Macherey-Nagel, Düren, Germany) drop by drop with a vacuum manifold. The cartridges were dried under a gentle stream of nitrogen and eluted by $10 \mathrm{~mL}$ of ethyl acetate and $10 \mathrm{~mL}$ methanol continuously. The eluates were combined, reduced to dryness under a gentle stream of nitrogen and reconstituted in $0.5 \mathrm{~mL}$ of methanol. They were diluted to appropriate enrichment factor when needed during chemical and biological analysis. A solvent blank and a HPLC water blank were processed along with the field samples for SPE.

In the case of LVSPE, the loaded cartridges were freeze-dried and eluted consecutively with 100 $\mathrm{mL}$ of ethyl acetate, $100 \mathrm{~mL}$ of methanol, $100 \mathrm{~mL}$ of methanol with $1 \%$ of formic acid and 100 $\mathrm{mL}$ of methanol with $2 \% 7 \mathrm{~N}$ ammonia and concentrated in methanol to achieve an enrichment factor of 1000 according to Schulze et al. ${ }^{1}$ A machine blank and a solvent blank were treated in parallel with the field samples. 
The freeze-dried SPM remained from passive equilibrium sampling (PES) and the LVSPE filters were put into individual accelerated solvent extraction (ASE) cells with $1 \mathrm{~g}$ of hydromatrix. The sediment was sieved with a $63 \mu \mathrm{m}$ mesh to exclude gravel and other larger particles and homogenized before extraction. Ethyl acetate and acetone with the ratio of 1:1 were used as the extraction solvents under two cycles of $5 \mathrm{~min}$ at $100^{\circ} \mathrm{C}$ and $10.3 \mathrm{MPa}$. Afterwards the solvents containing targets were concentrated and divided into two parts, one part was subsequently subjected to the following clean-up procedures. The silica gel columns of Chromabond Flash (Macherey-Nagel, Düren, Germany) were firstly preconditioned with dichloromethane. Then the concentrated extracts from ASE were loaded on the column and then eluted with dichloromethane and methanol sequentially. The eluates were collected separately. Half of the dichloromethane extracts was mixed with half methanol extracts and then evaporated and reconstituted in $0.5 \mathrm{~mL}$ of methanol. This mixed extracts were used for LC analysis and dosing bioassays. The dichloromethane extracts were used for GC analysis after solvent-exchange to ethyl acetate. Blanks with only hydromatrix and blank filter plus hydromatrix were treated with the same procedures as field samples. All the treatment of ASE and clean-up were processed in triplicates.

\section{Text S3. Passive equilibrium sampling}

Approximately $350 \mathrm{mg}$ of freeze-dried SPM or $1.50 \mathrm{~g}$ of sediment were resuspended with $5 \mathrm{~mL}$ of filtered water and equilibrated with polydimethylsiloxane (PDMS) disks (thickness of $0.6 \mathrm{~mm}$, weight of approximately $74 \mathrm{mg}$, pre-cleaned by Soxhlet with ethyl acetate) and $0.1 \%$ sodium azide $\left(\mathrm{NaN}_{3}\right)$ in $10 \mathrm{~mL}$ brown vials at $200 \mathrm{rpm}$ for 50 days. Process blanks contained only MilliQ water, $\mathrm{NaN}_{3}$ and PDMS sheets were included with every batch.

The mass balance is given by Eq. $\mathrm{S} 1$, where $\mathrm{n}_{\mathrm{i} \text {,particle,ww }}(\mathrm{mol})$ is the total molar amount of chemicals in bulk particles; $\mathrm{n}_{\mathrm{i}, \mathrm{OC}}$ is the molar amount of chemical $\mathrm{i}$ bound to $\mathrm{OC} ; \mathrm{n}_{\mathrm{i}, \mathrm{pw}}$ is the molar amount of chemical $\mathrm{i}$ dissolved in pore water; $\mathrm{n}_{\mathrm{i} \text {,residual }}$ is the molar amount of inaccessible chemical $\mathrm{i}$. The mass balance can interchangeably be expressed in molar or mass concentrations. We derived the equations on a molar basis but they can be converted with the molecular weight of chemical i $\mathrm{MW}_{\mathrm{i}}$ ( $\mathrm{g} / \mathrm{mol})$ into mass basis.

$\mathrm{n}_{\text {i.particle,ww }}=\mathrm{n}_{\mathrm{i} . \mathrm{OC}}+\mathrm{n}_{\mathrm{i}, \mathrm{pw}}+\mathrm{n}_{\mathrm{i}, \text { residual }}$

The mass ratios of PDMS to sediment or SPM fPDMS were predicted based on their OC content aiming at $50 \%$ of the depletion according to Eq. S2.

$\mathrm{f}_{\text {PDMS }}=\frac{n_{i, \text { PDMS }}}{n_{i, \text { PDMS }}+n_{i, O C}+n_{i, p w}}=\frac{C_{i, P D M S} \times m_{\text {PDMS }}}{C_{i, \text { PDMS }} \times m_{\text {PDMS }}+C_{i, O C} \times m_{O C}+C_{i, p w} \times m_{p w}}=\frac{1}{1+\frac{C_{i, O C}}{C_{i, P D M S}} \times \frac{m_{O C}}{m_{P D M S}}+\frac{C_{i, p w}}{C_{i, P D M S}} \times \frac{m_{p w}}{m_{\text {PDMS }}}}$

The actual depletion fractions ranged only $0.02 \%-2.67 \%$ in AhR CALUX, $2.95 \%-15.8 \%$ in PPAR $\gamma$ GeneBLAzer and $0.35 \%-15.9 \%$ in AREc32 bioassays (Table S3), generally meeting 
negligible-depletive conditions. For consistency, the full mass balance equation was applied in all cases.

Due to the limited amount of SPM available, the SPM slurry were freeze-dried again after PES and subjected to ASE, which expands the mass balance equation to Eq. S3. Therefore, the total concentrations of chemicals in SPM $\left(\mathrm{C}_{\mathrm{i}, \mathrm{SPM}}\left(\mathrm{ng} / \mathrm{g}_{\mathrm{SPM}, \mathrm{dw}}\right)\right.$ was calculated by the sum of those extracted by ASE ( $\left.\mathrm{n}_{\mathrm{i}, \mathrm{ASE}}, \mathrm{mol}\right)$ and PDMS sheets ( $\mathrm{n}_{\mathrm{i}, \mathrm{PDMS}}$, mol) minus those in water phase $\left(\mathrm{n}_{\mathrm{i}, \mathrm{w}}\right.$, mol) by Eq. S4, where mSPM,dw is the mass of freeze-dried SPM (g).

$\mathrm{n}_{\mathrm{i}, \text { total, ww }}=\mathrm{n}_{\mathrm{i} . \mathrm{ASE}}+\mathrm{n}_{\mathrm{i}, \mathrm{PDMS}}=\mathrm{n}_{\mathrm{i}, \mathrm{SPM}, \mathrm{dw}}+\mathrm{n}_{\mathrm{i}, \mathrm{w}}$

$\mathrm{C}_{\mathrm{i}, \mathrm{SPM}, \mathrm{dw}}=\frac{\mathrm{n}_{\mathrm{i}, \mathrm{ASE}}+\mathrm{n}_{\mathrm{i}, \mathrm{PDMS}}-\mathrm{n}_{\mathrm{i}, \mathrm{w}}}{\mathrm{m}_{\mathrm{SPM}, \mathrm{dw}}}$

The $\mathrm{C}_{\mathrm{i}, \mathrm{OC}}$ and $\mathrm{C}_{\mathrm{i}, \mathrm{pw}}$ was derived from $\mathrm{C}_{\mathrm{i}, \mathrm{PDMS}}$ with the compound-specific partition coefficient between PDMS and OC $\left(K_{\mathrm{i}, \mathrm{PDMS} / \mathrm{OC}}\right)$ (Eq. S5) and between PDMS and water $\left(K_{\mathrm{i}, \mathrm{PDMS} / \mathrm{w}}\right)$ (Eq. 2$){ }^{3}$

$\mathrm{C}_{\mathrm{i}, \mathrm{OC}}=\frac{\mathrm{C}_{\mathrm{i}, \mathrm{PDMS}}}{K_{\mathrm{i}, \mathrm{PDMS} / \mathrm{OC}}}$

The bioavailable fractions of individual chemicals in particles ( $\left.\mathrm{F}_{\mathrm{i}, \text { bioavailable,chem }}\right)$ can be obtained by the sum of the chemicals bound to organic carbon $\left(\mathrm{n}_{\mathrm{i}, \mathrm{OC}}\right)$ and dissolved in water phase $\left(\mathrm{n}_{\mathrm{i}, \mathrm{pw}}\right)$ divided by the ones in exhaustive extracts ( $\left.\mathrm{n}_{\mathrm{i}, \text { particle,ww }}\right)$.

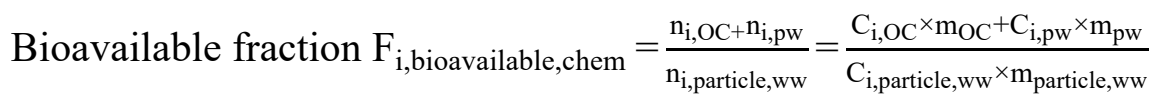

The bioavailable fraction of chemical mixtures from the bioassays $\left(\mathrm{F}_{\text {bioavailable,bio }}\right)$ can be calculated in a similar way with bioanalytical equivalent concentration (BEQ). It is practical to derive BEQoc from BEQpDMs with a consensus $K_{\mathrm{PDMS} / \mathrm{OC}}$ of 1 for all chemicals ${ }^{3}$ (Eq. S7). Since the $\mathrm{BEQ}_{\mathrm{w}}$ is typically far smaller than BEQoc if hydrophobic chemicals are present in the environmental mixtures and the $K_{\mathrm{PDMS} / \mathrm{w}}$ varied greatly between different chemicals, the calculation of $\mathrm{F}_{\text {bioavailable,bio }}$ can be simplified as Eq. S8.

$\mathrm{BEQ}_{\mathrm{bio}, \mathrm{OC}}=\frac{\mathrm{BEQ}_{\mathrm{PDMS}}}{K_{\mathrm{PDMS} / \mathrm{OC}}}$

Bioavailable fraction $\mathrm{F}_{\text {bioavailable, bio }}=\frac{\mathrm{BEQ}_{\mathrm{OC}} \times \mathrm{m}_{\mathrm{OC}}}{\mathrm{BEQ}_{\text {bio, particle,ww }} \times \mathrm{m}_{\text {particle,ww }}}$ 
Table S3. Depletion fractions f fDMs of chemical mixtures by polydimethylsiloxane (PDMS) from suspended particulate matter (SPM) and sediment in passive equilibrium sampling.

\begin{tabular}{lllll}
\hline \multirow{3}{*}{ SPM } & & AhR CALUX & PPAR $\boldsymbol{\gamma}$ GeneBLAzer & AREc32 \\
& Site A & $1.81 \%$ & $15.8 \%$ & $9.55 \%$ \\
\multirow{3}{*}{ Sediment } & Site B & $1.25 \%$ & $10.2 \%$ & $15.9 \%$ \\
& Site A & $2.67 \%$ & $2.95 \%$ & $5.68 \%$ \\
& Site B & $0.02 \%$ & $5.62 \%$ & $0.35 \%$ \\
\hline
\end{tabular}

\section{Text S4. Uptake kinetics experiment}

Before PES for all samples, a kinetics testing was conducted to determine how it will take for chemicals to reach equilibrium between PDMS, particles and water. Seven polychlorinated biphenyls (PCB 28, PCB 52, PCB 101, PCB 118, PCB 138, PCB 153 and PCB 180) were spiked in sediment as indicators to estimate the uptake kinetics of PDMS. Three thicknesses of PDMS sheets (around $65 \mathrm{mg}$ for $1 \mathrm{~mm}$-PDMS, $74 \mathrm{mg}$ for $0.6 \mathrm{~mm}$-PDMS and $58 \mathrm{mg}$ for $0.25 \mathrm{~mm}$-PDMS) with around 1.2-1.5 g of sediment from Site A were put together into $10 \mathrm{~mL}$ brown vials containing $5 \mathrm{~mL}$ of filtered river water and $0.1 \%$ of $\mathrm{NaN}_{3}$. The vials were agitated at $200 \mathrm{rpm}$ with an orbital shaker. The PDMS sheets were taken out and analyzed on the $16^{\text {th }}, 21^{\text {st }}, 40^{\text {th }}\left(33^{\text {rd }}\right.$ for $0.6 \mathrm{~mm}$ PDMS) and $50^{\text {th }}$ day.

The uptake rate constant $\mathrm{k}\left(\mathrm{d}^{-1}\right)$ for the uptake kinetics of PCBs were derived from Eq. S9 and the uptake curves together with the fits are shown in Fig. S1.

$\mathrm{m}_{\mathrm{i}, \mathrm{PDMS}, \mathrm{t}}=\mathrm{m}_{\mathrm{i}, \mathrm{PDMS}, \mathrm{eq}} \times\left(1-\mathrm{e}^{-\mathrm{kt}}\right)$

where $m_{i, P D M S}, t(n g)$ is the amount of PCBs in PDMS sheets at time $t(d) ; m_{i, P D M S}$,eq is the amount of PCBs in PDMS sheets at equilibrium.

The uptake kinetics of different thicknesses of PDMS sheets were similar for the less hydrophobic PCBs, whereas they differed for the more hydrophobic ones (Fig. S1) with uptake rate constants listed in Table S4. 

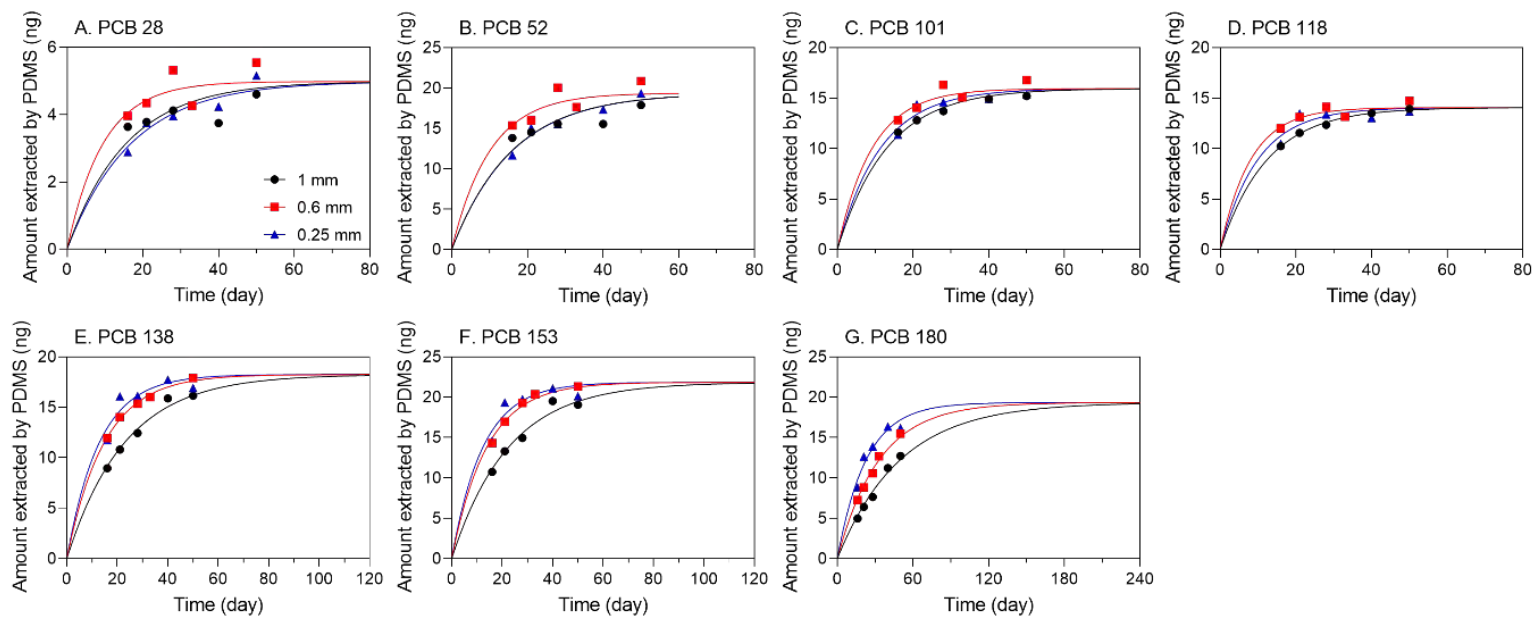

Fig. S1. Time- and thicknesses-series of uptake kinetics for polychlorinated biphenyls (PCBs) between polydimethylsiloxane (PDMS) and sediment. The curves were fitted using a one-compartment uptake model (Eq. S9).

The time for attaining $95 \%$ of the equilibrium $\left(\mathrm{t}_{95 \%}\right)$ was estimated by Eq. $\mathrm{S} 10$ and results are given in Table S4:

$\mathrm{t}_{95 \%}=\frac{\ln 20}{\mathrm{k}}$

Table S4. Kinetic parameters of PCB indicators between sediment and different thicknesses of polydimethylsiloxane (PDMS) sheets during passive equilibrium sampling.

\begin{tabular}{lllllll}
\hline & \multicolumn{2}{c}{ 1 mm-PDMS } & \multicolumn{2}{c}{ 0.6 mm-PDMS } & \multicolumn{2}{c}{ 0.25 mm-PDMS } \\
\cline { 2 - 7 } & $\mathrm{k}\left(\mathrm{d}^{-1}\right)$ & $\mathrm{t}_{95}(\mathrm{~d})$ & $\mathrm{k}\left(\mathrm{d}^{-1}\right)$ & $\mathrm{t}_{95 \%}(\mathrm{~d})$ & $\mathrm{k}\left(\mathrm{d}^{-1}\right)$ & $\mathrm{t}_{95}(\mathrm{~d})$ \\
\hline PCB 28 & 0.06 & 47 & 0.10 & 29 & 0.06 & 51 \\
PCB 52 & 0.06 & 48 & 0.10 & 30 & 0.06 & 48 \\
PCB 101 & 0.08 & 39 & 0.11 & 28 & 0.09 & 34 \\
PCB 118 & 0.08 & 37 & 0.12 & 24 & 0.10 & 30 \\
PCB 138 & 0.04 & 69 & 0.07 & 45 & 0.08 & 39 \\
PCB 153 & 0.04 & 67 & 0.07 & 42 & 0.08 & 37 \\
PCB 180 & 0.02 & 149 & 0.03 & 99 & 0.04 & 68 \\
\hline
\end{tabular}

The $t_{95} \%$ increased with the increasing of the $\log K_{\text {ow }}$ of PCBs (Fig. S2A). The $t_{95} \%$ were around 50 days and similar for all thicknesses of PDMS up to $\log K_{\text {ow }} 7$, and they were longer for thicker PDMS and for higher $\log K_{\text {ow. }}$. After 50 days, the chemicals with $\log K_{\text {ow }}<7.8$ were extracted by more than $80 \%$ and chemicals with $\log K_{\text {ow }}<6.5$ were fully extracted when compared to the 
equilibrium levels (Fig. S2B). Among the analyzed chemicals in this study, 10 of 642 chemicals have $\log K_{\text {ow }} \geq 7.8$ and 32 chemicals have $\log K_{\text {ow }} \geq 6.5$. Therefore, 50 days were deemed sufficient for the analyzed chemicals to reach approximate equilibrium between PDMS and particles, which guaranteed the following experiments and analysis.
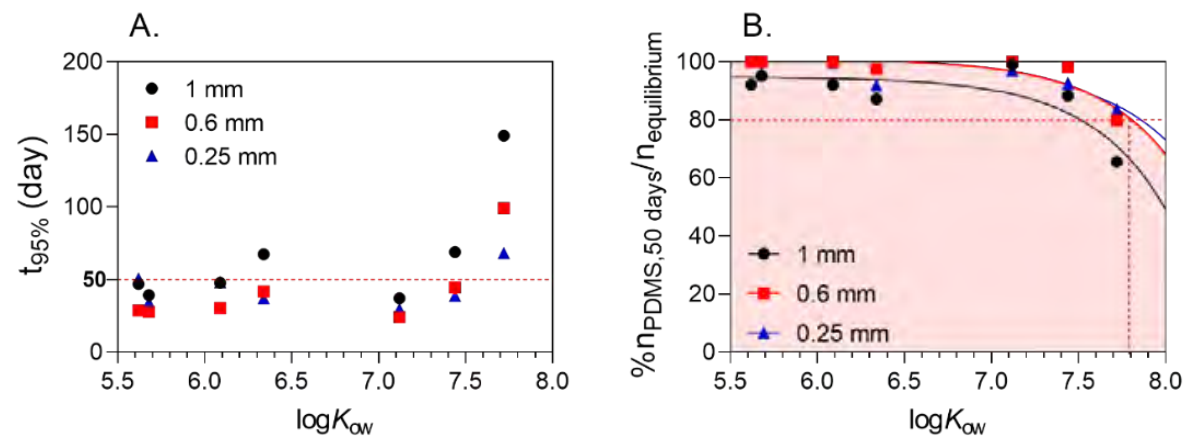

Fig. S2. Correlations (A) between the $\log K_{\text {ow }}$ and the $t_{95 \%}$ (Eq. S10) and (B) between the $\log K_{0 w}$ and the ratio of polychlorinated biphenyls (PCBs) extracted by polydimethylsiloxane (PDMS) on day 50.

Table S5. Summary of chemicals determined by LC and GC instruments (modified from Niu et al. ${ }^{3}$ ) - see Supporting Information excel file.

Table S6. Concentrations of detected chemicals in water samples, suspended particulate matter (SPM), sediment and polydimethylsiloxane (PDMS) extracts - see Supporting Information excel file. 
Table S7. Toxicity data of individual chemicals used in iceberg modeling for AhR CALUX, PPAR $\gamma$ GeneBLAzer and AREc32 bioassays (reprinted with permission from Niu, L. L.; Carmona, E.; Konig, M.; Krauss, M.; Muz, M.; Xu, C.; Zou, D. L.; Escher, B. I., Mixture Risk Drivers in Freshwater Sediments and Their Bioavailability Determined Using Passive Equilibrium Sampling. Environ. Sci. Technol. 2020, 54, (20), 13197-13206. Copyright (2020) American Chemical Society). ${ }^{3}$ - see Supporting Information excel file.

Table S8. Toxicity data of individual chemicals used in iceberg modeling for algae assay (reprinted from Glauch and Escher, 2020) ${ }^{4}$ - see Supporting Information excel file.

\section{Text S5. Data evaluation of bioassays}

The relative enrichment factor (REF) was used as the concentration unit of the chemical mixtures (Eqs. S11-S13).

Enrichment factor $E F=\frac{m_{\text {particle, }} \mathrm{dw}}{\mathrm{v}_{\text {extract }}}$ or $\mathrm{EF}=\frac{\mathrm{m}_{\text {PDMS }}}{\mathrm{V}_{\text {extract }}}$ or $\mathrm{EF}=\frac{\mathrm{V}_{\mathrm{w}}}{\mathrm{V}_{\text {extract }}}$

Dilution factor $\mathrm{DF}=\frac{\mathrm{V}_{\text {extract added to bioassay }}}{\mathrm{V}_{\text {bioassay }}}$

$\mathrm{REF}=\mathrm{EF} \times \mathrm{DF}$

The biological effect was expressed as bioanalytical equivalent concentrations BEQbio (Eq. S14) based on $\mathrm{EC}_{10}$ (concentration causing $10 \%$ of the effect) or $\mathrm{EC}_{\mathrm{IR} 1.5}$ (concentration causing an inhibition rate of 1.5$)$.

$\mathrm{BEQ}_{\mathrm{bio}}=\frac{\mathrm{EC}_{10, \text { ref }}}{\mathrm{EC}_{10 \text {,sample }}}$ or $\frac{\mathrm{EC}_{\mathrm{IR} 1.5, \text { ref }}}{\mathrm{EC}_{\mathrm{IR} 1.5, \text { sample }}}$

The toxic unit (TU) regarding the cytotoxicity in vitro bioassays caused by sample mixtures were derived based on the $10 \%$ of the maximum inhibitory concentration $\left(\mathrm{IC}_{10}\right)$ and the $\mathrm{TU}$ regarding the growth inhibition of algae were estimated based on the $10 \%$ of the maximum growth inhibition concentration $\left(\mathrm{IC}_{10}\right)$.

$\mathrm{TU}_{\mathrm{bio}}=\frac{1}{\mathrm{IC}_{10}}$

The $\mathrm{EC}_{10}$ for $\mathrm{AhR}, \mathrm{PPAR} \gamma$ and algae assays or the induction ratio IR of 1.5 (ECIR1.5) for AREc32 were obtained from the linear concentration-effect curves with effect concentrations lower than 
$30 \%$ or induction ratio lower than $4 .{ }^{5}$ Only concentrations below $\mathrm{IC}_{10}$ were considered in the estimation of BEQ.

The $\mathrm{BEQ}_{\text {chem }}$ and $\mathrm{TU}_{\text {chem }}$ were derived with Eqs. S16-S17.

$$
\begin{aligned}
& \mathrm{BEQ}_{\text {chem }}=\sum_{\mathrm{i}=1}^{\mathrm{n}}\left(\mathrm{C}_{\mathrm{i}} \times \mathrm{REP}_{\mathrm{i}}\right) \\
& \mathrm{REP}_{\mathrm{i}}=\frac{\mathrm{EC}_{10, \text { ref }}}{\mathrm{EC}_{10, \mathrm{i}}} \text { or } \frac{\mathrm{EC}_{\mathrm{IR} 1.5, \text { ref }}}{\mathrm{EC}_{\mathrm{IR} 1.5, \mathrm{i}}} \\
& \mathrm{TU}_{\text {chem }}=\sum_{\mathrm{i}=1}^{\mathrm{n}} \frac{\mathrm{C}_{\mathrm{i}}}{\mathrm{IC}_{10, \mathrm{i}}}
\end{aligned}
$$

\section{Text S6. Comparison of LVSPE and filtration methods on water monitoring}

The concentrations of chemicals bound to suspended particles and water phase determined using the LVSPE device and the conventional filtration method are listed in Table S6. The dissolved and SPM-bound chemicals were further compared between these two methods in Fig. S3. The dissolved neutral chemicals (Fig. S3A) and most of the hydrophilic chemicals (Fig. S3B) were well distributed along the 1:1 line, indicating the similar applicability of these two methods for the measurement of dissolved chemicals in water phase. However, nearly all the SPM-bound chemicals collected with LVSPE showed 1-100 times higher concentrations than those collected with metal filters (Fig. S3C and S3D). This might result from the uncertainty of the SPM weight on LVSPE filters because of the smaller amount of water filtered by LVSPE than by metal filters (40/20 L vs. 2000 L). In addition, even though we tried the best to remove the SPM from metal filters, there was still some clogging particles that could not be recovered. This might also result in the deviation of SPM-bound chemicals between the LVSPE and the filtration method.

The concentrations of chemicals in the total water column that composed of dissolved and SPMbound chemicals were further calculated and are plotted in Fig. S4. Due to the predominance of dissolved chemicals in water column, the concentrations of most individual chemicals estimated by the LVSPE and the filtration method varied within 1 order of magnitude. The total concentrations measured with the LVSPE were basically higher than those by the filtration method, with the median $\mathrm{C}_{\text {tot,LVSPE}} / \mathrm{C}_{\text {tot,SPM+SPE }}$ of 1.6 (Fig. S5A). However, this ratio showed no relationships with the $K_{\text {ow }}$ of chemicals (Fig. S5B). Considering the similarity of these two methods on characterizing the chemical concentrations for most of chemicals and the biological effects observed in total water column, we conclude that the LVSPE can be considered as an alternative to the conventional filtration method for water monitoring, but we suggest increasing the sampled amount of SPM obtained by LVSPE to improve the accuracy. 
A. Dissolved neutral and

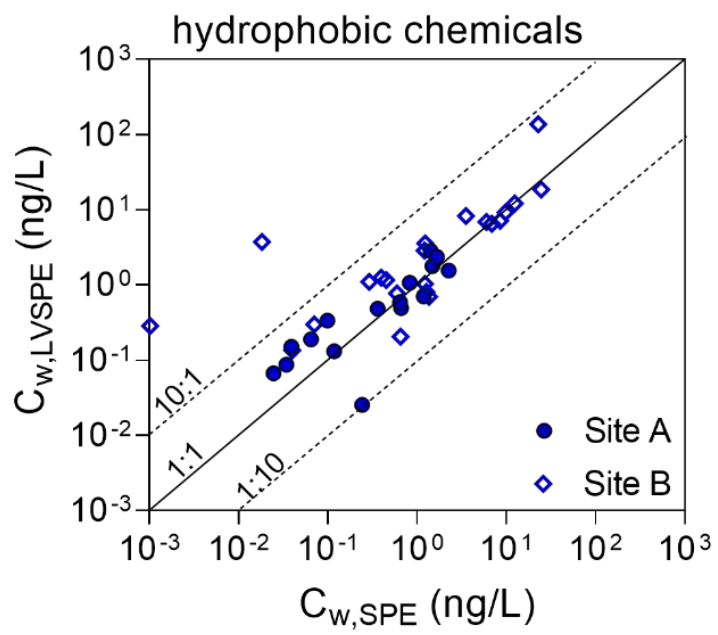

C. SPM-bound neutral and hydrophobic chemicals

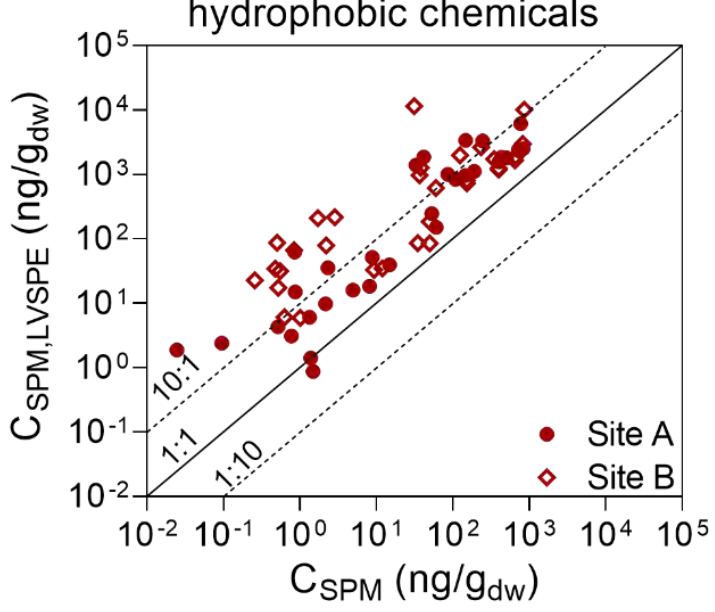

B. Dissoved charged or hydrophilic chemicals

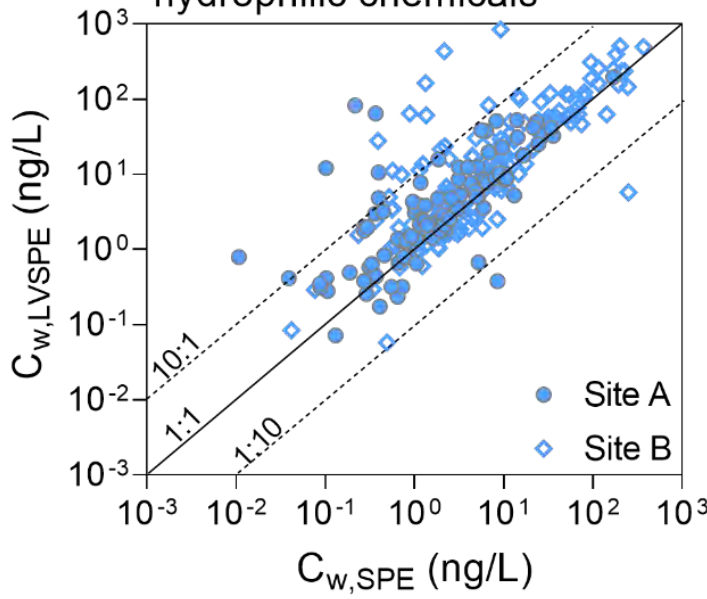

D. SPM-bound charged or hydrophilic chemicals

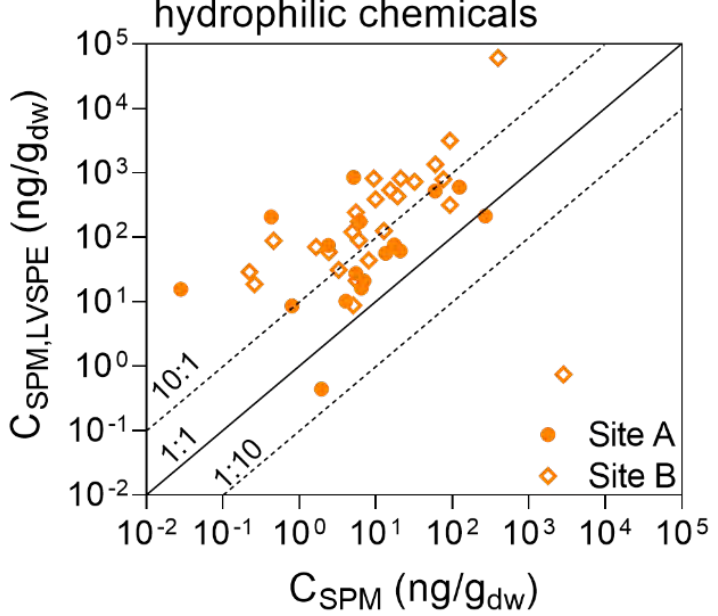

Fig. S3. Comparison of concentrations of dissolved and suspended particulate matter (SPM)-bound chemicals obtained from the large volume solid phase extraction (LVSPE) and the conventional filtration method. SPE: solid phase extraction. Concentrations are from Table S6. 

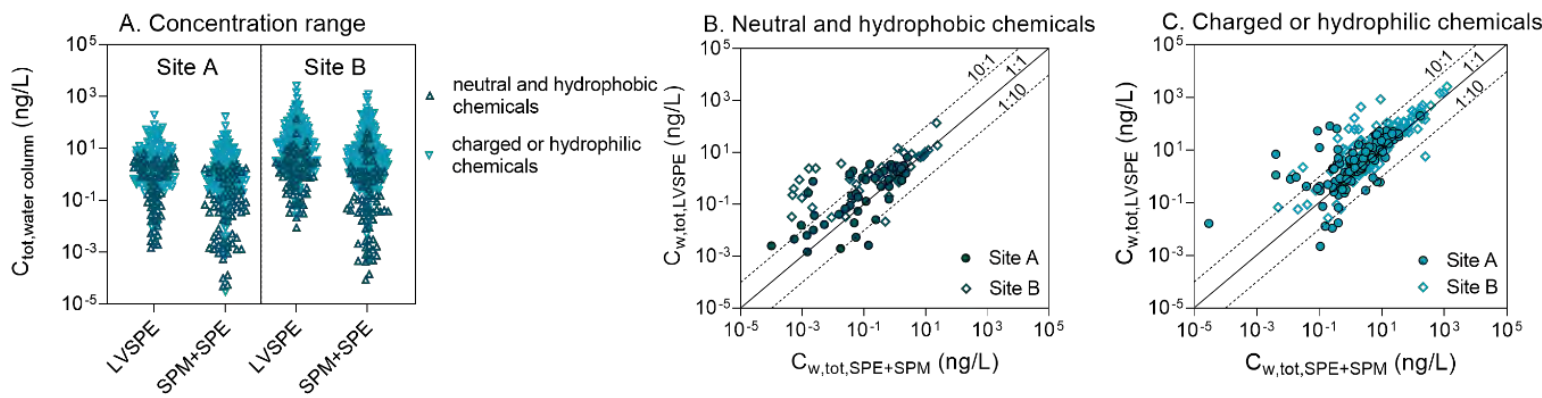

Fig. S4. Comparison of individual chemical concentrations in total water column estimated by the large volume solid phase extraction (LVSPE) and the filtration method. SPM: suspended particulate matter; SPE: solid phase extraction. Concentrations are from Table S6.
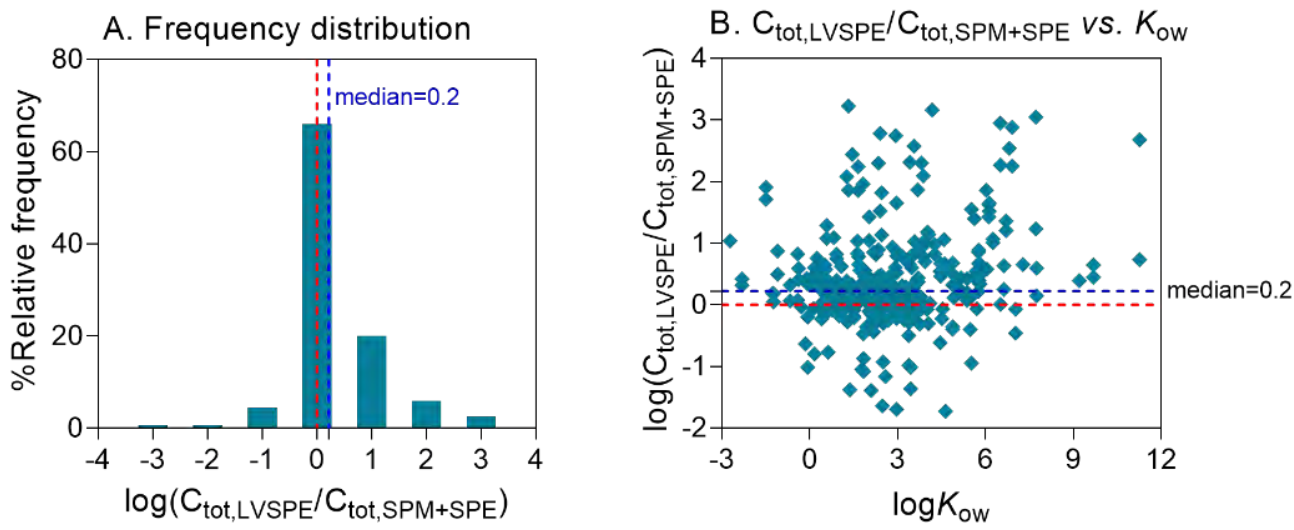

Fig. S5. (A) The frequency distribution of $\mathrm{C}_{\text {tot,LVSPE }} / \mathrm{C}_{\text {tot,SPM+SPE }}$ and (C) its relationship with the octanol water partition constants $K_{0 w}$ of chemicals. LVSPE: large volume solid phase extraction; SPM: suspended particulate matter; SPE: solid phase extraction. $\log K_{0 w}$ and concentrations are from Table S6.

Table S9. Number of chemicals measured, detected and with available toxicity data - see Supporting Information excel file. 

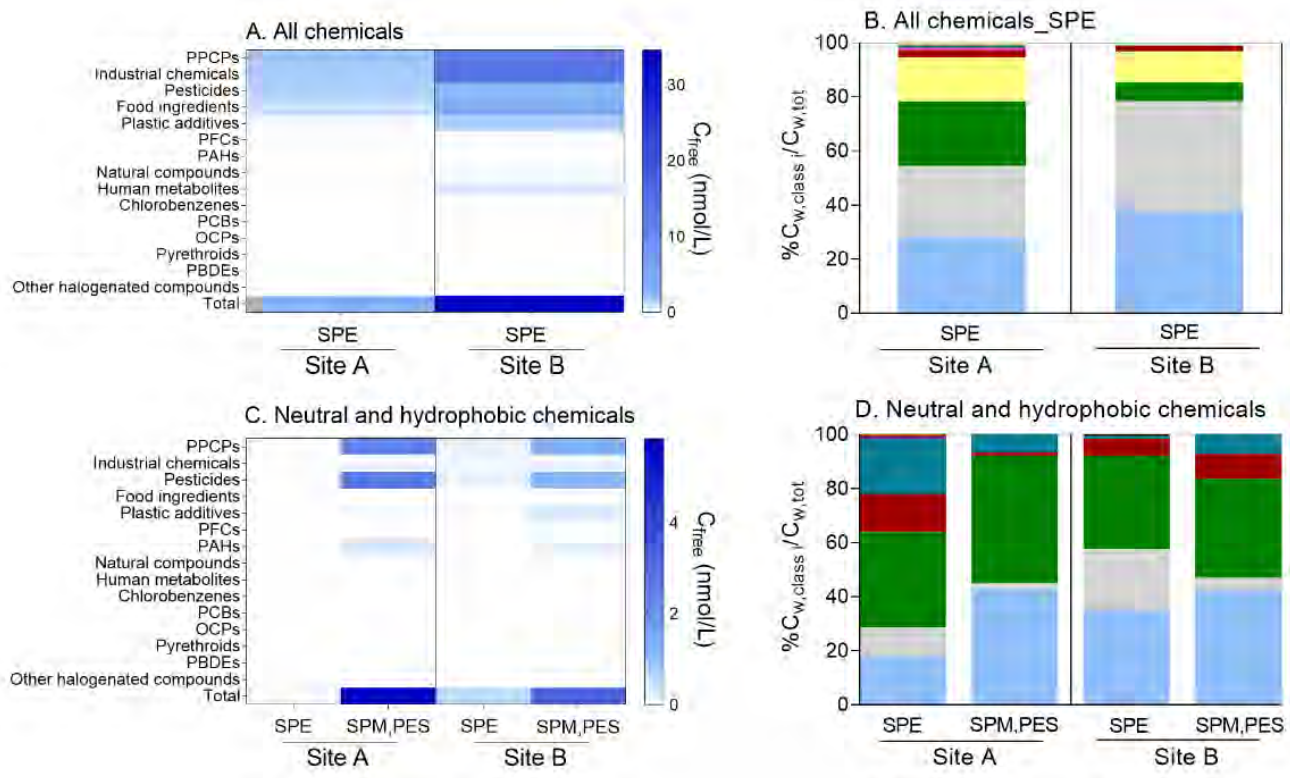

PPCPs

Industrial chemicals

- Pesticides food ingredients

- Plastic additives

n PFCs

- PAHs

Datural compounds

Human metabolites

- chlorobenzenes

- PCBs

OCPS

Pyrethroids

other halogenated

compounds

(1) PBDEs
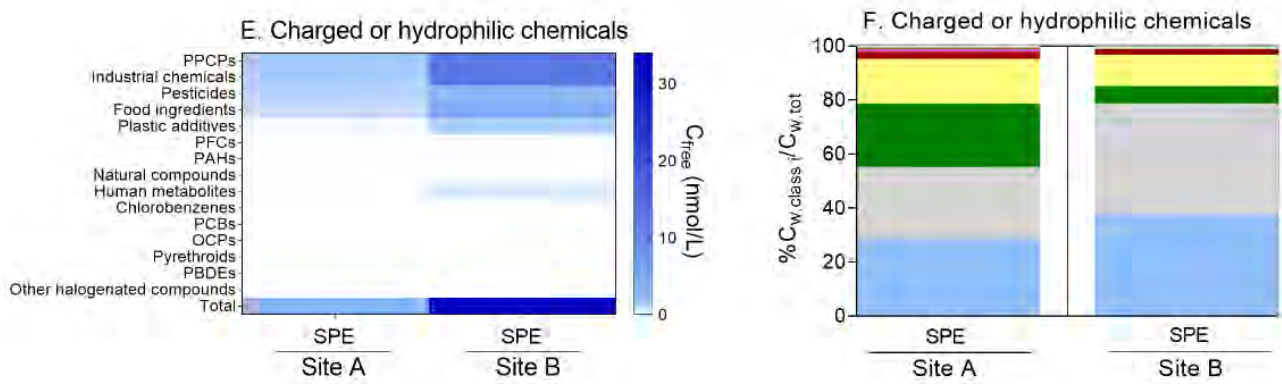

Fig. S6. (A, C and E) Sum of chemical concentrations for different chemical groups and (B, $D$ and $F$ ) composition of surface water extracts estimated by solid phase extraction (SPE) and passive equilibrium sampling (PES) method. PPCPs: pharmaceuticals and personal care products; PFCs: perfluorinated compounds; PAHs: polycyclic aromatic hydrocarbons; PCBs: polychlorinated biphenyls; OCPs: organochlorine pesticides; PBDE: polybrominated diphenyl ethers. Concentrations and grouping into compound classes are given in Table S6. 
Table S10. Top 20 chemicals identified according to their contributions to the total detected concentrations. - see Supporting Information excel file.
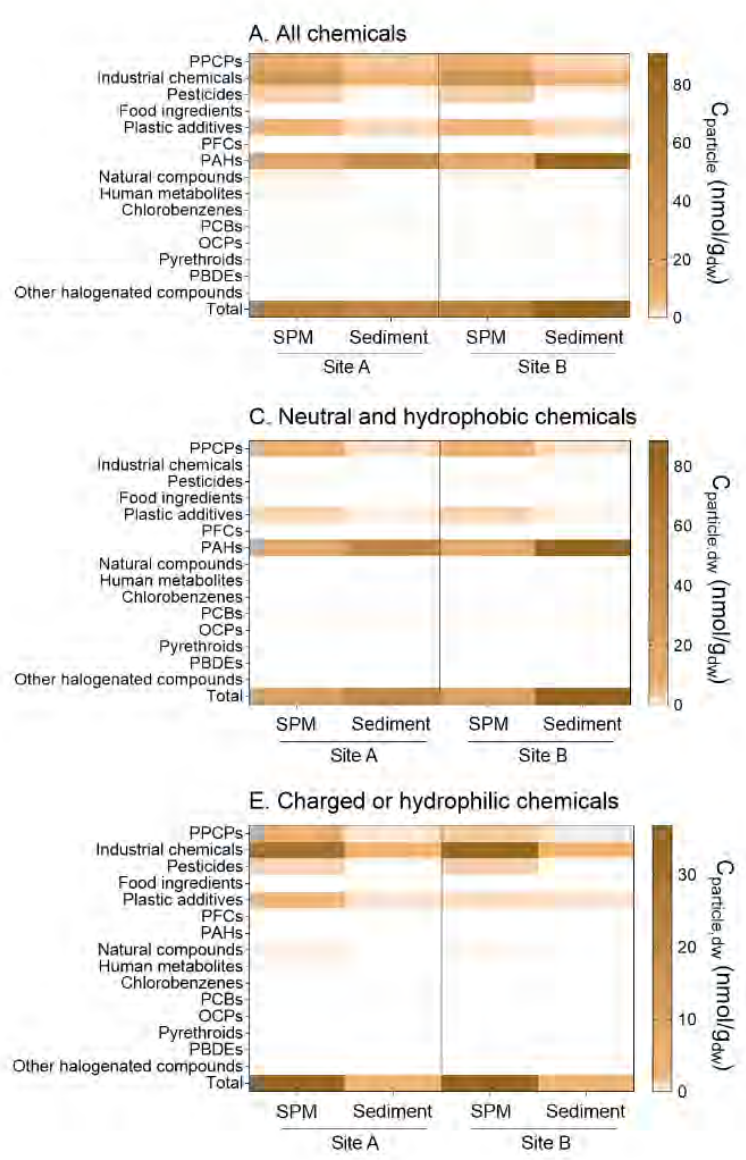

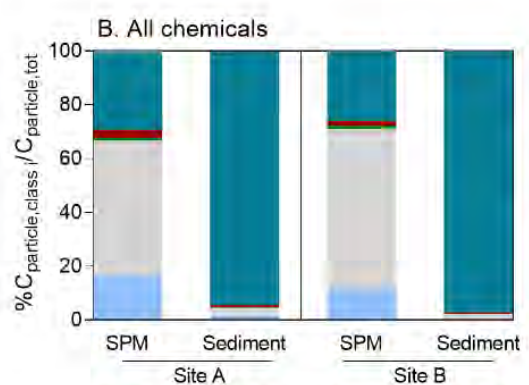

D. Neutral and hydrophobic chemicals

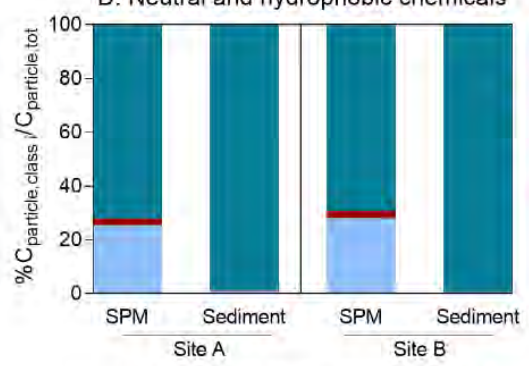

F. Charged or hydrophilic chemicals

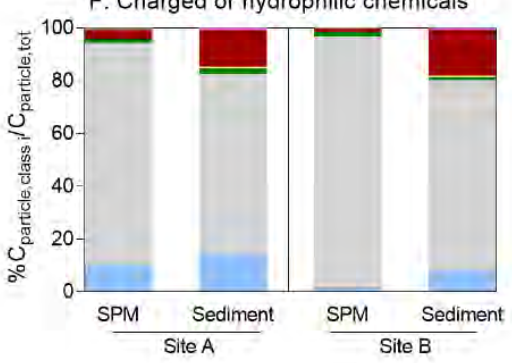

PPCPS

Industrial chemicals

- Pesticides

food ingredients

Plastic additives

In PFCs

D PAHs

In Natural compounds

Human metabolites

alorobenzenes

- PCBs

- OCPs

ayrethroids

other halogenated

compounds

In PBDEs

Fig. S7. (A, C and E) Sum of chemical concentrations for different chemical groups and (B, $D$ and F) composition of suspended particulate matter (SPM)- and sediment-associated contaminants. PPCPs: pharmaceuticals and personal care products; PFCs: perfluorinated compounds; PAHs: polycyclic aromatic hydrocarbons; PCBs: polychlorinated biphenyls; OCPs: organochlorine pesticides; PBDE: polybrominated diphenyl ethers. Concentrations and grouping into compound classes are given in Table S6. 

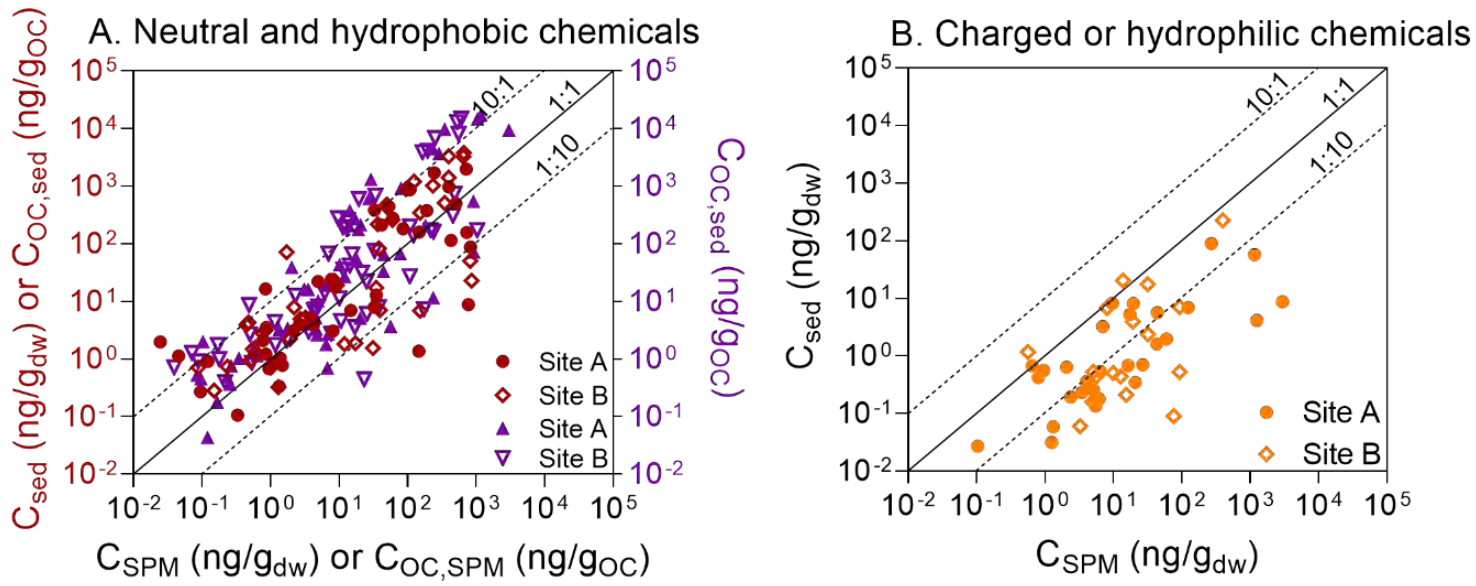

Fig. S8. Comparison of chemical concentrations in suspended particulate matter (SPM) and sediment for (A) neutral and hydrophobic chemicals and (B) charged or hydrophilic chemicals. Detailed concentrations are given in Table S6.
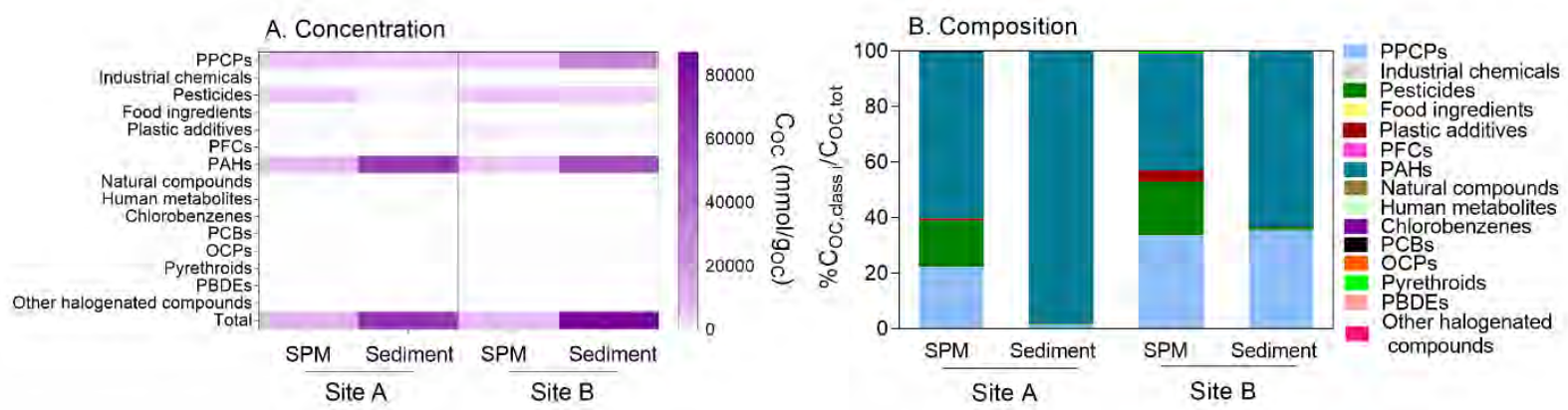

Fig. S9. (A) Sum of chemical concentrations for different chemical groups (B) and composition of organic carbon-bound chemicals in suspended particulate matter (SPM) and sediment. PPCPs: pharmaceuticals and personal care products; PFCs: perfluorinated compounds; PAHs: polycyclic aromatic hydrocarbons; PCBs: polychlorinated biphenyls; OCPs: organochlorine pesticides; PBDE: polybrominated diphenyl ethers. Concentrations and grouping into compound classes are given in Table S6. 


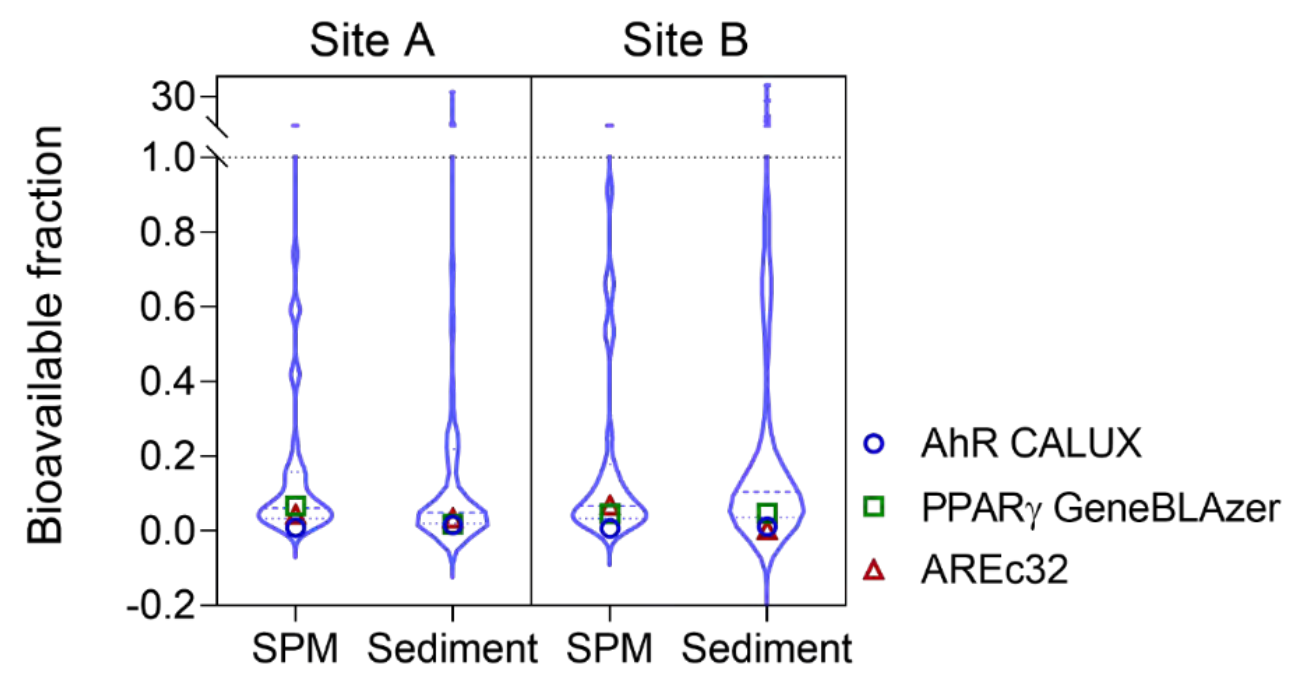

Fig. S10. Bioavailable fractions of individual contaminants $\left(F_{i, b i o a v a i l a b l e, c h e m ~}(\mathrm{Eq}\right.$. $\left.S 6)\right)$ and chemical mixtures ( $F_{\text {i,bioavailable,bio }}(\mathrm{Eq}$. S8) ) in suspended particulate matter (SPM) and sediment. Summary data are from Table $\mathrm{S} 11$. 
Table S11. Bioavailable fractions $F_{\text {bioavailable }}$ (Eqs. S6 and S8) of individual chemicals and chemical mixtures.

\begin{tabular}{llll}
\hline & & \multicolumn{2}{l}{ Bioavailable fraction F $_{\text {bioavailable }}$} \\
\hline SPM & & Site A & Site B \\
\hline chemical analysis & median & $6.1 \mathrm{E}-02$ & $6.6 \mathrm{E}-02$ \\
& min & $1.2 \mathrm{E}-02$ & $9.9 \mathrm{E}-03$ \\
& $5^{\text {th }}$ percentile & $1.2 \mathrm{E}-02$ & $1.2 \mathrm{E}-02$ \\
& $25^{\text {th }}$ percentile & $3.3 \mathrm{E}-02$ & $3.2 \mathrm{E}-02$ \\
& $75^{\text {th }}$ percentile & $1.6 \mathrm{E}-01$ & $1.8 \mathrm{E}-01$ \\
& $95^{\text {th }}$ percentile & $7.7 \mathrm{E}-01$ & $1.1 \mathrm{E}+00$ \\
& max & $1.4 \mathrm{E}+00$ & $1.5 \mathrm{E}+00$ \\
Bioanalysis & AhR CALUX & $1.6 \mathrm{E}-02$ & $1.1 \mathrm{E}-02$ \\
& PPAR $\gamma$ GeneBLAzer & $1.7 \mathrm{E}-02$ & $4.7 \mathrm{E}-02$ \\
& AREc32 & $3.3 \mathrm{E}-02$ & $2.9 \mathrm{E}-03$ \\
\hline Sediment & & Site A & Site B \\
\hline chemical analysis & median & $4.8 \mathrm{E}-02$ & $1.0 \mathrm{E}-01$ \\
& min & $2.2 \mathrm{E}-04$ & $1.3 \mathrm{E}-04$ \\
& $5^{\text {th }}$ percentile & $6.0 \mathrm{E}-03$ & $1.0 \mathrm{E}-02$ \\
& $25^{\text {th }}$ percentile & $1.9 \mathrm{E}-02$ & $3.5 \mathrm{E}-02$ \\
& $75^{\text {th }}$ percentile & $2.2 \mathrm{E}-01$ & $3.6 \mathrm{E}-01$ \\
& $95^{\text {th }}$ percentile & $3.45 \mathrm{E}+00$ & $1.1 \mathrm{E}+01$ \\
& max & $3.5 \mathrm{E}+01$ & $4.1 \mathrm{E}+01$ \\
& AhR CALUX & $8.6 \mathrm{E}-03$ & $6.2 \mathrm{E}-03$ \\
Bioanalysis & PPAR $\gamma$ GeneBLAzer & $6.7 \mathrm{E}-02$ & $4.6 \mathrm{E}-02$ \\
& AREc32 & $4.4 \mathrm{E}-02$ & $6.8 \mathrm{E}-02$ \\
\hline
\end{tabular}


AhR CALUX: water_Site A
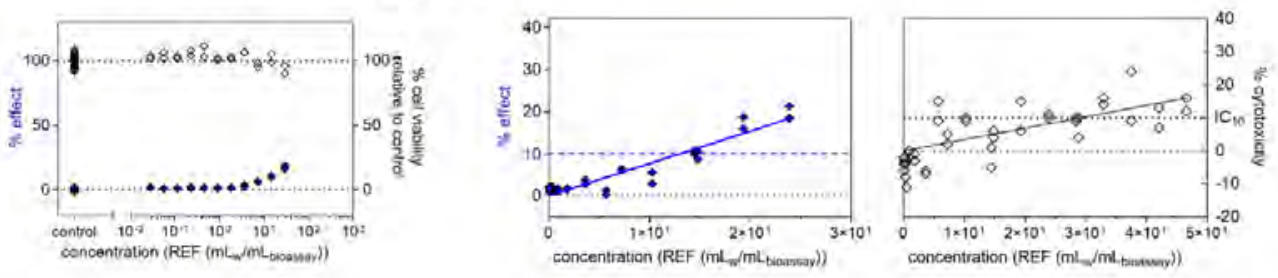

AhR CALUX: water_Site B
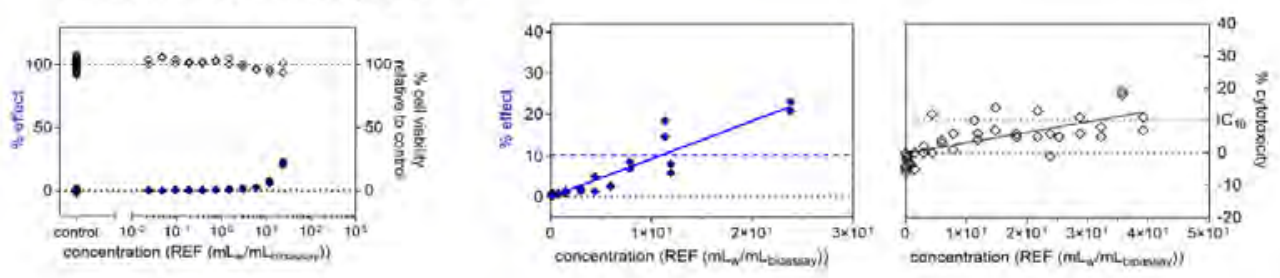

AhR CALUX: ASE_SPM_Site A
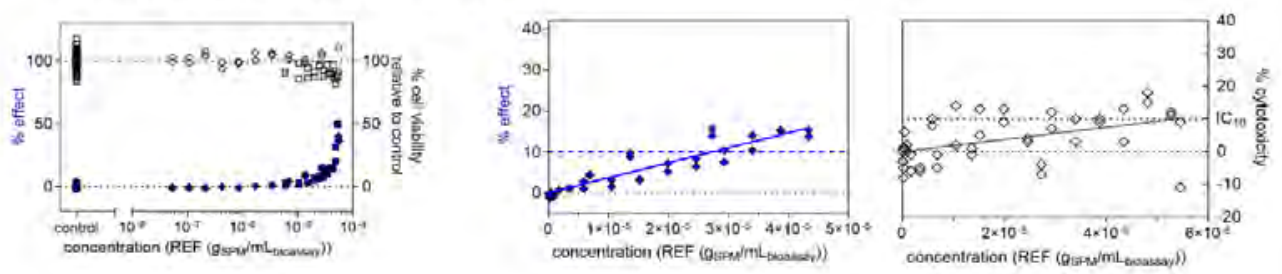

AhR CALUX: ASE_SPM_Site B
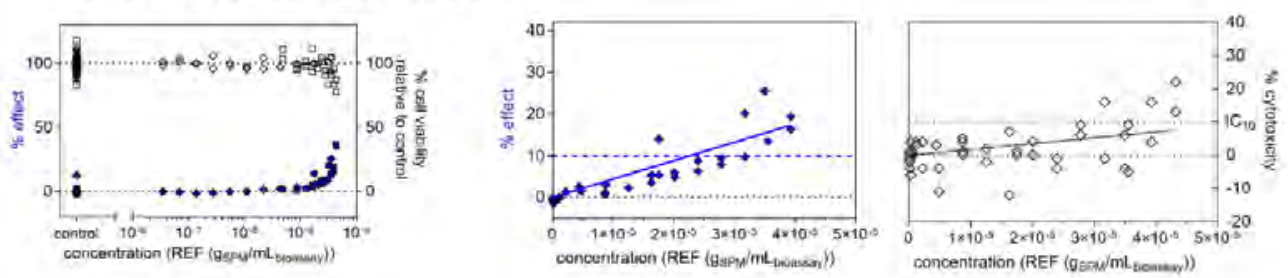

Fig. S11. Concentration-effect and concentration-cytotoxicity curves of water, suspended particulate matter (SPM) and sediment by accelerated solvent extraction (ASE) and polydimethylsiloxane (PDMS) samples in AhR CALUX. On the left are depicted all cytotoxicity and activation data, in the middle only valid activation data (effect $<30 \%$, concentration $<$ inhibition concentration $10 \%\left(\mathrm{IC}_{10}\right)$ to derive the effect concentration $\mathrm{EC}_{10}$ and on the right only valid cytotoxicity data (cytotoxicity $<40 \%$ ) to derive the $\mathrm{IC}_{10}$. The resulting $\mathrm{IC}_{10}$ and $\mathrm{EC}_{10}$ are listed in Table $\mathrm{S12}$. 
AhR CALUX: ASE_sed_Site A
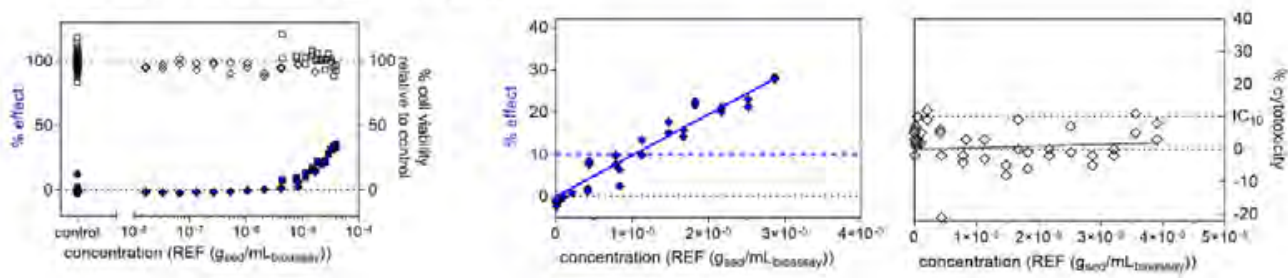

AhR CALUX: ASE_sed_Site B
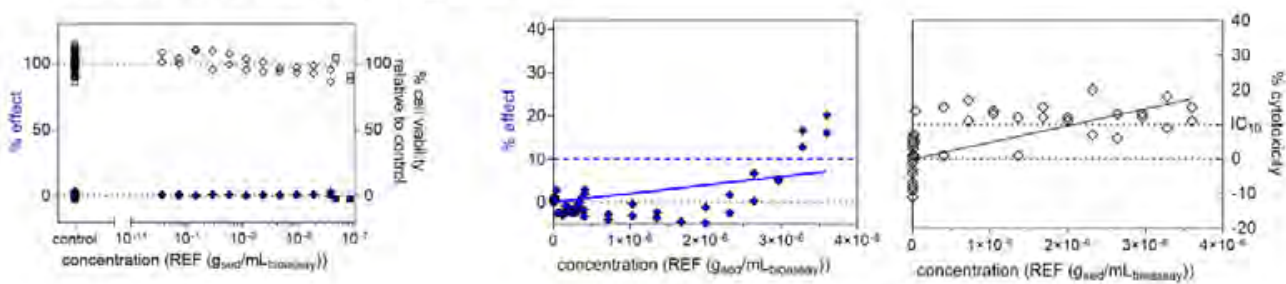

AhR CALUX:PDMS_SPM_Site A
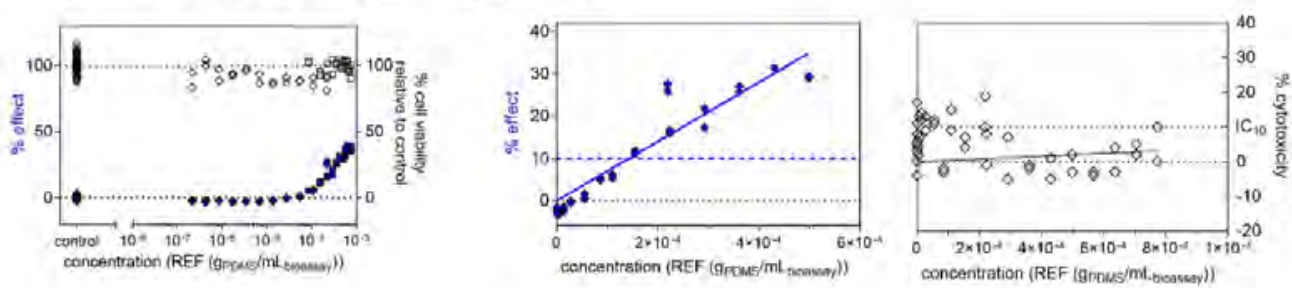

AhR CALUX:PDMS_SPM_Site B
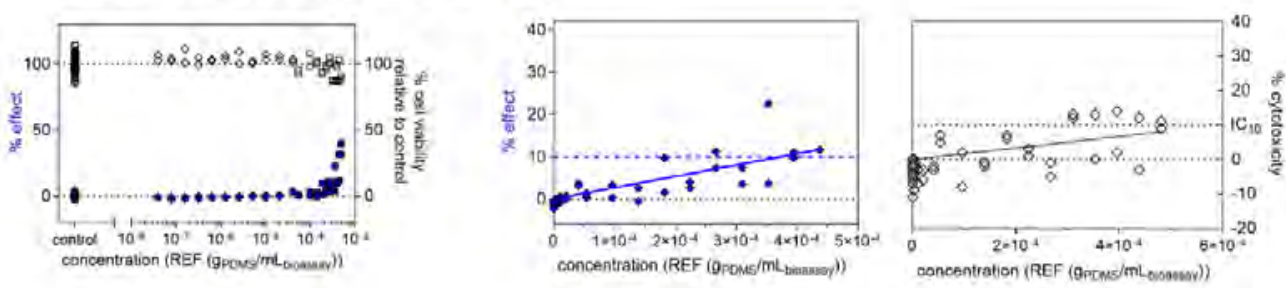

Fig. S11. Continued. Concentration-effect and concentration-cytotoxicity curves of water, suspended particulate matter (SPM) and sediment by accelerated solvent extraction (ASE) and polydimethylsiloxane (PDMS) samples in AhR CALUX. On the left are depicted all cytotoxicity and activation data, in the middle only valid activation data (effect $<30 \%$, concentration $<$ inhibition concentration $10 \%\left(\mathrm{IC}_{10}\right)$ to derive the effect concentration $\mathrm{EC}_{10}$ and on the right only valid cytotoxicity data (cytotoxicity $<40 \%$ ) to derive the $\mathrm{IC}_{10}$. The resulting $\mathrm{IC}_{10}$ and $\mathrm{EC}_{10}$ are listed in Table $\mathrm{S} 12$. 
AhR CALUX: PDMS_sed_Site A
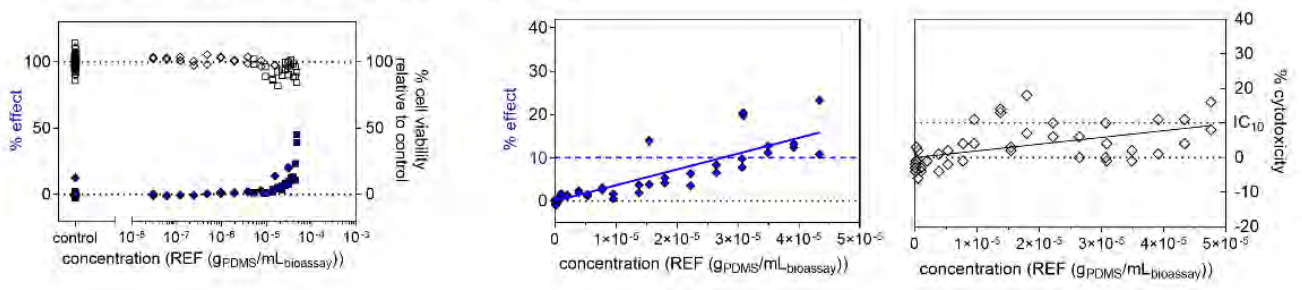

AhR CALUX: PDMS_sed_Site B
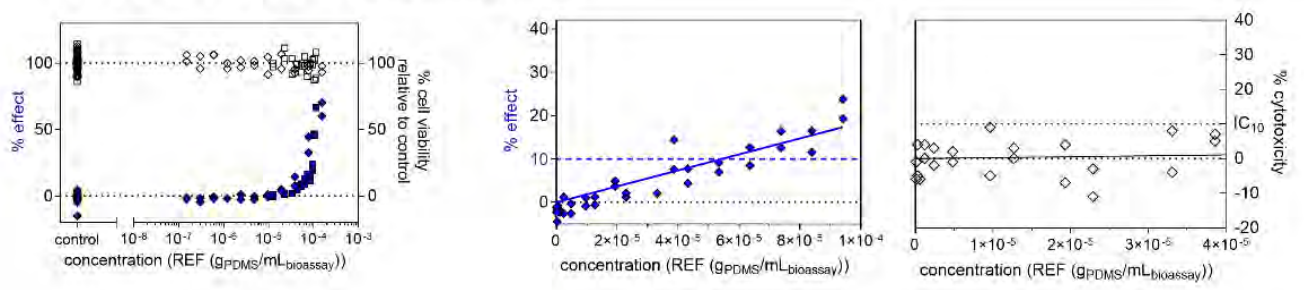

Fig. S11. Continued. Concentration-effect and concentration-cytotoxicity curves of water, suspended particulate matter (SPM) and sediment by accelerated solvent extraction (ASE) and polydimethylsiloxane (PDMS) samples in AhR CALUX. On the left are depicted all cytotoxicity and activation data, in the middle only valid activation data (effect $<30 \%$, concentration $<$ inhibition concentration $10 \%\left(\mathrm{IC}_{10}\right)$ to derive the effect concentration $\mathrm{EC}_{10}$ and on the right only valid cytotoxicity data (cytotoxicity $<40 \%$ ) to derive the $\mathrm{IC}_{10}$. The resulting $\mathrm{IC}_{10}$ and $\mathrm{EC}_{10}$ are listed in Table $\mathrm{S} 12$. 

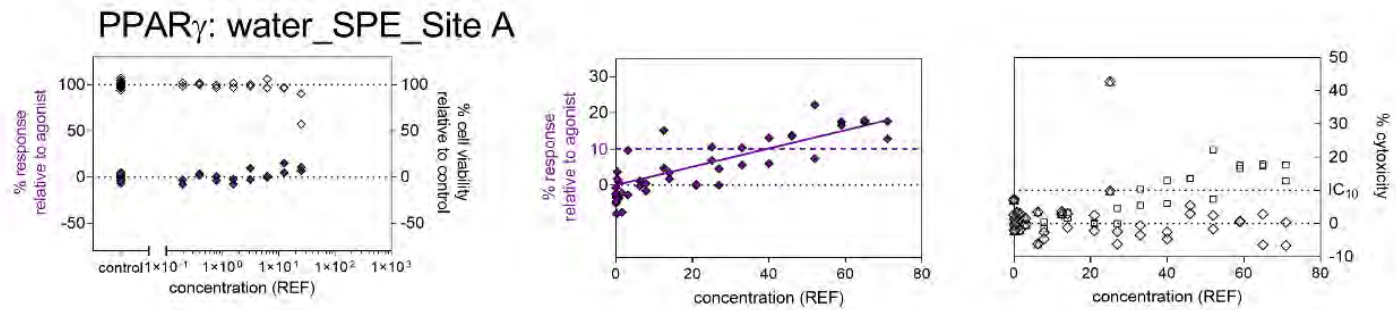

PPAR $\gamma$ : water_SPE_Site B
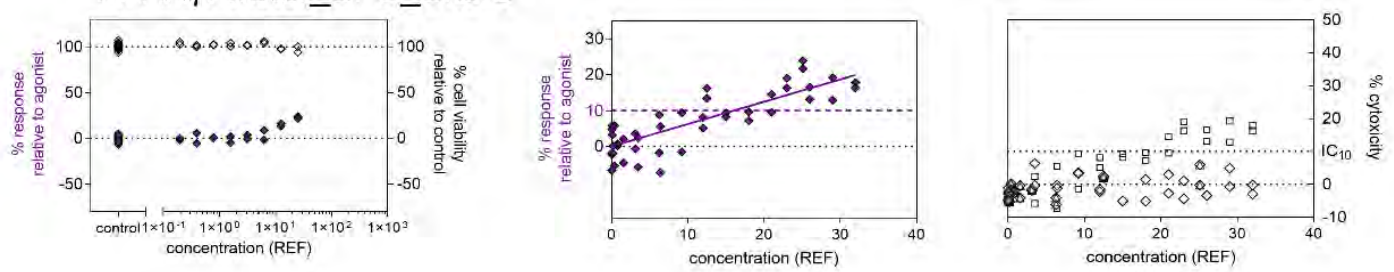

PPAR $\gamma:$ ASE_SPM_Site A
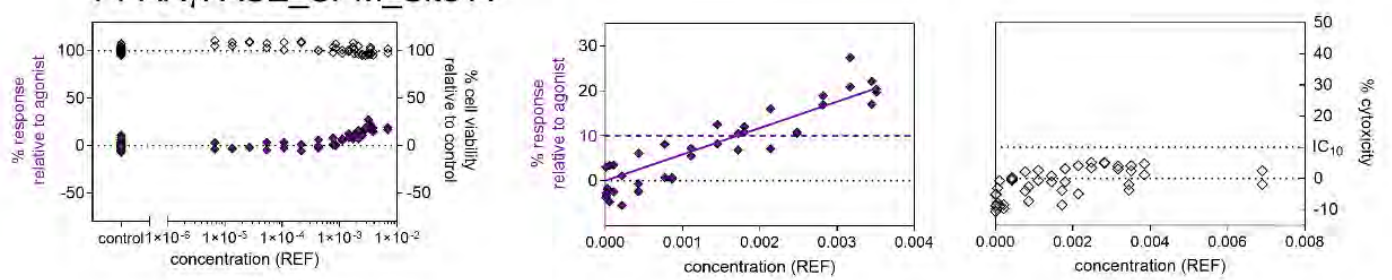

PPAR $\gamma$ : ASE_SPM_Site B
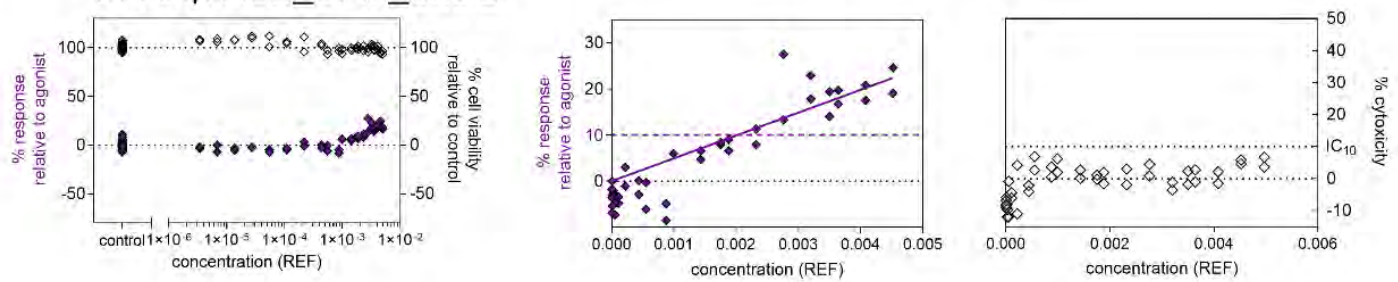

Fig. S12. Concentration-effect and concentration-cytotoxicity curves of water, suspended particulate matter (SPM) and sediment by accelerated solvent extraction (ASE) and polydimethylsiloxane (PDMS) samples in PPAR $\gamma$ GeneBLAzer. On the left are depicted all cytotoxicity and activation data, in the middle only valid activation data (effect $<30 \%$, concentration $<$ inhibition concentration $10 \%\left(\mathrm{IC}_{10}\right)$ to derive the effect concentration $\mathrm{EC}_{10}$ and on the right only valid cytotoxicity data (cytotoxicity $<40 \%$ ) to derive the $\mathrm{IC}_{10}$. The resulting $\mathrm{IC}_{10}$ and $\mathrm{EC}_{10}$ are listed in Table $\mathrm{S} 12$. 

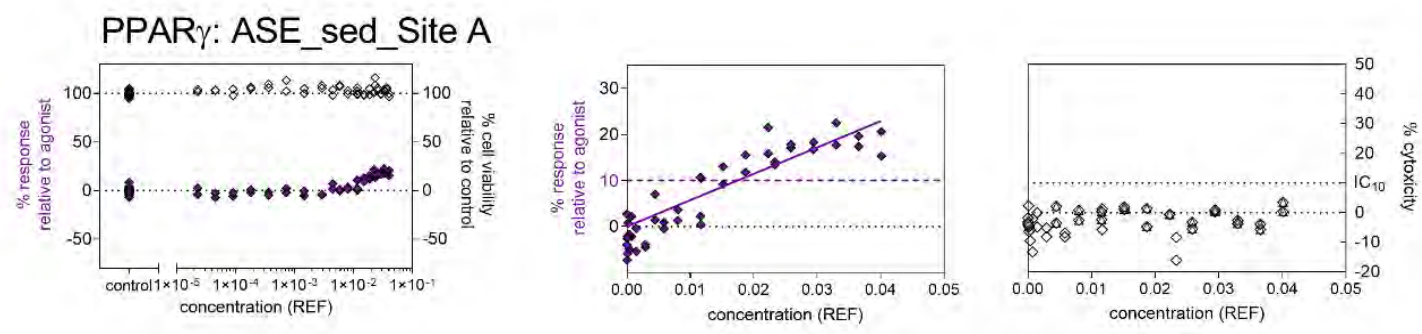

PPAR $\gamma$ : ASE_sed_Site B
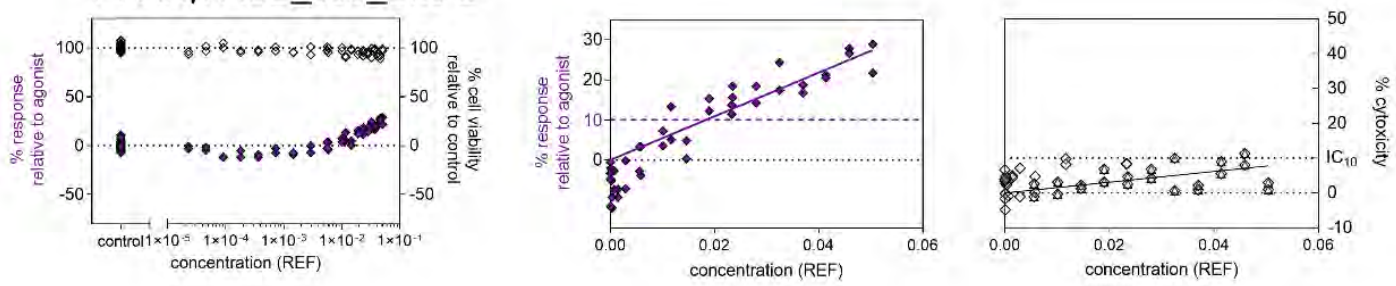

PPAR $\gamma:$ PDMS_SPM_Site A
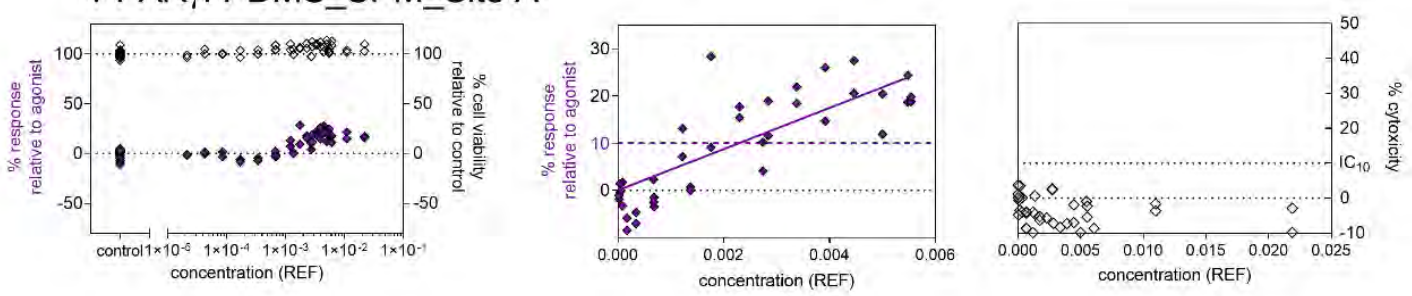

PPAR $\gamma:$ PDMS_SPM_Site B
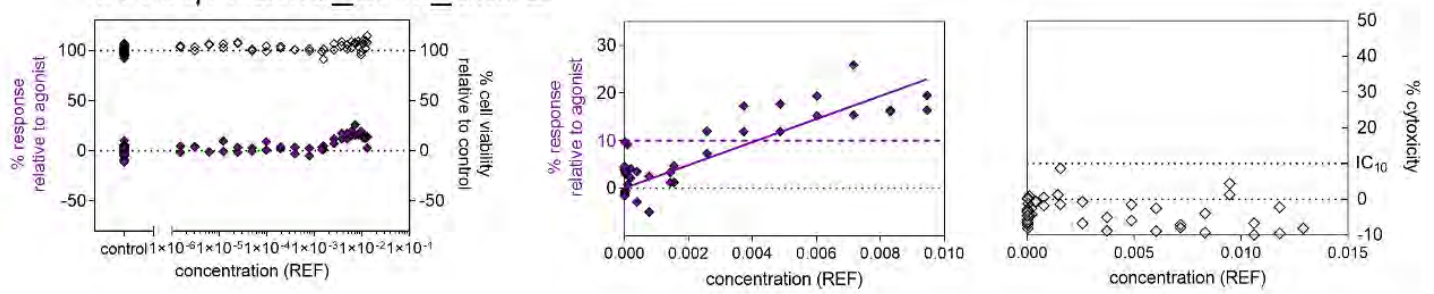

Fig. S12. Continued. Concentration-effect and concentration-cytotoxicity curves of water, suspended particulate matter (SPM) and sediment by accelerated solvent extraction (ASE) and polydimethylsiloxane (PDMS) samples in PPAR $\gamma$ GeneBLAzer. On the left are depicted all cytotoxicity and activation data, in the middle only valid activation data (effect $<30 \%$, concentration $<$ inhibition concentration $10 \%\left(\mathrm{IC}_{10}\right)$ to derive the effect concentration $\mathrm{EC}_{10}$ and on the right only valid cytotoxicity data (cytotoxicity $<40 \%$ ) to derive the $\mathrm{IC}_{10}$. The resulting $\mathrm{IC}_{10}$ and $\mathrm{EC}_{10}$ are listed in Table $\mathrm{S12}$. 

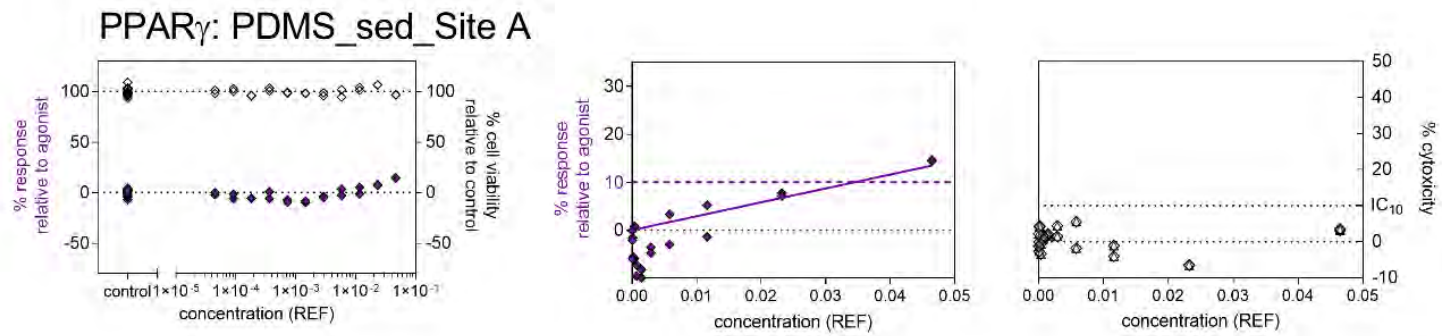

PPAR $\gamma$ :PDMS_sed_Site B
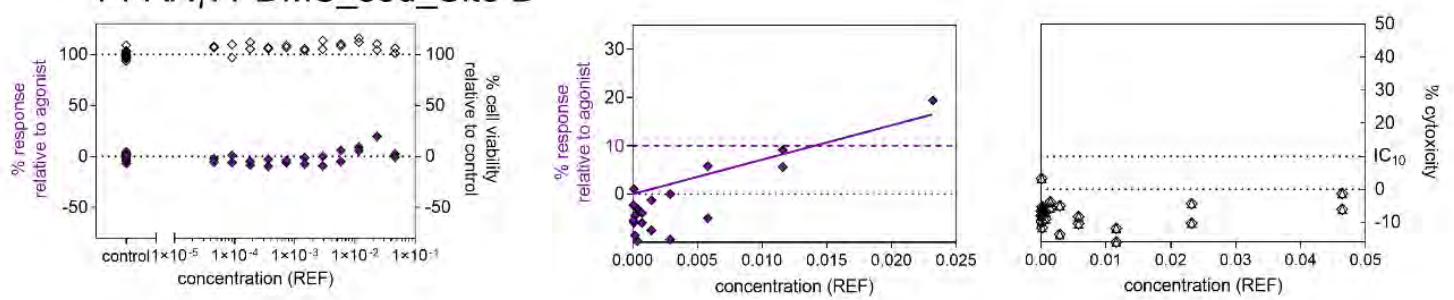

Fig. S12. Continued. Concentration-effect and concentration-cytotoxicity curves of water, suspended particulate matter (SPM) and sediment by accelerated solvent extraction (ASE) and polydimethylsiloxane (PDMS) samples in PPAR $\gamma$ GeneBLAzer. On the left are depicted all cytotoxicity and activation data, in the middle only valid activation data (effect $<30 \%$, concentration $<$ inhibition concentration $10 \%\left(\mathrm{IC}_{10}\right)$ to derive the effect concentration $\mathrm{EC}_{10}$ and on the right only valid cytotoxicity data (cytotoxicity $<40 \%$ ) to derive the $\mathrm{IC}_{10}$. The resulting $\mathrm{IC}_{10}$ and $\mathrm{EC}_{10}$ are listed in Table $\mathrm{S12}$. 
AREc32: water_SPE_Site A
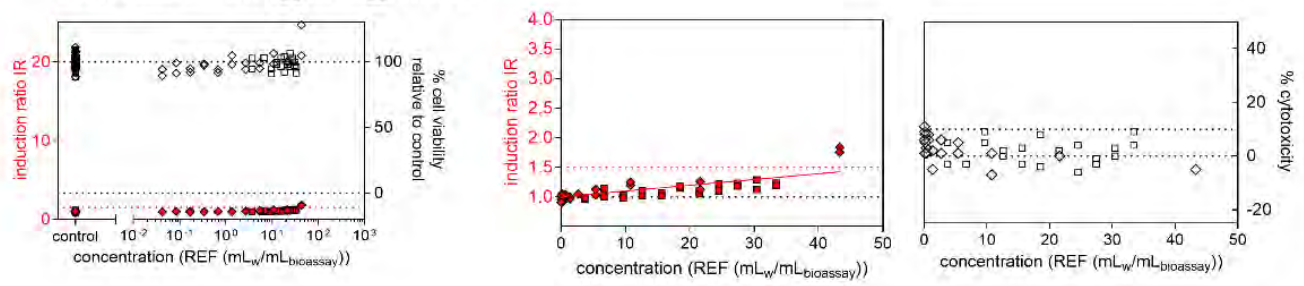

AREc32: water_SPE_Site B
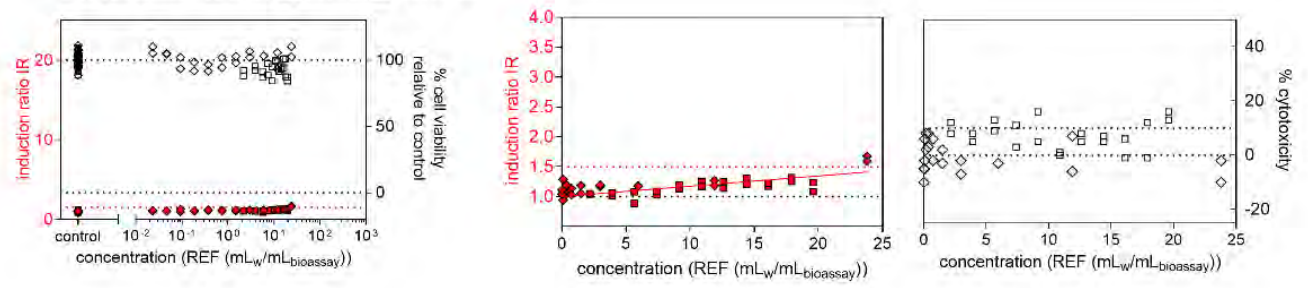

AREc32: ASE_SPM_Site A
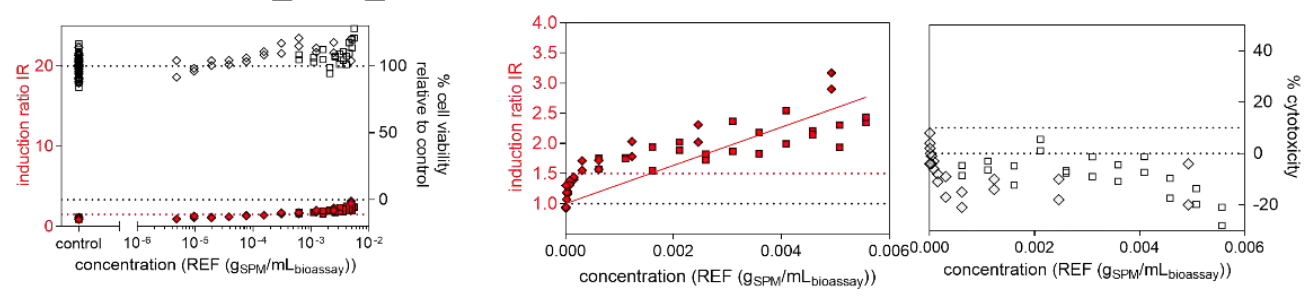

AREc32: ASE_SPM_Site B
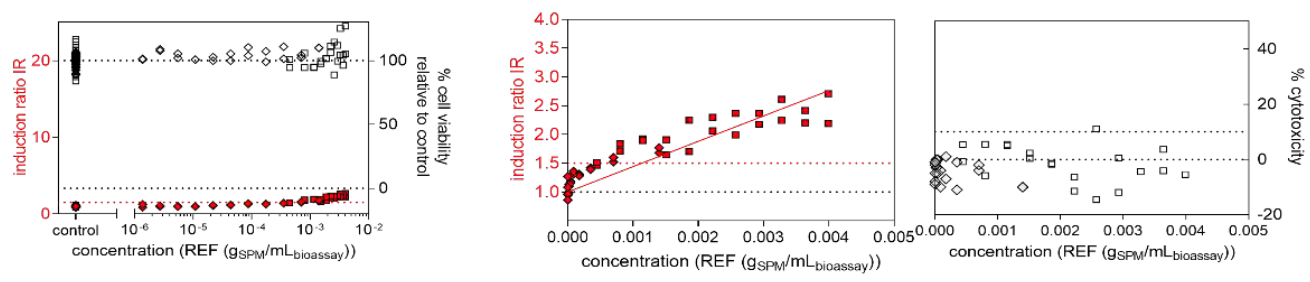

AREc32: ASE_sed_Site A
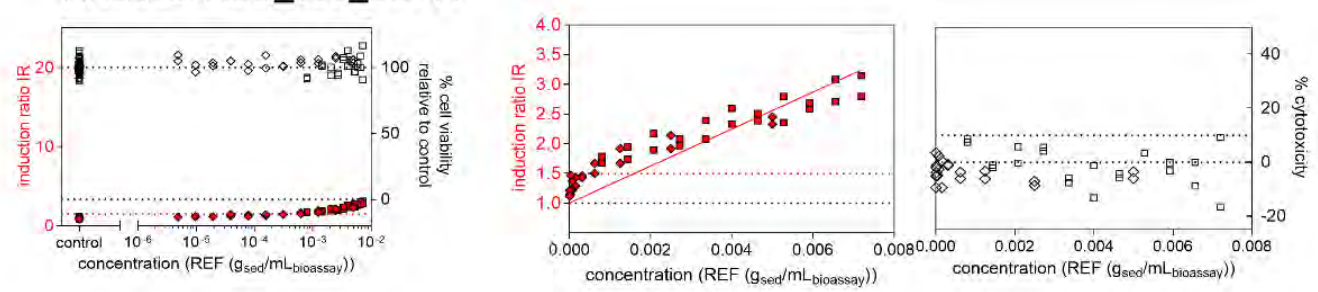

Fig. S13. Concentration-effect and concentration-cytotoxicity curves of water, suspended particulate matter (SPM) and sediment by accelerated solvent extraction (ASE) and polydimethylsiloxane (PDMS) samples in AREc32 assay. On the left are depicted all cytotoxicity and activation data, in the middle only valid activation data (induction ratio < 4 , concentration $<$ inhibition concentration $10 \%\left(\mathrm{IC}_{10}\right)$ and on the right only valid cytotoxicity data (cytotoxicity $<40 \%$ ). The resulting $\mathrm{IC}_{10}$ and $\mathrm{EC}_{10}$ are listed in Table S12. 
AREc32: ASE_sed_Site B
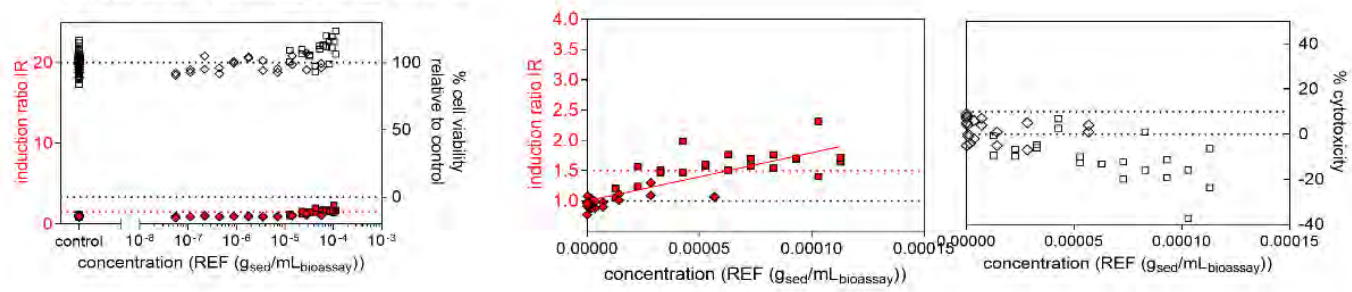

AREc32: PDMS_SPM_Site A
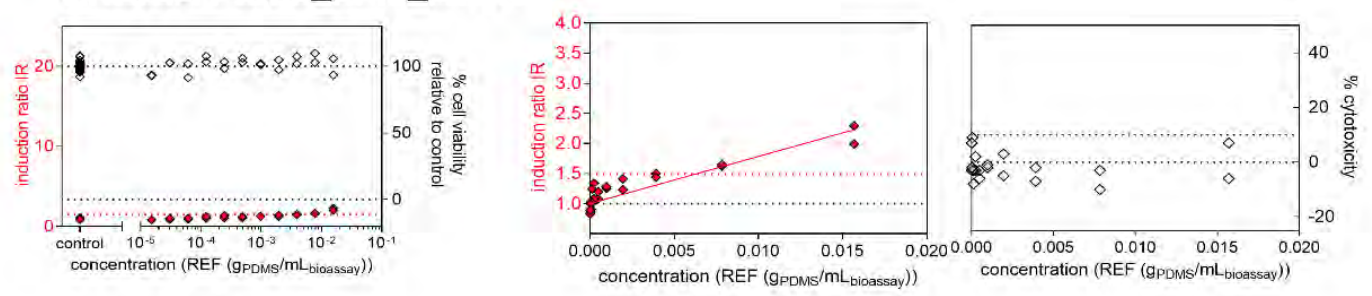

AREc32: PDMS_SPM_Site B
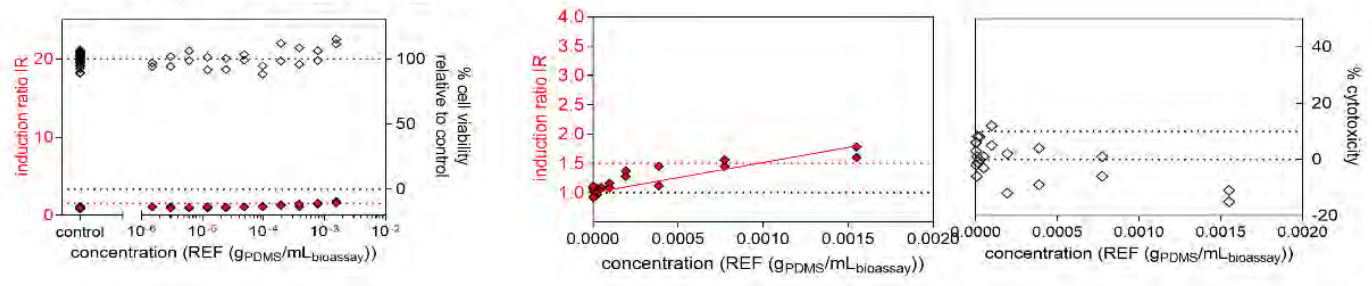

AREc32: PDMS_sed_Site A
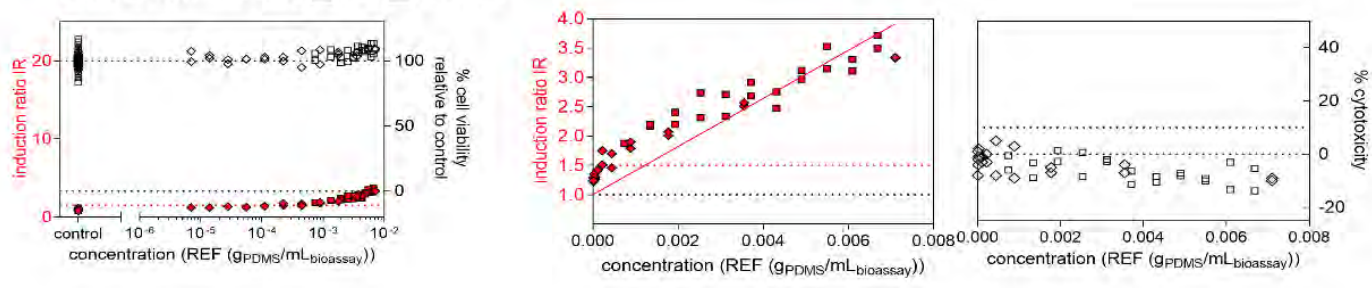

AREc32: PDMS_sed_Site B
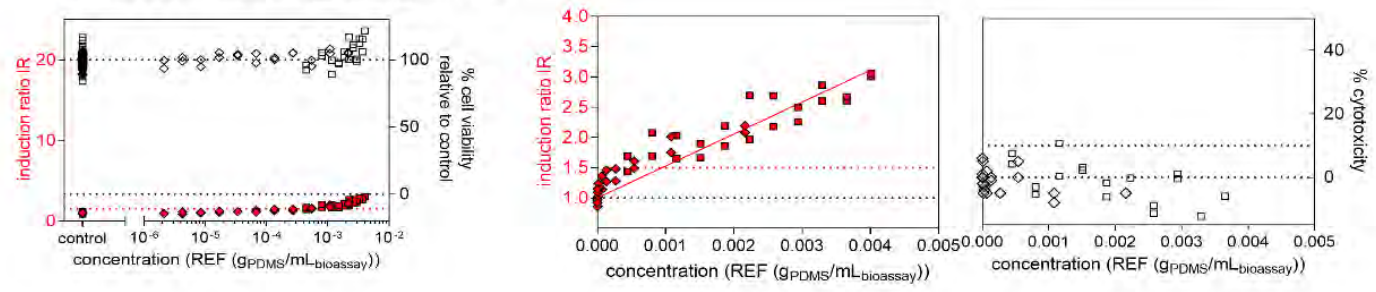

Fig. S13. Continued. Concentration-effect and concentration-cytotoxicity curves of water, suspended particulate matter (SPM) and sediment by accelerated solvent extraction (ASE) and polydimethylsiloxane (PDMS) samples in AREc32 assay. On the left are depicted all cytotoxicity and activation data, in the middle only valid activation data (induction ratio < 4 , concentration < inhibition concentration $10 \%\left(\mathrm{IC}_{10}\right)$ and on the right only valid cytotoxicity data (cytotoxicity $<\mathbf{4 0 \%}$ ). The resulting $\mathrm{IC}_{10}$ and $\mathrm{EC}_{10}$ are listed in Table S12. 
Algae: water_SPE_Site A
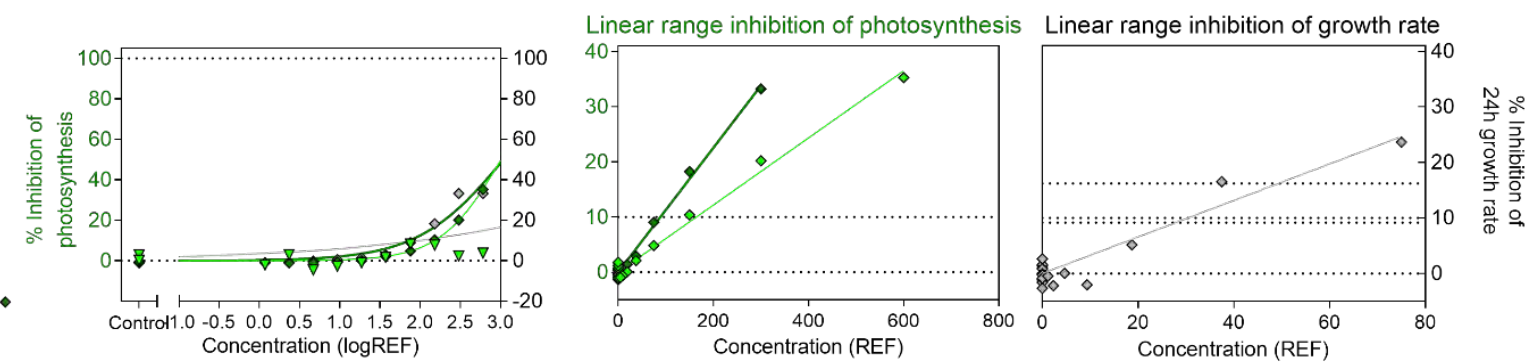

Algae: water_SPE_Site B
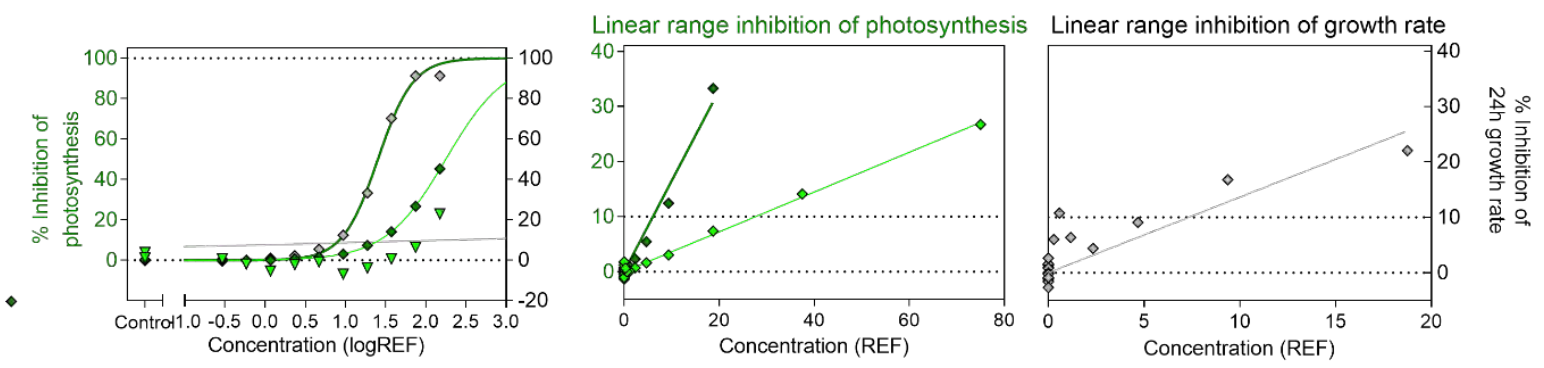

Fig. S14. Concentration-effect and concentration-inhibition of growth rate curves of water, samples in combined algae testing assay. On the left are depicted all growth inhibition and photosynthesis inhibition data, in the middle only valid activation data (induction ratio $<4$, concentration $<$ inhibition concentration $10 \%\left(\mathrm{IC}_{10}\right)$ and on the right only valid growth inhibition data $(<40 \%)$. The light green ones indicate $2 \mathrm{~h}$ photosynthesis inhibition, the dark green ones indicate $24 \mathrm{~h}$ photosynthesis inhibition. The resulting $\mathrm{IC}_{10}$ and $\mathrm{EC}_{10}$ are listed in Table S12. 
Table S12. The effect concentration that caused $10 \%$ of the maximum effect $\left(\mathrm{EC}_{10}\right)$ or an induction ratio of $1.5\left(E C_{\text {IR1.5 }}\right)$ and $10 \%$ of the maximum inhibitory concentration $\left(\mathrm{IC}_{10}\right)$ in water, suspended particulate matter (SPM), sediment and polydimethylsiloxane (PDMS) samples. The errors refer to standard errors propagated from the standard error of the regression of the concentration response curve according to Escher et al. (2018) $)^{5}$ or calculated from standard deviation (SD/number of replicates) of triplicated experiments.

\begin{tabular}{|c|c|c|c|c|c|}
\hline & & Site A & Site B & Site A & Site B \\
\hline \multicolumn{2}{|c|}{ Water extracts } & \multicolumn{2}{|c|}{$E C_{10}$ or $E C_{I R 1.5}\left(\mathrm{~mL} / m L_{\text {bioassay }}\right)$} & \multicolumn{2}{|c|}{$I C_{10}\left(\mathrm{~mL} / \mathrm{mL} L_{\text {bioassay }}\right)$} \\
\hline AhR CALUX & $\mathrm{B}[\mathrm{a}] \mathrm{P}-\mathrm{EQ}_{\text {bio }}$ & $14.02 \pm 0.61$ & $9.04 \pm 0.70$ & $33.4 \pm 4.05$ & $31.1 \pm 3.46$ \\
\hline $\begin{array}{c}\text { PPAR } \gamma \\
\text { GenBLAzer }\end{array}$ & Rosiglitazone-EQbio & $39.5 \pm 3.34$ & $16.1 \pm 1.14$ & $822 \pm 239$ & no cytotoxicity \\
\hline AREc32 & Dichlorvos-EQbio & $1028 \pm 499$ & $580 \pm 265$ & no cytotoxicity & $34.7 \pm 0.95$ \\
\hline \multirow{2}{*}{ Algae assay } & 2 h Diuron-EQbio & $164 \pm 4.5$ & $27.7 \pm 0.4$ & \multirow{2}{*}{$30.4 \pm 2.9$} & \multirow{2}{*}{$7.33 \pm 1.26$} \\
\hline & 24 h Diuron-EQbio & $88.7 \pm 2.1$ & $6.07 \pm 0.31$ & & \\
\hline \multicolumn{2}{|c|}{ Exhaustive extracts of SPM } & \multicolumn{2}{|c|}{$E C_{10}$ or $E C_{I R 1.5}\left(g_{S P M} / m L_{b i o a s s a y}\right)$} & \multicolumn{2}{|c|}{$I C_{10}\left(g_{S P M} / m L_{\text {bioassay }}\right)$} \\
\hline \multirow{3}{*}{$\begin{array}{l}\text { AhR CALUX } \\
\text { PPAR } \gamma \\
\text { GenBLAzer } \\
\text { AREc32 }\end{array}$} & $\mathrm{B}[\mathrm{a}] \mathrm{P}-\mathrm{EQ}$ bio & $2.0 \times 10^{-5} \pm 8.2 \times 10^{-6}$ & $2.3 \times 10^{-5} \pm 6.9 \times 10^{-7}$ & $1.5 \times 10^{-4} \pm 1.4 \times 10^{-4}$ & $3.9 \times 10^{-4} \pm 5.6 \times 10^{-4}$ \\
\hline & Rosiglitazone-EQbio & $1.5 \times 10^{-3} \pm 2.1 \times 10^{-4}$ & $1.9 \times 10^{-3} \pm 2.3 \times 10^{-4}$ & no cytotoxicity & no cytotoxicity \\
\hline & Dichlorvos-EQbio & $3.7 \times 10^{-2} \pm 5.2 \times 10^{-3}$ & $2.2 \times 10^{-2} \pm 1.6 \times 10^{-3}$ & no cytotoxicity & no cytotoxicity \\
\hline \multicolumn{2}{|c|}{ PDMS extracts of SPM } & \multicolumn{2}{|c|}{$E C_{10}$ or $E C_{I R 1.5}\left(g_{\text {PDMS }} / m L_{\text {bioassay }}\right)$} & \multicolumn{2}{|c|}{$I C_{10}\left(g_{P D M S} / m L_{\text {bioassay }}\right)$} \\
\hline \multirow{3}{*}{$\begin{array}{l}\text { AhR CALUX } \\
\text { PPAR } \gamma \\
\text { GenBLAzer } \\
\text { AREc32 }\end{array}$} & $\mathrm{B}[\mathrm{a}] \mathrm{P}-\mathrm{EQ}$ bio & $2.3 \times 10^{-4} \pm 7.4 \times 10^{-5}$ & $4.2 \times 10^{-4} \pm 6.2 \times 10^{-5}$ & $1.0 \times 10^{-3} \pm 1.3 \times 10^{-3}$ & $7.3 \times 10^{-4} \pm 2.5 \times 10^{-4}$ \\
\hline & Rosiglitazone-EQbio & $2.1 \times 10^{-3} \pm 2.6 \times 10^{-4}$ & $4.2 \times 10^{-3} \pm 5.6 \times 10^{-4}$ & no cytotoxicity & no cytotoxicity \\
\hline & Dichlorvos-EQbio & $8.9 \times 10^{-2} \pm 3.4 \times 10^{-2}$ & $3.5 \times 10^{-2} \pm 1.4 \times 10^{-2}$ & no cytotoxicity & no cytotoxicity \\
\hline \multicolumn{2}{|c|}{ Exhaustive extracts of sediment } & \multicolumn{2}{|c|}{$E C_{10}$ or $E C_{I R 1.5}\left(g_{\text {sed }} / m L_{\text {bioassay }}\right)$} & \multicolumn{2}{|c|}{$I C_{10}\left(g_{\text {sed }} / m L_{\text {bioassay }}\right)$} \\
\hline AhR CALUX & $\mathrm{B}[\mathrm{a}] \mathrm{P}-\mathrm{EQ}$ bio & $1.0 \times 10^{-5} \pm 2.1 \times 10^{-6}$ & $1.6 \times 10^{-5} \pm 1.2 \times 10^{-5}$ & $2.1 \times 10^{-4} \pm 2.1 \times 10^{-4}$ & $2.0 \times 10^{-6} \pm 1.2 \times 10^{-7}$ \\
\hline $\begin{array}{l}\text { PPAR } \gamma \\
\text { GenBLAzer }\end{array}$ & Rosiglitazone-EQbio & $1.5 \times 10^{-2} \pm 3.0 \times 10^{-3}$ & $1.8 \times 10^{-2} \pm 1.4 \times 10^{-3}$ & no cytotoxicity & $7.1 \times 10^{-2} \pm 8.7 \times 10^{-3}$ \\
\hline AREc32 & Dichlorvos-EQbio & $3.0 \times 10^{-2} \pm 4.5 \times 10^{-3}$ & $1.8 \times 10^{-3} \pm 1.3 \times 10^{-3}$ & no cytotoxicity & no cytotoxicity \\
\hline \multicolumn{2}{|c|}{ PDMS extracts of sediment } & \multicolumn{2}{|c|}{$E C_{10}$ or $E C_{I R 1.5}\left(g_{P D M S} / m L_{\text {bioassay }}\right)$} & \multicolumn{2}{|c|}{$I C_{10}\left(g_{P D M S} / m L_{\text {bioassay }}\right)$} \\
\hline AhR CALUX & $\mathrm{B}[\mathrm{a}] \mathrm{P}-\mathrm{EQ}$ bio & $2.1 \times 10^{-5} \pm 7.8 \times 10^{-6}$ & $4.0 \times 10^{-5} \pm 1.4 \times 10^{-5}$ & $3.0 \times 10^{-4} \pm 3.6 \times 10^{-4}$ & $4.9 \times 10^{-4} \pm 1.6 \times 10^{-4}$ \\
\hline $\begin{array}{l}\text { PPAR } \gamma \\
\text { GenBLAzer }\end{array}$ & Rosiglitazone-EQbio & $2.7 \times 10^{-2} \pm 8.1 \times 10^{-3}$ & $1.6 \times 10^{-2} \pm 2.4 \times 10^{-3}$ & $2.0 \times 10^{-1} \pm 2.1 \times 10^{-1}$ & $4.5 \times 10^{-1} \pm 3.3 \times 10^{-1}$ \\
\hline AREc32 & Dichlorvos-EQbio & $2.6 \times 10^{-2} \pm 1.3 \times 10^{-3}$ & $1.9 \times 10^{-2} \pm 1.8 \times 10^{-3}$ & no cytotoxicity & $1.5 \times 10^{-2} \pm 6.0 \times 10^{-2}$ \\
\hline
\end{tabular}


Table S13. Bioanalytical equivalent concentrations $\left(B E Q_{b i o}\right)$ and toxic unit for cytotoxicity $\left(T U_{b i o}\right)$ of chemical mixtures in water, suspended particulate matter (SPM), sediment and polydimethylsiloxane (PDMS) samples The errors refer to standard errors propagated from the standard error of the regression of the concentration response curve according to Escher et al. (2018) $)^{5}$ or calculated from standard deviation (SD/number of replicates) of triplicated experiments.

\begin{tabular}{|c|c|c|c|c|c|}
\hline & & Site A & Site B & Site A & Site B \\
\hline \multicolumn{2}{|c|}{ Water extracts } & \multicolumn{2}{|c|}{$B E Q_{\text {bio }}\left(n g_{r e f} / L\right)$} & \multicolumn{2}{|c|}{$T U_{\text {bio }}\left(L_{\text {bioassay }} / L\right)$} \\
\hline AhR CALUX & $\mathrm{B}[\mathrm{a}] \mathrm{P}-\mathrm{EQ}_{\text {bio }}$ & $19.2 \pm 1.5$ & $29.8 \pm 3.0$ & 0.25 & 0.29 \\
\hline PPAR $\gamma$ GenBLAzer & Rosiglitazone-EQbio & $4.20 \pm 0.40$ & $10.3 \pm 0.9$ & 0.0004 & no cytotoxicity \\
\hline AREc32 & Dichlorvos-EQ bio & $1246 \pm 607$ & $2207 \pm 1013$ & no cytotoxicity & 1.05 \\
\hline \multirow{2}{*}{ Algae assay } & $2 \mathrm{~h}$ Diuron-EQ bio & $5.73 \pm 2.49$ & $34.0 \pm 0.4$ & \multirow{2}{*}{0.03} & \multirow{2}{*}{0.14} \\
\hline & $24 \mathrm{~h}$ Diuron-EQ $\mathrm{E}_{\text {bio }}$ & $17.2 \pm 4.0$ & $252 \pm 0.3$ & & \\
\hline \multicolumn{2}{|c|}{$\begin{array}{c}\text { Exhaustive extracts of suspended } \\
\text { particulate matter (SPM) }\end{array}$} & \multicolumn{2}{|c|}{$B E Q_{\text {bio }}\left(\mu g_{r e f} / g_{S P M, d w}\right)$} & \multicolumn{2}{|c|}{$T U_{\text {bio }}\left(L_{\text {bioassay }} / g_{S P M, d w}\right)$} \\
\hline AhR CALUX & $\mathrm{B}[\mathrm{a}] \mathrm{P}-\mathrm{EQ}_{\text {bio }}$ & $15.8 \pm 7.6$ & $11.7 \pm 0.3$ & 12.1 & 11.3 \\
\hline PPAR $\gamma$ GenBLAzer & Rosiglitazone-EQ $\mathrm{EQ}_{\text {bio }}$ & $0.13 \pm 0.02$ & $0.10 \pm 0.01$ & no cytotoxicity & no cytotoxicity \\
\hline AREc32 & Dichlorvos-EQ $\mathrm{E}_{\text {bio }}$ & $38.3 \pm 6.2$ & $68.6 \pm 4.2$ & no cytotoxicity & no cytotoxicity \\
\hline \multicolumn{2}{|c|}{$\begin{array}{c}\text { PDMS extracts of suspended particulate } \\
\text { matter (SPM) }\end{array}$} & \multicolumn{2}{|c|}{$B E Q_{\text {bio }}\left(\mu g_{r e f} / g_{P D M S}\right)$} & \multicolumn{2}{|c|}{$T U_{\text {bio }}\left(L_{\text {bioassay }} / g_{\text {PDMS }}\right)$} \\
\hline AhR CALUX & $\mathrm{B}[\mathrm{a}] \mathrm{P}-\mathrm{EQ}_{\text {bio }}$ & $1.29 \pm 0.51$ & $0.65 \pm 0.09$ & 0.98 & 1.38 \\
\hline PPAR $\gamma$ GenBLAzer & Rosiglitazone-EQbio & $0.08 \pm 0.01$ & $0.04 \pm 0.01$ & no cytotoxicity & no cytotoxicity \\
\hline AREc32 & Dichlorvos-EQ $Q_{\text {bio }}$ & $15.8 \pm 5.3$ & $41.6 \pm 21.1$ & no cytotoxicity & no cytotoxicity \\
\hline \multicolumn{2}{|c|}{ Exhaustive extracts of sediment } & \multicolumn{2}{|c|}{$B E Q_{\text {bio }}\left(\mu g_{r e f} / g_{\text {sed,dw }}\right)$} & \multicolumn{2}{|c|}{$T U_{\text {bio }}\left(L_{\text {bioassay }} / g_{\text {sed,dww }}\right)$} \\
\hline AhR CALUX & $\mathrm{B}[\mathrm{a}] \mathrm{P}-\mathrm{EQ}_{\text {bio }}$ & $27.8 \pm 6.17$ & $27.5 \pm 23.1$ & 4.95 & 503 \\
\hline PPAR $\gamma$ GenBLAzer & Rosiglitazone-EQ $Q_{\text {bio }}$ & $0.01 \pm 0.002$ & $0.01 \pm 0.0008$ & no cytotoxicity & 0.01 \\
\hline AREc32 & Dichlorvos-EQ bio & $43.3 \pm 7.0$ & $945 \pm 531$ & no cytotoxicity & no cytotoxicity \\
\hline \multicolumn{2}{|c|}{ PDMS extracts of sediment } & \multicolumn{2}{|c|}{$B E Q_{\text {bio }}\left(\mu g_{r e f} / g_{\text {sed,dw }}\right)$} & \multicolumn{2}{|c|}{$T U_{\text {bio }}\left(L_{\text {bioassay }} / g_{\text {PDMS }}\right)$} \\
\hline AhR CALUX & $\mathrm{B}[\mathrm{a}] \mathrm{P}-\mathrm{EQ}_{\mathrm{bio}}$ & $15.0 \pm 6.6$ & $7.32 \pm 2.47$ & 3.29 & 2.06 \\
\hline PPAR $\gamma$ GenBLAzer & Rosiglitazone-EQ $\mathrm{bio}_{\mathrm{o}}$ & $0.007 \pm 0.002$ & $0.011 \pm 0.002$ & 0.005 & 0.002 \\
\hline AREc32 & Dichlorvos-EQ bio & $49.7 \pm 2.5$ & $66.7 \pm 6.0$ & no cytotoxicity & 0.07 \\
\hline
\end{tabular}

Text S7. Cytotoxicity of chemical mixtures in water, suspended particulate matter and sediment in in vitro bioassay and the growth inhibition they caused on algae.

The TU of water, SPM and sediment, as well as the bioavailable fraction of solid samples are tabulated in Table S13. Quite a lot of samples did not reach cytotoxicity within the range of dosed concentrations used in this study. The extrapolated total numbers of cytotoxic chemicals were evidently higher than the numbers of bioactive chemicals regarding to corresponding specific effect and ranged from 1096 to 166,106 in water, from 15,637 to 154,094,745 in particles and from 979 to $1,455,123$ in the bioavailable fraction of particles (Table S14). Even though the B[a]P-EQ 
values of water sample at Site B were 2 times higher than those at Site A, the TU values did not show considerable difference in AhR CALUX. However, the growth inhibition of algae showed a similar trend with diuron-EQ, with the TU of water samples collected at Site B higher than those at Site A. For SPM, both the exhaustive and bioavailable extracts showed similar TU in the employed in vitro bioassays at these two Sites. It is interesting to note that even though the BEQ values of bulk sediment were similar, the TU at Site B was higher than that at Site A with a factor of 10 . However, the bioavailable extracts of sediment showed similar TU between sites.

Compared to specific effects, more detected caused cytotoxicity (10\%-43\%) (Tables S7 and S8). However, the contributions of these chemicals only explained up to $2.6 \%$ (Fig. S15), indicating that most of the baseline toxicity is not explainable by detected chemicals. The cytotoxicity observed in AhR CALUX were the lowest regarding all samples.

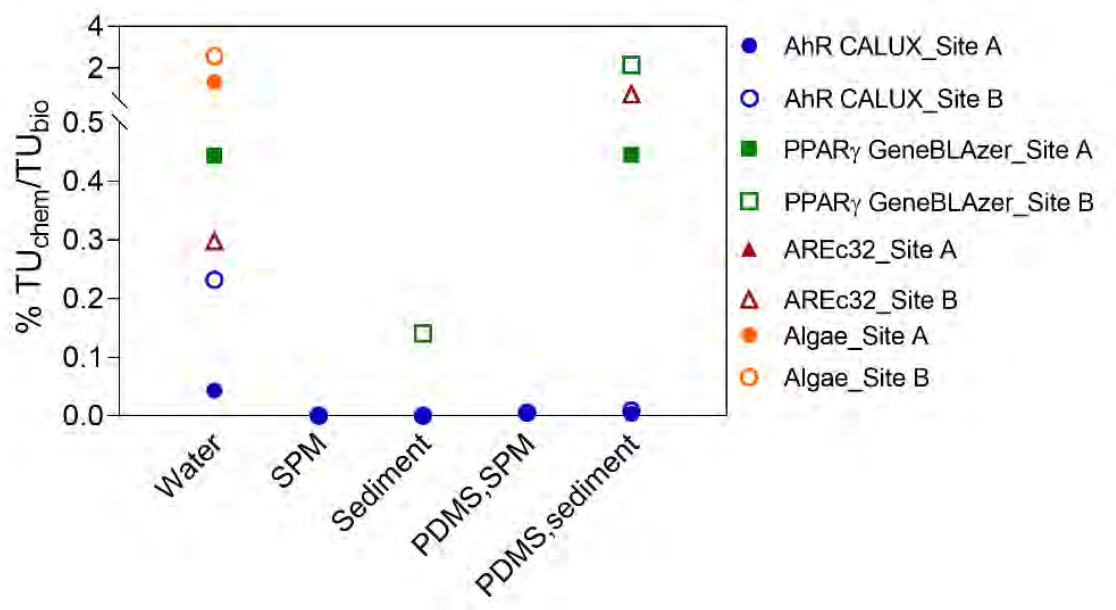

Fig. S15. Contribution of detected chemicals to the observed cytotoxicity in in vitro bioassays and the growth inhibition of algae.

Table S14. Bioanalytical equivalent concentrations $\left(B E Q_{\text {chem }}\right)$ and toxic units $\left(\mathbf{T U}_{\text {chem }}\right)$ estimated from chemical concentrations of detected chemicals in water, bulk suspended particulate matter (SPM), bulk sediment and organic carbon (OC) of particles for AhR CALUX, PPAR $\gamma$ GeneBLAzer and AREc32 assays - see Supporting Information excel file.

Table S15. Bioanalytical equivalent concentrations $\left(\mathrm{BEQ}_{\mathrm{chem}}\right)$ and toxic units $\left(\mathrm{TU}_{\mathrm{chem}}\right)$ estimated from chemical concentrations of detected chemicals in water for algae assay - see Supporting Information excel file. 

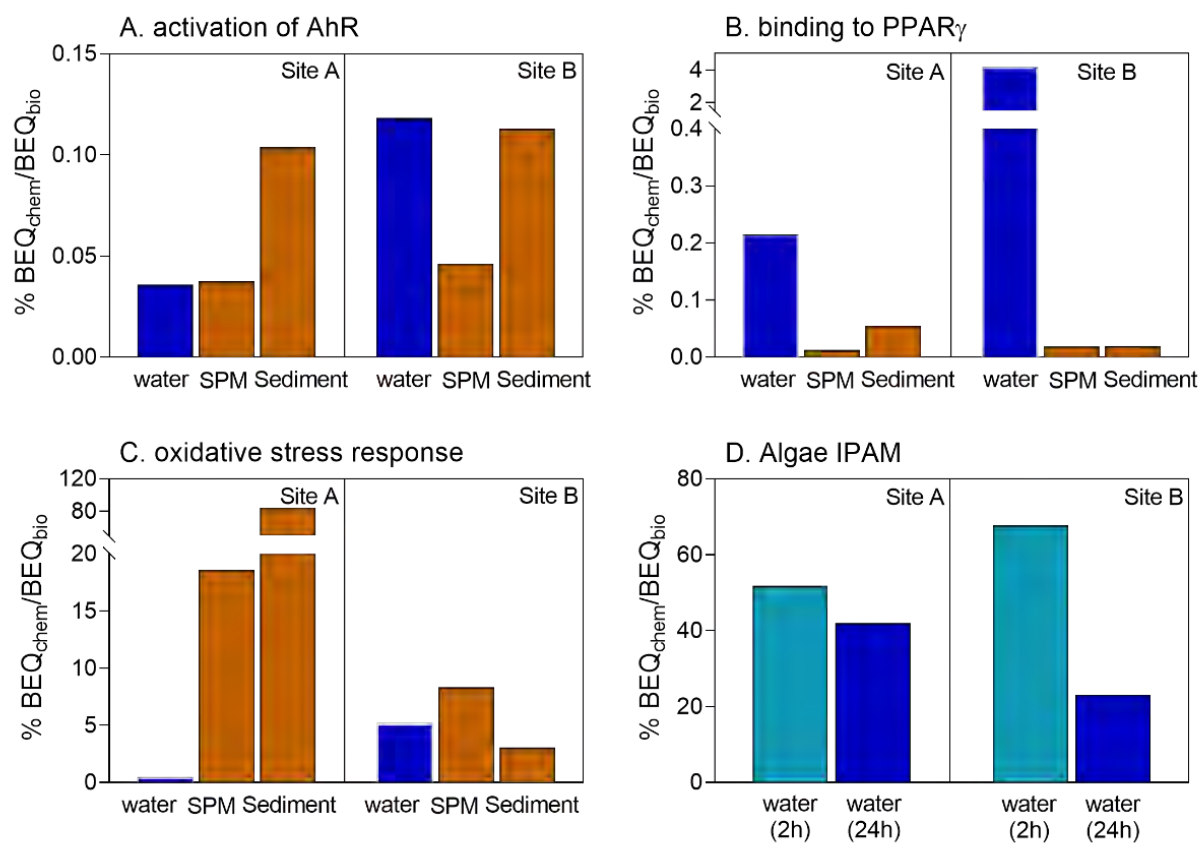

Fig. S16. Contribution of detected chemicals to the observed effects regarding (A) the activation of AhR, (B) binding to PPAR $\gamma,(C)$ oxidative stress response and (D) photosynthesis inhibition in algae.

Text 8. Extrapolations to estimate the total number of chemicals in water, suspended particulate matter, sediment and the bioavailable fractions of particles.

We extrapolated the total number of cytotoxic and bioactive chemicals in samples with Eqs. S19 and S20. These equations assume that the detected chemicals are a random selection of all chemicals with their sensitivity distribution representing the distribution of all chemicals. Of course, these extrapolated numbers can be biased by extraction efficacy of the sample preparation methods and by detection limits.

Extrapolated number of bioactive chemicals $=\frac{\# \text { detected and bioactive chemicals }}{\frac{\mathrm{BEQ}_{\text {chem }}}{\mathrm{BEQ}_{\text {bio }}}}$

Extrapolated number of cytotoxic chemicals $=\frac{\# \text { detected and cytotoxic chemicals }}{\frac{\mathrm{TU}_{\text {chem }}}{\mathrm{TU}_{\text {bio }}}}$

The extrapolation results are shown in Table S16. Based on the $0.04 \%-0.1 \%$ of the observed AhR activation by $24-34$ detected chemicals, $0.2 \%-4.2 \%$ of the observed PPAR $\gamma$ binding by 11-19 chemicals and $0.5 \%-5.2 \%$ of the observed oxidative stress response by $28-36$ chemicals, the number of bioactive chemicals in water samples would be expected to be 28,791-67,067 for 
the activation of AhR, 456-5,166 for PPAR $\gamma$ binding and 695-6040 for the oxidative stress response. For the algae assay, the extrapolated number of chemicals in water extracts was 46-125 according to the $24-28$ detected chemicals contributing $22.5 \%-67.9 \%$ of the photosynthesis inhibition. The extrapolated number of chemicals was much more for cytotoxicity, where all chemicals are active, ranging from 1,096 to 1,791 for the growth inhibition of algae and from 7,211 to 166,106 for the cell variability of the other three in vitro bioassays.

The extrapolated number of chemicals in particles showed no significant difference from that in water samples. In bulk particles, this number was in the range of 26,984-53,175 for the activation of AhR, of 9,085-46,856 for the PPAR $\gamma$ binding and of 34-941 for oxidative stress response. The extrapolated number of chemicals estimated for bioavailable part of particles was higher than that for bulk particles due to the smaller number of chemicals detected. In PDMS extracts, the extrapolation yielded a total of 30,429 to 75,007 chemicals for the activation of AhR, 670 to 1,886 chemicals active the binding of PPAR $\gamma$ and 137 to 1,166 chemicals active the oxidative stress response.

The cytotoxicity caused by the exhaustive and PDMS extracts of particles were mostly not visible within the dosed concentrations for the PPAR $\gamma$ GeneBLAzer assay and oxidative stress response assay. In terms of cytotoxicity in the AhR CALUX assay, the extrapolated number of chemicals in particles was much higher than that in water samples, ranging from 2,722,039 to $154,094,745$ in bulk particles and from 681,545 to $1,455,123$ in the bioavailable fractions. Of course, such a number is not realistic but could be caused by nondetected highly hydrophobic and hence highly cytotoxic chemicals. It must be kept in mind that all chemicals contribute to cytotoxicity and the hydrophobic chemicals with a higher weight.

The extrapolated data evidenced that the chemicals we detected were only a very small part of the existed chemicals in samples and in turn explained the small contribution we estimated for the observed effects.

Table S16. Extrapolated number of bioactive and cytotoxic chemicals in water, suspended particulate matter (SPM), sediment and polydimethylsiloxane (PDMS) extracts - see Supporting Information excel file. 

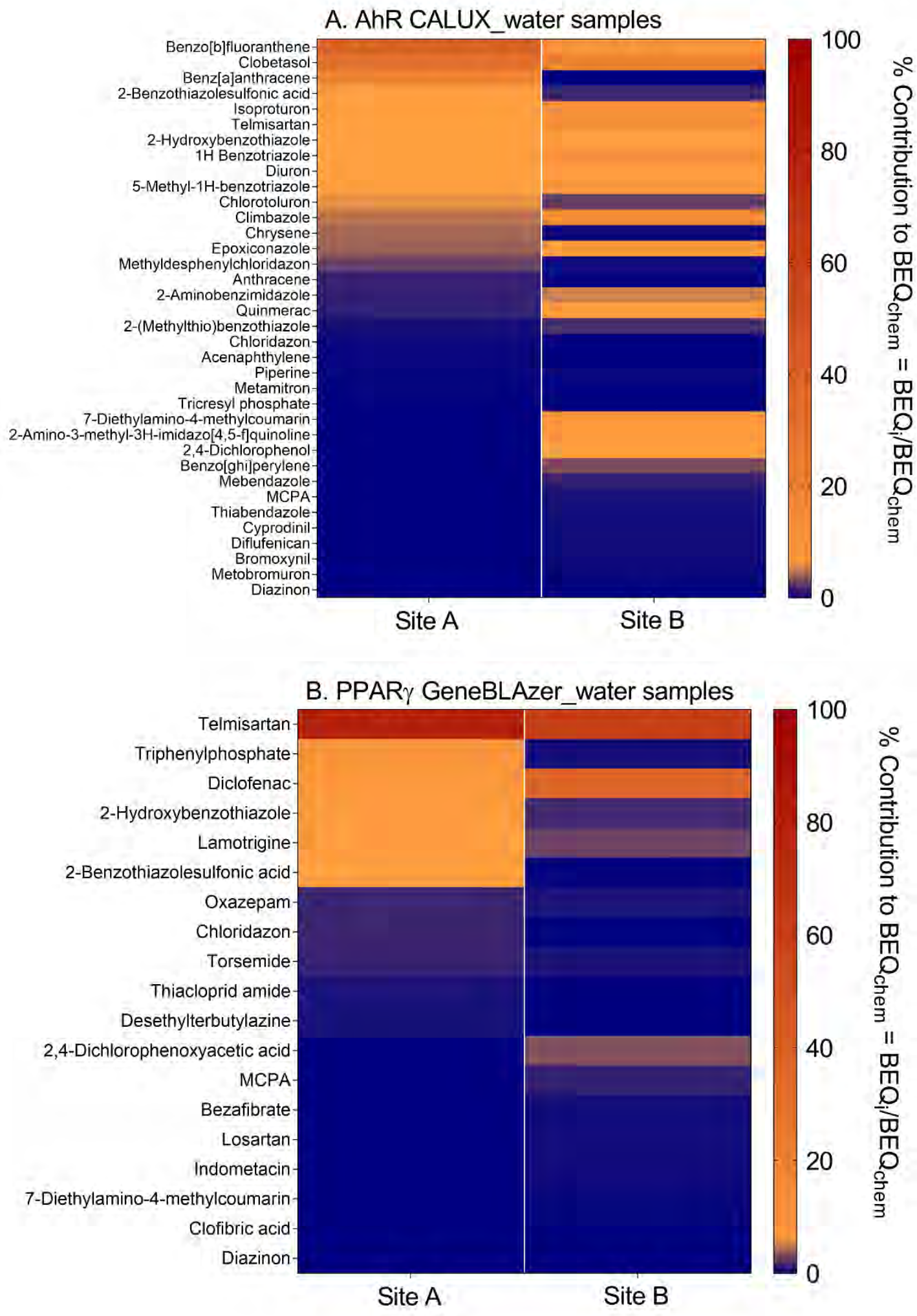

Fig. S17. Contribution of individual chemicals to the total bioanalytical equivalent concentrations (BEQ $Q_{\text {chem }}$ ) of water samples. Calculated from data of Table S14 and S15. 

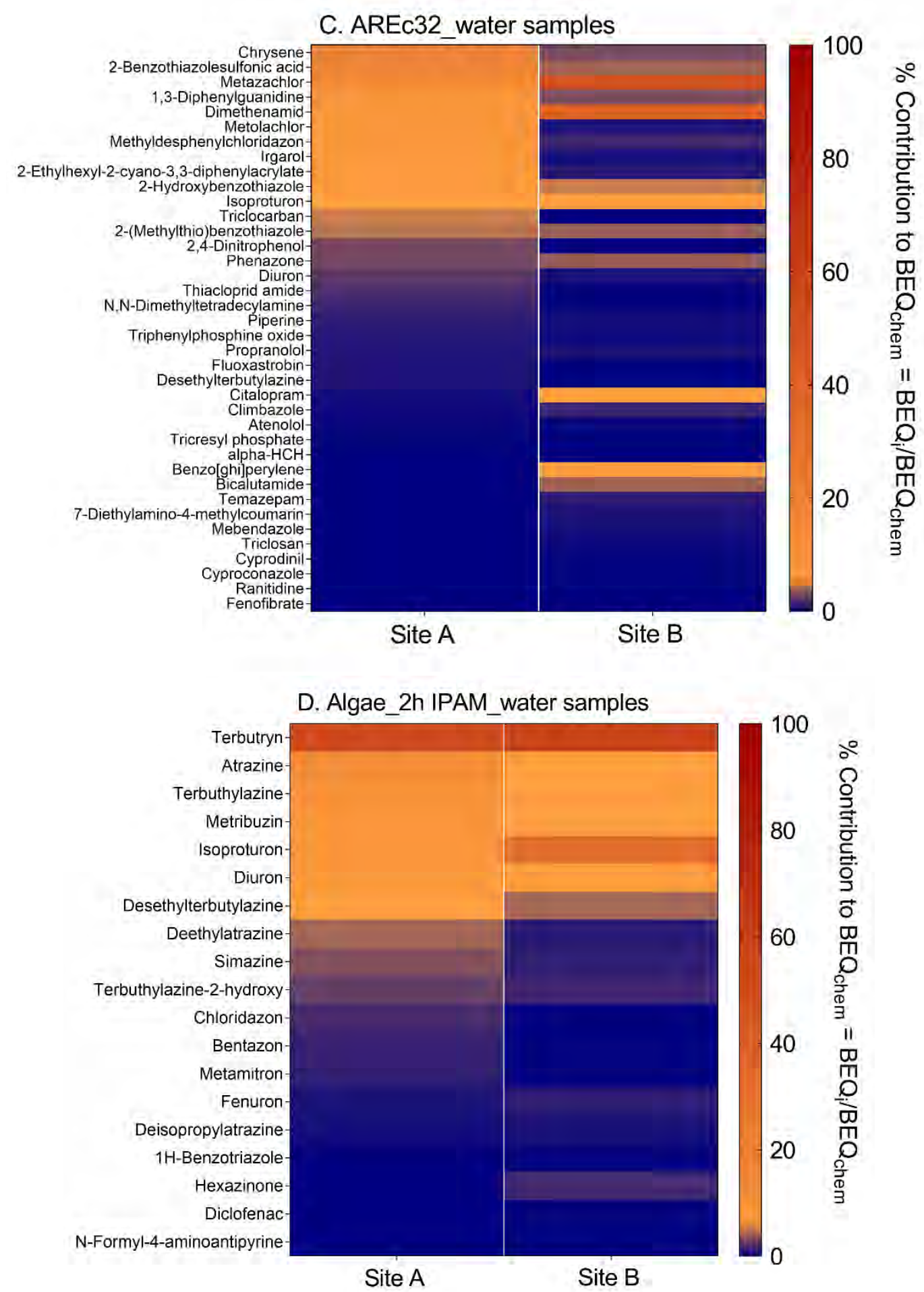

Fig. S17. Continued. Contribution of individual chemicals to the total bioanalytical equivalent concentrations $\left(B E Q_{c h e m}\right)$ of water samples. Calculated from data of Table S14 and S15. 


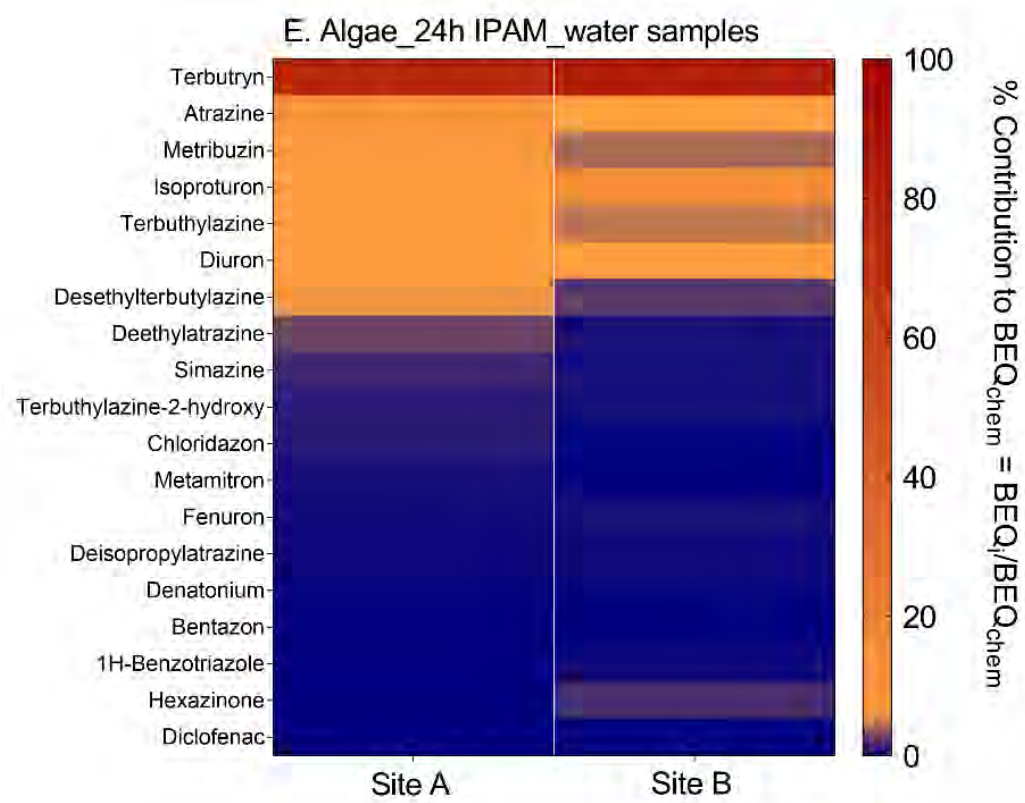

Fig. S17. Continued. Contribution of individual chemicals to the total bioanalytical equivalent concentrations (BEQ $Q_{\text {chem }}$ ) of water samples. Calculated from data of Table S14 and S15.

Table S17. Top 10 risk drivers (top 6 for algae toxicity) in chemical mixtures identified by iceberg modeling and their contribution to $B E Q_{c h e m}-$ see Supporting Information excel file.

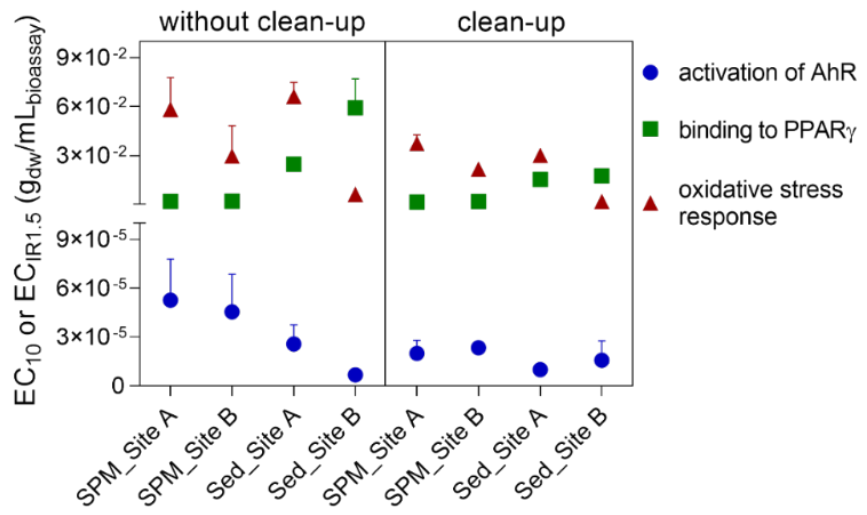

Fig. S18. Comparison of biological effects caused by exhaustively extracted suspended particulate matters (SPM) and sediment samples with and without clean-up. $\mathbf{E C}_{10}$ : concentration causing $10 \%$ of the maximum effect; $\mathrm{EC}_{\text {IR1.5: }}$ concentration causing an induction ratio of 1.5 . 


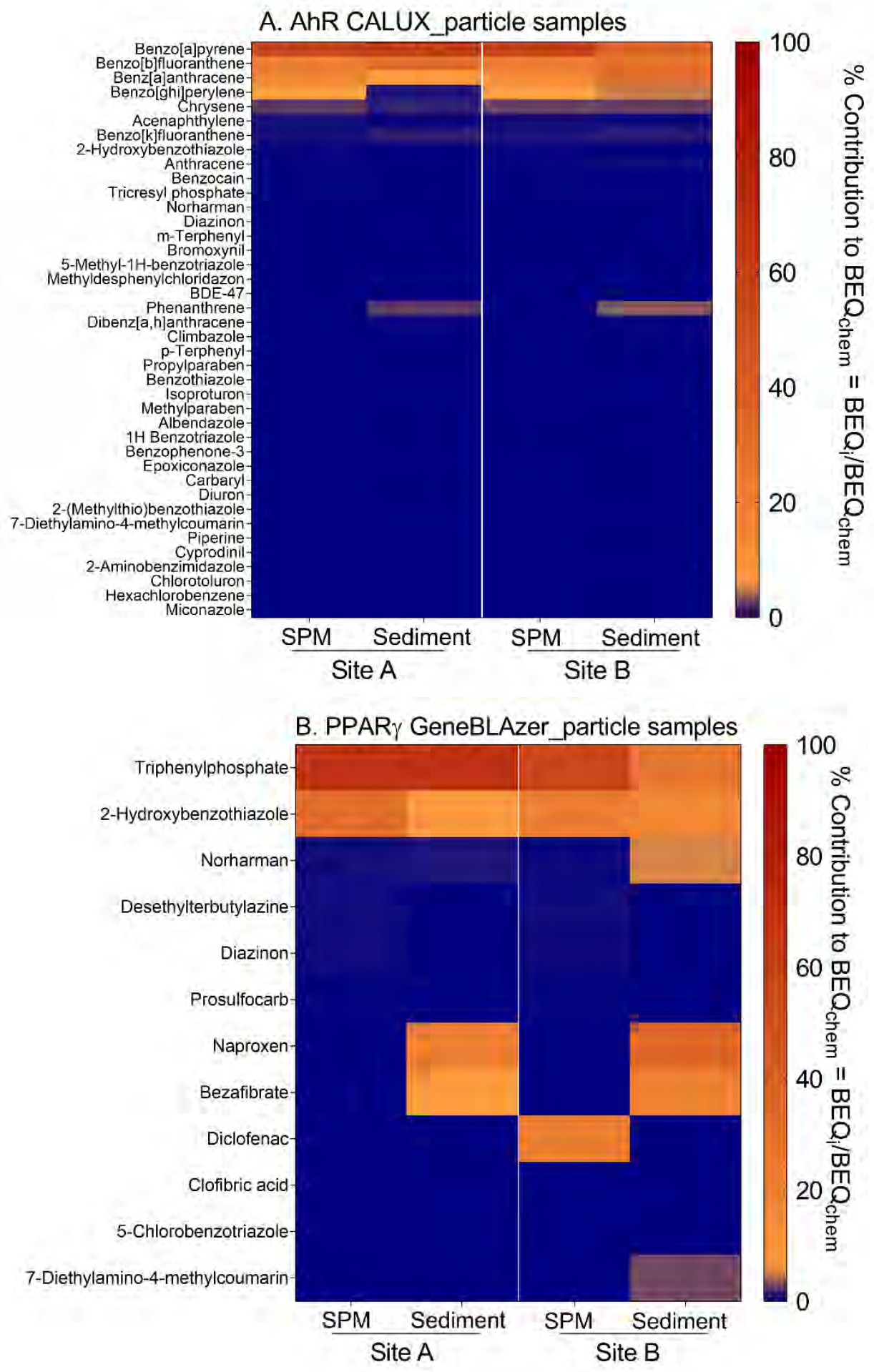

Fig. S19. Contribution of individual chemicals to the total bioanalytical equivalent concentrations $\left(B E Q_{\text {chem }}\right)$ of particle samples and their polydimethylsiloxane (PDMS) extracts. Calculated from data of Table S14. 

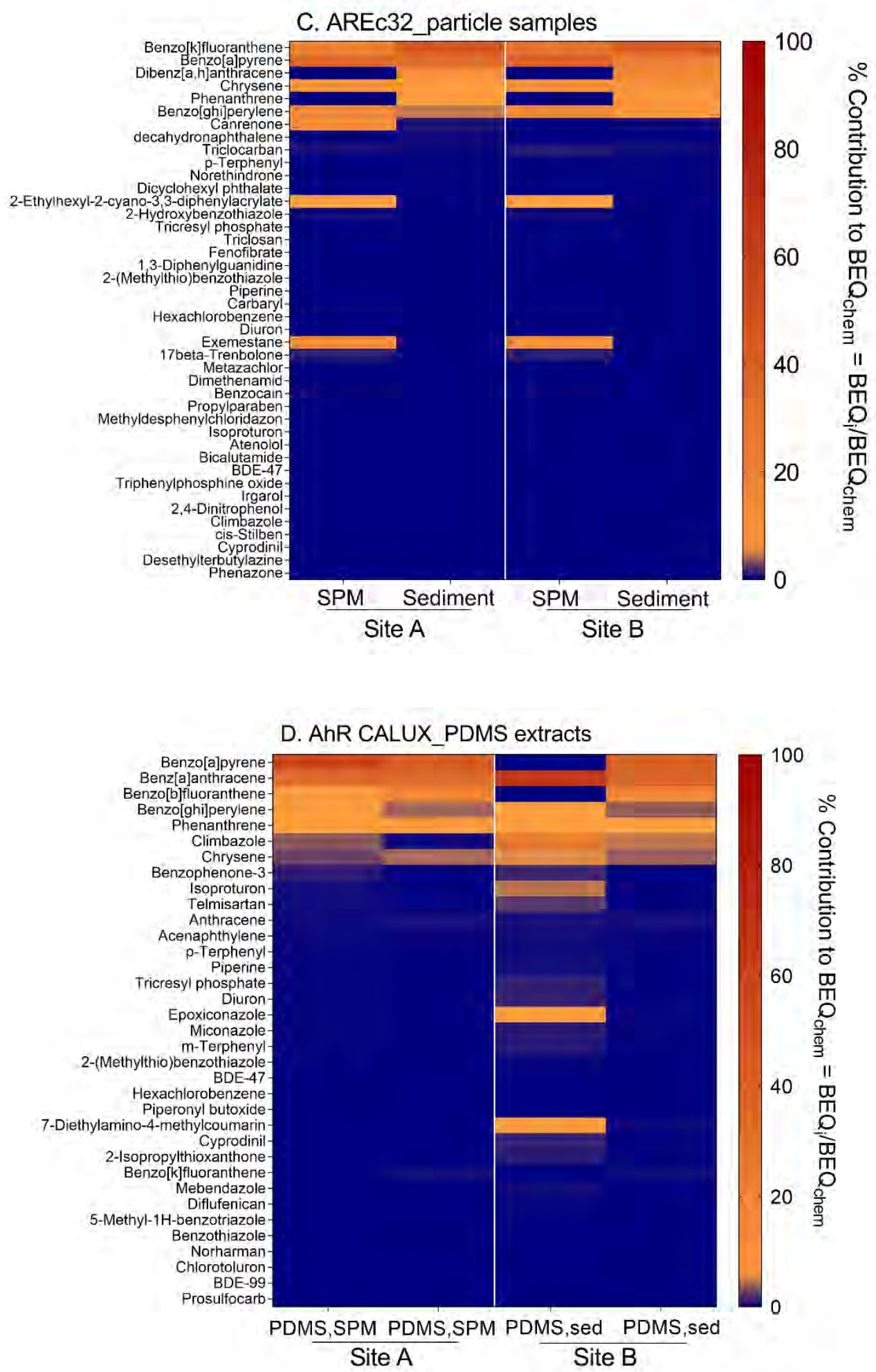

Fig. S19. Continued. Contribution of individual chemicals to the total bioanalytical equivalent concentrations (BEQ $Q_{\text {chem }}$ ) of particle samples and their polydimethylsiloxane (PDMS) extracts. Calculated from data of Table S14. 

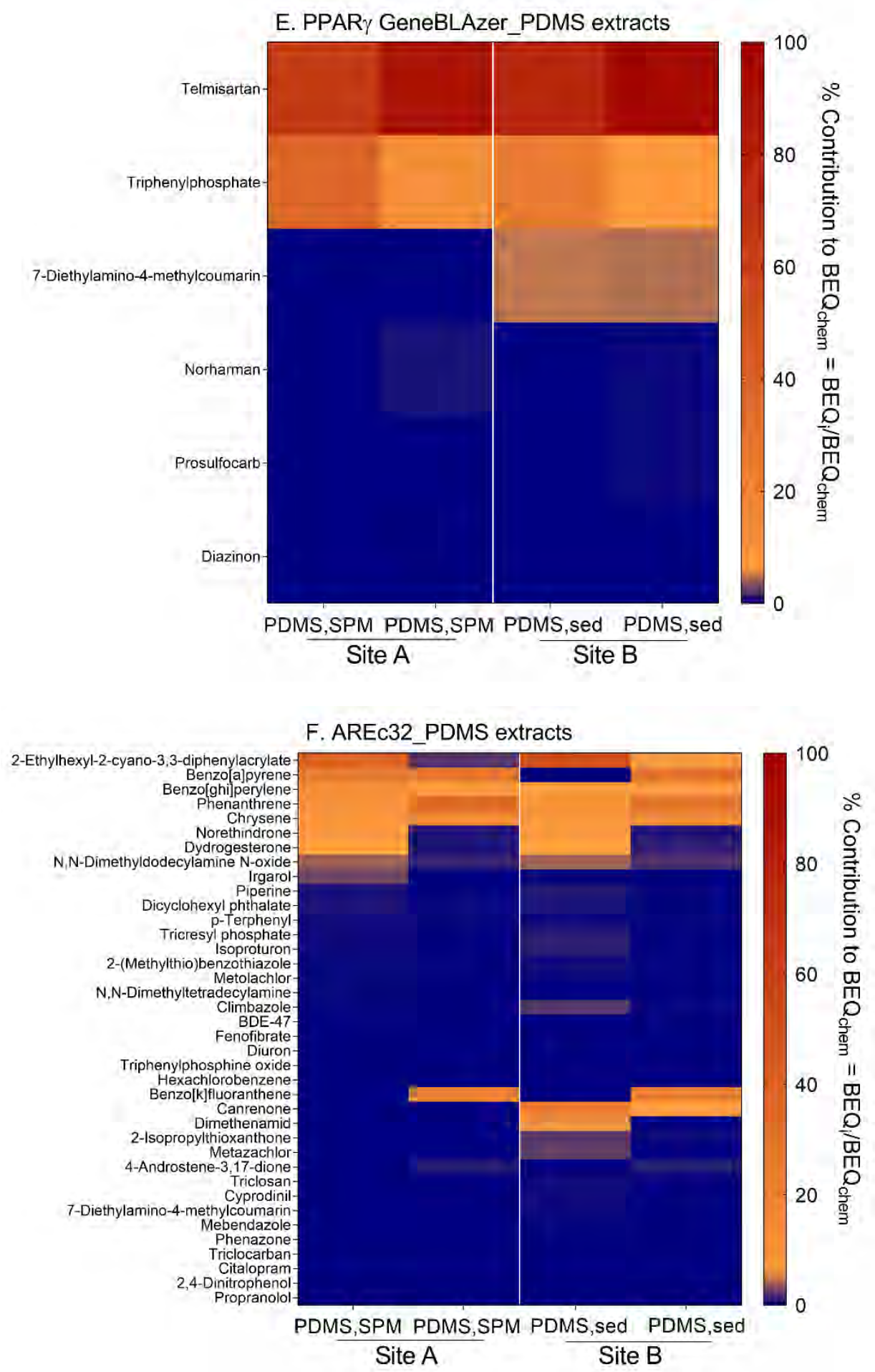

Fig. S19. Continued. Contribution of individual chemicals to the total bioanalytical equivalent concentrations (BEQ $Q_{\text {chem }}$ ) of particle samples and their polydimethylsiloxane (PDMS) extracts. Calculated from data of Table S14. 
A. $\mathrm{C}_{\mathrm{w}, \mathrm{SPE}}(\mathrm{ng} / \mathrm{L})$

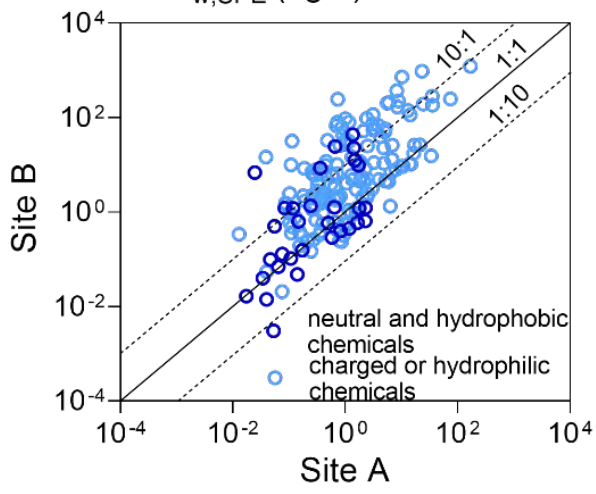

C. $C_{\text {tot, SPM }+S P E}(\mathrm{ng} / \mathrm{L})$

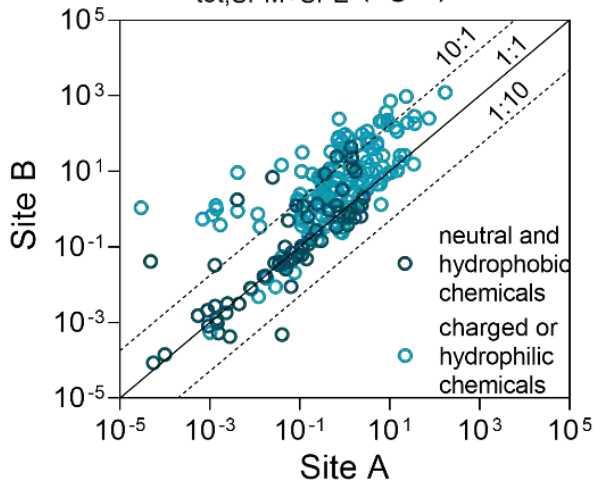

B. $C_{S P M}\left(n g / g_{d w}\right)$ and $C_{O C, S P M}\left(n g / g_{O C}\right)$
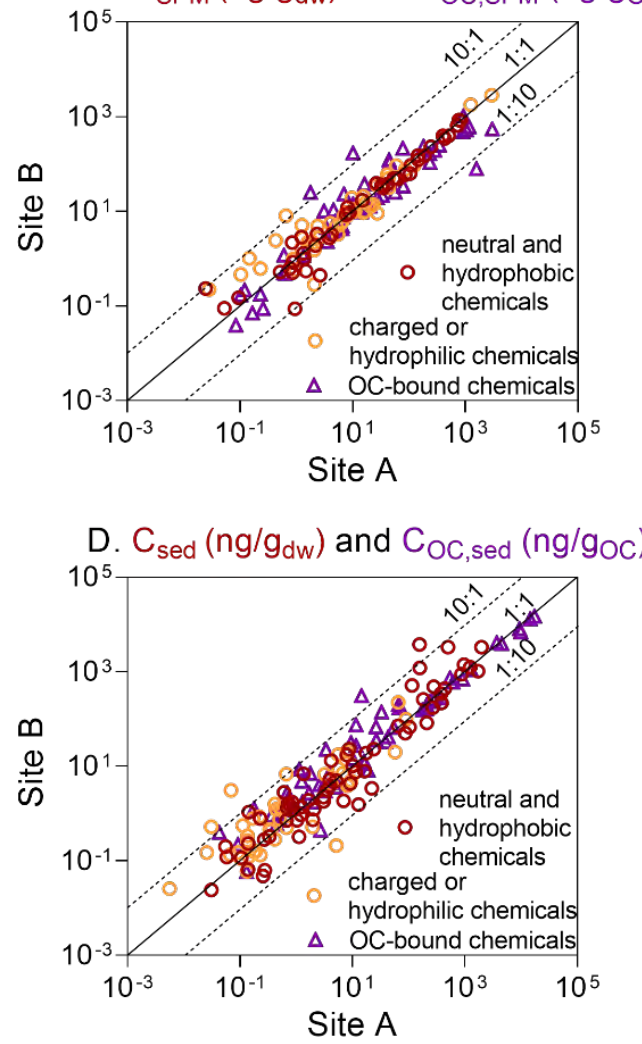

Fig. S20. Spatial variation of chemical concentrations in (A) dissolved phase, (B) suspended particulate matter (SPM) and its organic carbon (OC) phase, (C) water column and (D) sediment and its OC phase.
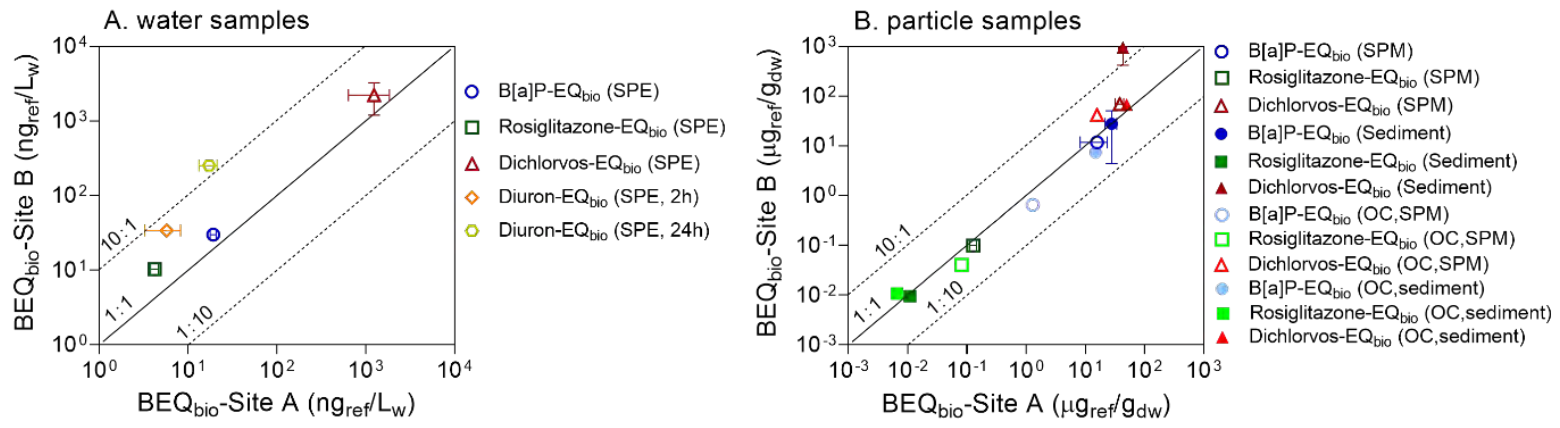

Fig. S21. Spatial variation of bioanalytical equivalent concentrations (BEQ) of chemical mixtures in (A) surface water estimated by solid phase extraction (SPE), (B) suspended particulate matter (SPM), sediment and the organic carbon (OC) phase. 


\section{References}

1. Schulze, T.; Ahel, M.; Ahlheim, J.; Ait-Aissa, S.; Brion, F.; Di Paolo, C.; Froment, J.; Hidasi, A. O.; Hollender, J.; Hollert, H.; Hu, M.; Klolss, A.; Koprivica, S.; Krauss, M.; Muz, M.; Oswald, P.; Petre, M.; Schollee, J. E.; Seiler, T. B.; Shao, Y.; Slobodnik, J.; Sonavane, M.; Suter, M. J. F.; Tollefsen, K. E.; Tousova, Z.; Walz, K. H.; Brack, W., Assessment of a novel device for onsite integrative large-volume solid phase extraction of water samples to enable a comprehensive chemical and effect-based analysis. Sci. Total Environ. 2017, 581, 350-358. 2. Glaser, C.; Zarfl, C.; Rugner, H.; Lewis, A.; Schwientek, M., Analyzing particleassociated pollutant transport to identify in-stream sediment processes during a high flow event. Water 2020, 12, (6), 1794.

3. Niu, L.; Carmona, E.; König, M.; Krauss, M.; Muz, M.; Xu, C.; Zou, D.; Escher, B. I., Mixture risk drivers in freshwater sediments and their bioavailability determined using passive equilibrium sampling. Environ. Sci. Technol. 2020, 54, (20), 13197-13206.

4. Glauch, L.; Escher, B. I., The combined algae test for the evaluation of mixture toxicity in environmental samples. Environ. Toxicol. Chem. 2020, (12), 2496-2508.

5. Escher, B. I.; Neale, P. A.; Villeneuve, D. L., The advantages of linear concentrationresponse curves for in vitro bioassays with environmental samples. Environ. Toxicol. Chem.

2018, 37, (9), 2273-2280. 